\title{
Uncovering Secrets of the "Fish of 10,000 Casts": The Physiological Ecology and \\ Behaviour of Muskellunge (Esox masquinongy)
}

By

Sean Joseph Landsman

B.Sc., University of Illinois at Urbana-Champaign, 2009

A thesis submitted to

The Faculty of Graduate and Postdoctoral Affairs

in partial fulfillment of

the requirements for the degree of

Master of Science

\author{
Ottawa Carleton Institute of Biology \\ Carleton, University \\ Ottawa, Ontario, Canada
}

(C2011, Sean Joseph Landsman 
Library and Archives

Canada

Published Heritage

Branch

395 Wellington Street

Ottawa ON K1A ON4

Canada
Bibliothèque et

Archives Canada

Direction du

Patrimoine de l'édition

395 , rue Wellington

Ottawa ON K1A ON4

Canada
Your file Votre référence

ISBN: 978-0-494-87852-1

Our file Notre référence

ISBN: $978-0-494-87852-1$

\section{NOTICE:}

The author has granted a nonexclusive license allowing Library and Archives Canada to reproduce, publish, archive, preserve, conserve, communicate to the public by telecommunication or on the Internet, loan, distrbute and sell theses worldwide, for commercial or noncommercial purposes, in microform, paper, electronic and/or any other formats.

The author retains copyright ownership and moral rights in this thesis. Neither the thesis nor substantial extracts from it may be printed or otherwise reproduced without the author's permission.
AVIS:

L'auteur a accordé une licence non exclusive permettant à la Bibliothèque et Archives Canada de reproduire, publier, archiver, sauvegarder, conserver, transmettre au public par télécommunication ou par l'Internet, prêter, distribuer et vendre des thèses partout dans le monde, à des fins commerciales ou autres, sur support microforme, papier, électronique et/ou autres formats.

L'auteur conserve la propriété du droit d'auteur et des droits moraux qui protege cette thèse. $\mathrm{Ni}$ la thèse ni des extraits substantiels de celle-ci ne doivent être imprimés ou autrement reproduits sans son autorisation.
In compliance with the Canadian Privacy Act some supporting forms may have been removed from this thesis.

While these forms may be included in the document page count, their removal does not represent any loss of content from the thesis.
Conformément à la loi canadienne sur la protection de la vie privée, quelques formulaires secondaires ont été enlevés de cette thèse.

Bien que ces formulaires aient inclus dans la pagination, il n'y aura aucun contenu manquant. 


\section{Dedication}

To my parents, thank you for encouraging and supporting my love and appreciation for the natural world. Be it fishing the shores of Lake Park, heli-hiking to the top of Franz Joseph Glacier in New Zealand, or peering into the tops of pine trees for great horned owls; you helped cultivate the experiences that have shaped my life.

To my friends in the Cooke Lab, past and present, you all were like a second family to me. To Steve, thank you for the support and all the wonderful opportunities you provided me in my short two years with you. I could not have asked for a better advisor. To Cory, thank you for taking the time to field my many questions and for providing such thorough responses. I am very fortunate to have been under your instruction as both an undergrad and Master's student.

To all of my angler volunteers, I cannot thank you enough. The memories I made will last a lifetime. To be able to share my knowledge and give you the opportunities to help collect scientific data made those long, hot, bluebird sky, high pressure, too-manypleasure boats-on-the-water-I-can't-think-straight days all worth it.

Throughout this process there was one person who became my balance, motivation, and voice-of-reason: Sarah McConnachie. The English dictionary contains too few words to describe how thankful I am to have met you.

Perhaps I owe the greatest thanks to my trusty sidekick, Hedrik Wachelka. There was, without question, no one person more influential to me during my program. You became my friend, confidant, mentor, and father-figure. On and off the water, every interaction was an absolute pleasure. 


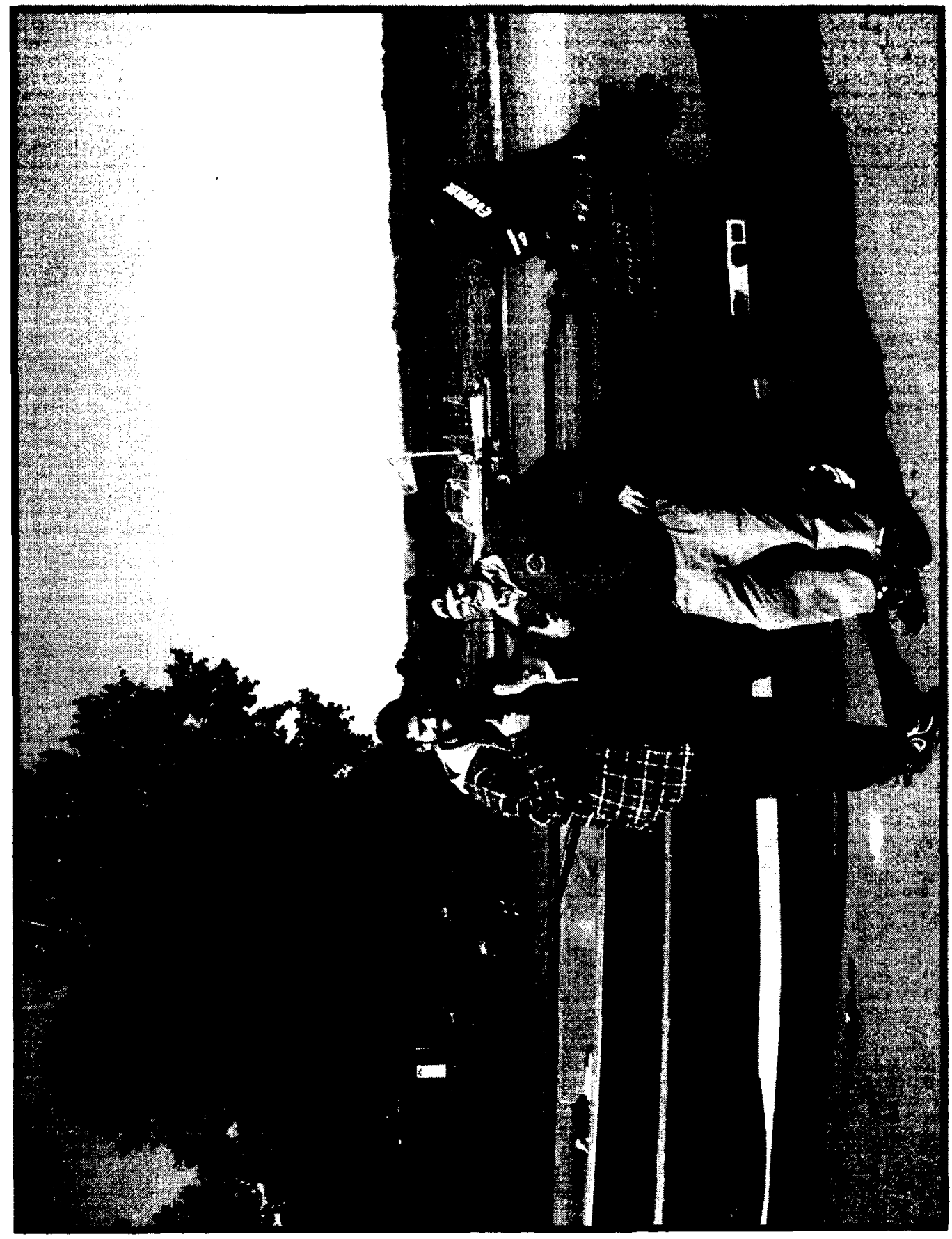




\begin{abstract}
Touted as one of North America`s largest and most difficult freshwater sport fish to angle, nearly all muskellunge (Esox masquinongy) caught are released, particularly by specialized anglers. In Chapter 2, I coupled field and laboratory methods to demonstrate minimal sub-lethal and lethal impacts of specialized catch-and-release (C\&R) angling on muskellunge. In Chapter 3 , acoustic transmitters equipped with tri-axial acceleration and pressure sensors were used to assess the fine-scale activity and depth patterns of muskellunge as a function of time of day, water temperature, fish size, and lunar cycles. Despite remaining primarily inactive and relatively shallow (i.e., $<3.0 \mathrm{~m}$ ), muskellunge activity and depth varied greatly as a function of these four biotic and abiotic variables. The novel findings presented in this thesis support the conservation and management of muskellunge populations throughout North America.
\end{abstract}




\section{Acknowledgements}

Several key funding agencies must be recognized. for without their support this thesis could not have been completed. Thank you to, in no particular order, the Hugh C. Becker Foundation, Muskies Canada Inc., Muskies Inc., NSERC Discovery Grants, the Ontario Ministry of Research and Innovation, the Canada Foundation for Innovation, the Canada Research Chairs Program, and Carleton University. The Ontario Ministry of Natural Resources should also be acknowledged for providing us with the necessary permits to carry out our fieldwork.

Obviously, a critical component of one's thesis is the written portion. I could not have accomplished much of the writing without the support of my co-authors, but in particular my advisors Drs. Steven Cooke and Cory Suski. Mark Taylor and Dr. Karen Murchie deserve special thanks for fielding telemetry-related questions. Many thanks are also extended to Drs. Marie-Ange Gravel and Caleb Hasler for allowing me to pester them with innumerable stats questions. Also, many thanks to Dr. Tom Betka for spending hours chatting with me about ways to interpret data.

The most exciting component of this thesis was the data collection. A huge thank you to the $30+$ anglers that joined me on my mission!

Thank you to Alison Colotelo for pre-thesis transmitter attachment and blood sampling training. Keith Stamplecoskie and Amanda O'Toole deserve a special thank you as well for making sure 1 didn't become hypothermic while deploying and retrieving acoustic receivers. 


\section{Co-Authorship}

\section{Chapter 2: Evaluation of the physiology, behaviour, and survival of adult}

muskellunge (Esox masquinongy) captured and released by specialized anglers. S.J. Landsman, H.J. Wachelka, C.D. Suski, and S.J. Cooke.

While this study is my own, the research was undertaken as part of a collaborative effort and each co-author played a valuable role in its completion. The project was conceived by Landsman, Wachelka, and Cooke. Fieldwork was completed by Landsman, Wachelka, and additional volunteers. All computer and data analysis was conducted by Landsman. Data were interpreted by Landsman, Wachelka, Suski, and Cooke. All writing was conducted by Landsman. All co-authors provided comments and feedback on the manuscript.

Landsman, S.J., Wachelka, H.J., Suski, C.D., and Cooke, S.J. Evaluation of the physiology, behaviour, and survival of adult muskellunge (Esox masquinongy) captured and released by specialized anglers. Fisheries Research 110, 377-386.

\section{Chapter 3: Fine-scale behaviour of muskellunge (Esox masquinongy) assessed using} tri-axial acceleration and pressure sensing transmitters. S.J. Landsman, E. Martins, C.D. Suski, and S.J. Cooke.

While this study is my own, the research was undertaken as part of a collaborative effort and each co-author played a valuable role in its completion. The project was conceived by Landsman and Cooke. Fieldwork was completed by Landsman and additional volunteers. Computer and data analysis was conducted by Landsman with assistance from Martins. Data were interpreted by Landsman. All writing was conducted by Landsman. All co-authors provided comments and feedback on the manuscript. 
Table of Contents

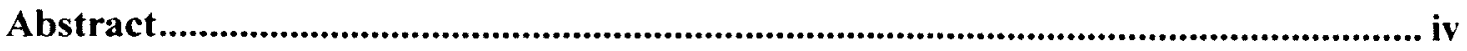

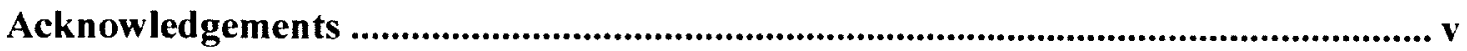

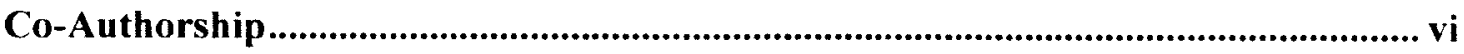

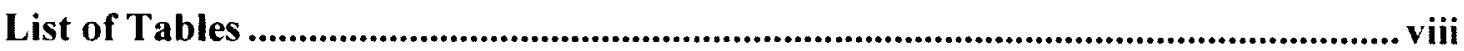

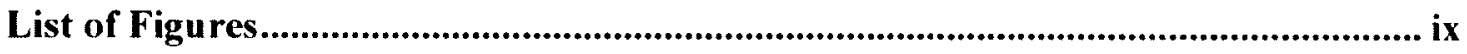

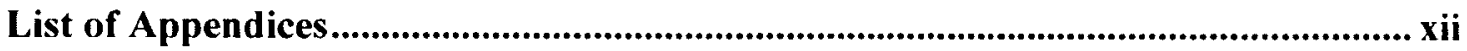

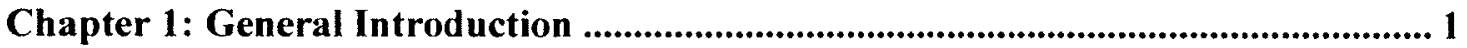

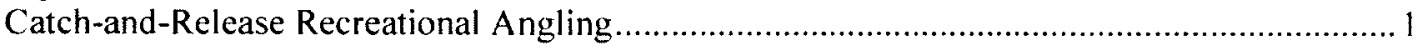

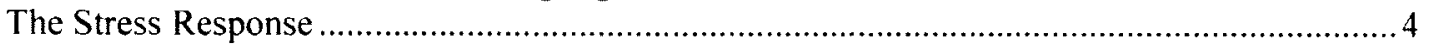

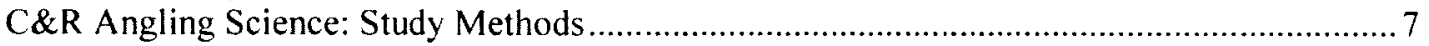

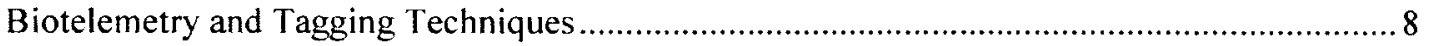

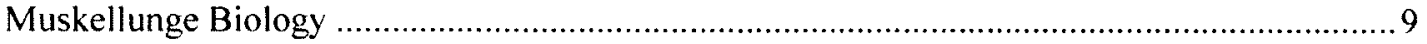

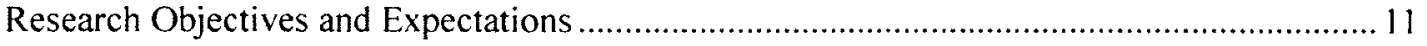

Chapter 2: Evaluation of the physiology, behaviour, and survival of adult muskellunge (Esox masquinongy) captured and released by specialized anglers..... 13

Abstract.....
Introduction
Methods .
Results
Discussion
Conclusions
Tables

Chapter 3: Fine-scale behaviour of muskellunge (Esox masquinongy) assessed using tri-axial acceleration and pressure sensing transmitters ............................................45

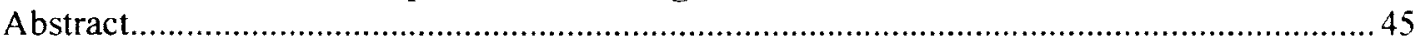

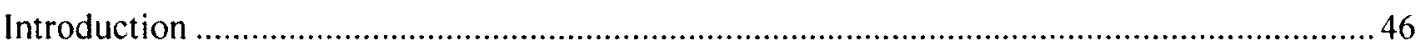

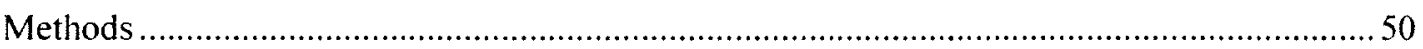

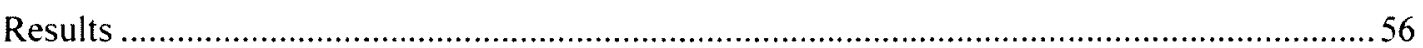

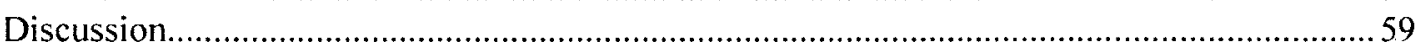

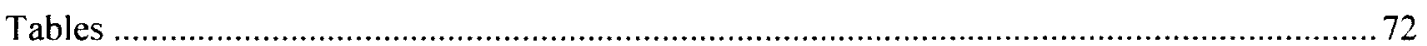

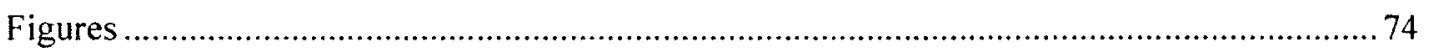

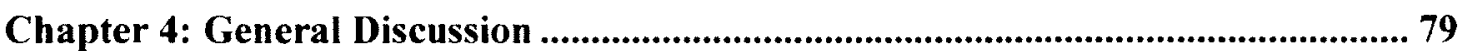

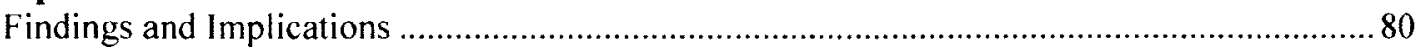

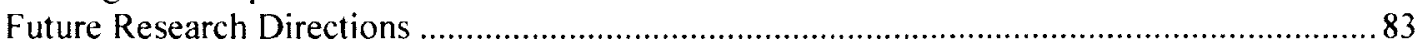

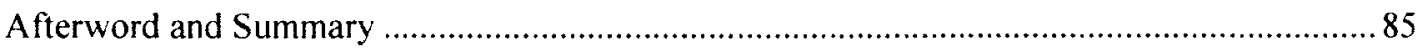

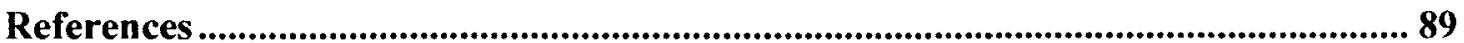

Appendix I: Alternative options to J-hook swallow rigs for angling muskellunge (Esox masquinongy) with live-bait ............................................................................... 118

Reprint Request and Permissions to Publish .......................................................... 131 


\section{List of Tables}

Table 2-1......

Results of the rank-transformed two-way ANOVA test examining the effects of treatment, temperature, and treatment $\times$ temperature on seven physiological parameters for control and angled muskellunge. Significant effects are denoted by bolded $P$-values. t+ signifies parameters without control data and excluding 2010 data from angled muskellunge.

Table 2-2. .37

Movement data for all radio tagged $(N=30)$ muskellunge. Recaptures, the sum of distances moved up to $48 \mathrm{~h}$, and the number of upstream movements for the entire tracking period were used to assess survival. An asterisk denotes individuals tracked after being recaptured.

Table 3-1..

Summary table of AICc candidate models for factors affecting activity patterns of free-swimming muskellunge. Models $(N=130)$ with $\triangle \mathrm{AICc}$ values $>5.00$ are not shown. The abbreviations TOD, TL, TEMP, $\sin (\theta)$, and $\cos (\theta)$ were used for time of day, total length (i.e., fish size), temperature, half lunar, and new/full lunar phases. respectively.

Table 3-2.

Summary table of AlCc candidate models for factors explaining depth use in freeswimming muskellunge. Models $(N=132)$ with $\triangle \mathrm{AICc}>30.00$ are not shown. The abbreviations TOD, TL, TEMP, $\sin (\theta)$, and $\cos (\theta)$ were used for time of day, total length (i.e., fish size), temperature, half lunar, and new/full lunar phases, respectively. 


\section{List of Figures}

Figure 2-1.

Map of the Ottawa River study site (a) east of the city of Ottawa. Ontario and two stretches of the Rideau River south of Ottawa near Kemptville, Ontario (b) and between the Black Rapids and Long Island Locks (c). The thin black line splitting the Ottawa River separates the provinces of Ontario and Québec. For the Rideau River, solid lines indicate bridges and dashed lines indicate dam and lock systems.

Figure 2-2.

A selection of muskellunge-specific artificial lures with up to nine barbed hook points.

Figure 2-3.

Concentrations of blood glucose (a), lactate (b), and hematocrit (c; percent packed cell volume) for control (solid circle) and angled muskellunge subjected to alternative (hollow triangle) and normal (solid square) handling treatments. The sample sizes for glucose and lactate at low, moderate, and high temperatures for the three treatments were as follows: control $(N=8,3,7)$, alternative $(N=4,11,18)$, and normal $(N=4,13,15)$. Samples sizes for hematocrit at low, moderate, and high temperatures for the three treatments were: control $(N=8,3,6)$, alternative $(N=4,10,15)$, and normal $(N=4,8$. 10). An asterisk $\left({ }^{*}\right)$ denotes a significant difference between controls and angled muskellunge. Dissimilar upper case letters joined by horizontal lines denote significant differences between temperature groups.

Figure 2-4.

Concentrations of plasma sodium (a), potassium (b), chloride (c), and cortisol (d) for control muskellunge ( $a-b$, solid circle) and angled muskellunge subjected to gentle (hollow triangle) or normal (solid square) handling treatments. The samples sizes for plasma sodium and potassium ions at low, moderate, and high temperatures for the three treatments were as follows: control $(N=8,3,6)$, alternative $(N=4,10,14)$, normal $(N=$ $4,9,9)$. Sample sizes for plasma chloride ions and cortisol were: alternative $(N=7,9)$ and normal $(N=7,4)$. Dissimilar upper case letters joined by horizontal lines denote significant differences between temperature groups, and asterisks $(*)$ indicate treatment groups at given temperatures that are statistically different from each other (i.e., interaction effect).

Figure 2-5.

Mean distance moved for angled muskellunge subject to normal handling procedures (solid squares) used by specialized anglers as well as an alternative handling procedure (hollow triangles). Sample sizes were $N=15$ for both treatments except at when one individual could not be located (i.e., $N=14$ ) at 120 min post-release for the normal treatment and 10 and $30 \mathrm{~min}$ post-release for the alternative treatment.

Figure 3-1. 
Map of the Rideau River between the Black Rapids and Long Island Locks. Dashed lines point to the lock systems and solid circles indicate acoustic receiver positions.

Figure 3-2. depth (b).

Frequency histogram for the number of detections at a given acceleration (a) and

Figure 3-3.

The proportion of active detections at cool (black lines) and warm (grey lines) water temperatures for small (solid), medium (dash-dot), and large (dash) sized muskellunge (a). Panel (b) illustrates diel patterns of activity at cool (black) and warm (grey) during dawn (solid), day (dash-dot), dusk (dashed), and night (dash-dot-dot). Panel (c) demonstrates activity for small (black) and large (grey) muskellunge during dawn (solid), day (dash-dot), dusk (dashed), and night (dash-dot-dot).

Figure 3-4.

Depth at cool (black lines) and warm (grey lines) temperatures for small (solid), medium (dash-dot), and large (dashed) sized muskellunge across the lunar month (a). Panel (b) illustrates depths inhabited at cool (black lines) and warm (grey lines) water temperatures during dawn (solid), day (dash-dot), dusk (dash), and night (dash-dot-dot) across the lunar month. Panel (c) demonstrates depth patterns of small (black) and large (grey) sized muskellunge at dawn (solid), day (dash-dot), dusk (dash), and night (dashdot-dot).

Figure 3-5.

Acceleration (a) and depth (b) of post-release angled (black) muskellunge compared to free-swimming (white) individuals over $24 \mathrm{~h}$ periods.

Figure I-1. 125

Study sites along the Rideau River near Kemptville, Ontario (i.e., Long Reach; a) and between the Long Island and Black Rapids Locks (i.e., Eccolands; b). Solid lines represent locks and dashed lines represent bridges.

Figure I-2. Bette).

Quick-strike rigged white sucker (Camersonii camersonii; photo credit John

Figure I-3.

Two styles of circle hook $(\mathrm{a}, \mathrm{b})$ and a conventional J-hook (c; used with permission from S.J. Cooke).

Figure I-4.

Circle hook operation after the angler reels and applies pressure to the line. Both lateral and frontal views are shown (used with permission from S.J. Cooke). 
Figure I-5.

Photograph of post-mortem necropsy (photo credit S. Landsman). A $2.5 \mathrm{~cm}$ tear (a) is shown and the scalpel handle points to another tear in the pericardial cavity (b).

Figure 1-6. 130 Ideal hooking location using a circle hook (photo credit S. Landsman). 


\section{List of Appendices}

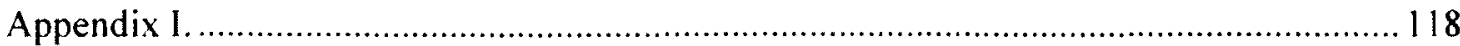

Alternative options to J-hook swallow rigs for angling muskellunge (Esox

masquinongy) with live-bait. 
Acronyms

$\mathrm{L}_{\mathrm{T}}$ : Total length

C\&R: Catch-and-release

ELISA: Enzyme-linked immunosorbent assay

RIA: Radioimmunoassay

SE: Standard Error

ANOVA: Analysis of variance

RAMP: Reflex action mortality predictor

AIC: Akaike's Information Criterion 


\section{Chapter 1: General Introduction}

\section{Catch-and-Release Recreational Angling}

The first account of angling as a recreational activity can be traced to ancient Egypt over 3,000 years ago (Pitcher and Hollingsworth, 2002). Over time, this activity has evolved from something reserved for slaves and peasants to an endeavour fit for high society (Arlinghaus et al., 2007a). Indeed, recreational angling holds cultural significance, offers a means for supplying food, and provides pleasure through nature be it in the form of psychological, aesthetic, social, physical, or spiritual - for those engaging in the sport (Arlinghaus et al., 2007a). It is regarded as a leisure activity as opposed to a commercial enterprise (e.g., Cooke and Cowx, 2004; Arlinghaus et al., 2007a), despite the multi-billion dollar industry is has created in North America (DFO, 2005; USFWS 2006). Recreational angling, however, is considered a contributing factor, along with commercial fishing, in the depletion of worldwide fish stocks (Post et al., 2002; Cooke and Cowx, 2004). Although some fish are kept, many others are released either voluntarily or under mandate (Quinn, 1996). This concept, known as catch-andrelease (C\&R) angling, can be an effective tool to reduce the ill-effects (e.g., overharvest) of high angling pressure on stocks (Policansky, 2002; Post et al., 2002).

C\&R angling is practiced worldwide with estimates suggesting $60 \%$ of fish captured in recreational fisheries are released (Cooke and Cowx, 2004). Marine releases in United States fisheries increased by $97 \%$ between 1981 and 1999 where the percentage of released fishes was 58\% (Bartholomew and Bohnsack, 2005). In Canada, from 2000 to 2005 over 215 million fishes were caught and nearly 72 million fishes kept, translating to over 143 million individuals released, or $67 \%$ of the total catch (DFO, 2005). Release 
rates can vary from $0 \%$ in subsistence fisheries to nearly $100 \%$ in specialized sport fisheries such as bonefish (Albula spp.), steelhead (Oncorhynchus mykiss), and carp (Cyprinus carpio; Arlinghaus et al., 2007a,b).

Bryan (1977) describes anglers as existing on a continuum and their degree of specialization a function of interest, experience, and the importance of angling to their lifestyle. Specialized anglers may also have a stronger conservation ethic as evidenced by their support for more restrictive management regulations that reduce harvest and improve the size of their catches (Bryan, 1977; Chipman and Helfrich, 1988; Quinn, 1996). For example, muskellunge-specific anglers in Wisconsin supported larger statewide minimum length limits than generalist anglers (Margenau and Petchenik, 2004). Similarly, specialized largemouth bass (Micropterus salmoides) anglers in Texas supported more restrictive regulations including increased size limits (Loomis and Holland, 1997). However, the success of regulations such as high minimum length limits and low bag limits hinges on the successful release of an angler's catch (Brousseau and Armstrong, 1987). Proper handling procedures are critical for the survival of released fishes and the success of a given management scheme. Yet, releasing fishes - regardless of whether it is voluntary or mandatory - is not free from criticism.

One of the most common questions asked with regard to sport fishing is: "Do fish feel pain?" Animal rights activists and groups such as People for the Ethical Treatment of Animals (PETA) have created several campaigns against recreational angling. The imagery can often be disturbing, with one particular ad campaign depicting a large hook driven through the snout of a dog. The underlying belief of such organizations is that fish feel pain. However, pain is an anthropomorphized term associated with actions 
expressed by non-human organisms appearing similar to our own, a concept known as 'theory of mind' (Rose, 2002). Detecting pain, however, is different from having the capacity to recognize and respond to negative stimuli (Sneddon et al., 2003). This process, known as nociception. has been demonstrated in teleost fishes when. for example, a noxious substance was applied to the snouts of rainbow trout (Oncorhynchus mykiss) which in turn exhibited abnormal behaviours and increased opercular beat rate (Sneddon, 2003). Rose (2002) advocates that fishes do not have the ability to feel pain and while a critique of Rose (2002) by Braithwaite and Huntingford (2004) admits that fishes, indeed, may not be able to feel pain as humans do, the capacity to do so exists (Braithwaite and Huntingford, 2004). Although evidence regarding this issue remains inconclusive, some European countries such as Germany maintain that the act of "setting the hook' on a fish causes pain and as such has prompted the basis for establishing laws requiring anglers to keep the fish they catch (Arlinghaus, 2007b). This has spurred much heated debate over the ethics of $C \& R$ angling, particularly with regard to function- versus feelings-based welfare. The latter definition of fish welfare advocates that fishes "should feel well, being free from negative experiences such as pain" (Huntingford et al., 2006). The former emphasizes the need to handle fishes in such a manner that injury and stress are reduced and fishes are able to reproduce in the future (Arlinghaus et al., 2007c).

Despite its regular use and incorporation into management activities, there are several biological issues associated with $C \& R$ angling that have the potential to negatively impact fishes and/or fish populations. For instance, barotrauma (Gravel and Cooke, 2008), physical injury (Cooke et al., 2003a; Gutowsky et al., 2011), and physiological changes (e.g., Kieffer, 2000; Cooke et al., 2002; Arlinghaus et al., 2009) can occur during 
the angling event. all of which can impact survival, reproduction, and/or fitness of angled fishes. From an evolutionary perspective. recreational angling has been shown to exert selective pressures on fishes. Over three successive years, Philipp et al. (2009) produced two lines of largemouth bass that displayed low and high vulnerabilities to angling, demonstrating that vulnerability is a heritable trait. Bold or aggressive fish are selected against as this type of behaviour makes them vulnerable to angling (Mezzera and Largiadér, 2001). Size selection can occur when large fish are kept as trophies and smaller fish are released (e.g., Isermann et al., 2005), possibly truncating the size structure of a population, increasing abundance of smaller fish species, reducing genetic diversity, and reducing the reproductive capacity of a population (reviewed in Lewin et al., 2006). High exploitation rates also have the potential to cause "contemporary evolution' (Stockwell et al.. 2003) whereby life history traits such as age at sexual maturity decreases with increased angling pressure (Diana, 1983). Regardless of the sublethal impacts of $C \& R$ angling, the fundamental assumption of $C \& R$ angling is that released fishes survive (Wydoski, 1977). However, no hook-and-line fishery can ever achieve true $100 \%$ survival (Arlinghaus et al., 2007a). Therefore, a major focus of C\&R research is identifying the sub-lethal and lethal impacts of this activity on various fish species (Arlinghaus et al., 2007a) and determining ways to improve the survival of released fishes.

\section{The Stress Response}

Stress is defined as a deviation from physiological homeostasis (Barton and Iwama, 1991; Wendelaar Bonga, 1997). Fish have adapted abilities to respond to stress, but 
depending on the magnitude and duration of a stressor(s) the response can become maladaptive (Barton and Iwama, 1991; Barton, 2002). The stress response is triggered when the central nervous system responds to a potential threat (Barton. 2002) and occurs in three phases: the primary reaction begins in the brain and stimulates production of adrenocorticotrophic hormone $(\mathrm{ACTH})$, which triggers production of cortisol; the secondary reaction creates changes in blood and tissue physiology; and the tertiary reaction can cause long-term effects associated with growth, reproduction, and survival (e.g., Wedemeyer et al., 1990; Wendelaar Bonga, 1997; Barton, 2002). Cortisol can be measured relatively quickly following blood sampling and is a common measurement of fish stress (see Barton and lwama, 1991).

In the second phase of the stress response (i.e., secondary reaction), there are suites of physiological changes that occur which can also be measured, in addition to cortisol, to determine the degree of stress imposed upon a fish. Cortisol concentrations are considered tightly linked with glucose (Leach and Taylor, 1980) where cortisol production triggers the breakdown of glycogen into glucose (Barton and Iwama, 1991). As an energy store, the mobilization of glucose provides one of the main sources of fuel for whole-body maintenance, which is used by fishes to meet increased energy demands following the onset of a stressor (Portz et al., 2006). Under a stressor such as exhaustive exercise (e.g., angling), however, fish may be forced to perform anaerobic glycolysis, which stimulates lactic acid production and the subsequent dissociation of protons and lactate anions (Wood, 1991; Wood et al., 1993; Kieffer, 2000). Following exercise, freshwater fishes gain large amounts of water and lose ions at the gills (Wood, 1991). Finally, an increase in the ratio between red blood cells and whole blood volume (i.e., 
hematocrit; Wendelaar Bonga, 1997: Barton. 2002) may occur as red blood cell production increases in an attempt to raise oxygen carrying capacities in the blood (see Portz et al., 2006). Indeed, many physiological parameters can be measured to quantify the level of physiological disturbance. Nevertheless, the degree and magnitude of the stressor will ultimately dictate whether long-term effects arise, and minimizing the magnitude of the stress response can have important short- and long-term benefits for angled fish.

Should the amount of physiological disturbance exceed a fish's ability to respond, a variety of maladaptive responses may ensue. For instance, when a fish must allocate a disproportionate amount of energy to dealing with a stressor(s), energies allocated to other processes are compromised (Barton and Iwama, 1991; Wendelaar Bonga, 1997; Barton, 2002). A classic example of maladaptive responses, particularly in fish propagation, is the effect on immune function. Here, suppression of the immune response leaves fishes vulnerable to disease, and is well documented in the scientific literature (see Barton and Iwama, 1991). Reductions in growth, condition, reproduction. swimming capacity, and feeding behaviour are other maladaptive responses to stress (as reviewed in Barton and Iwama, 1991; Wendelaar Bonga, 1997; Portz et al., 2006). Such 'whole animal responses' are difficult to measure, despite being the most ecologically relevant (Barton and Iwama, 1991). Ultimately, unbalanced energy budgets can affect survival (Diana, 1983: Wendelaar Bonga, 1997). One of the challenges associated with the responses of fish to angling is quantifying the disturbances that follow an angling event, particularly for animals in a field setting. 


\section{C\&R Angling Science: Study Methods}

Issues related to $C \& R$ angling have been assessed using a variety of methodologies. For example, net pens have been used to hold fishes for quantifying postrelease condition and survival (Muoneke and Childress, 1994), but such enclosures may exacerbate stress and mortality leading to overestimations (Pollock and Pine, 2007;

Donaldson et al., 2008). Mark-recapture methods allow for large numbers of fishes to be tagged, but under-reporting and natural mortality can affect survival estimates (Donaldson et al., 2008). The issues associated with these techniques, particularly with regards to survival estimations and assessment of post-release physiology and behaviour. make them less desirable to use compared with biotelemetry methods.

Recently, researchers have begun turning towards the use of electronic tags that allow the remote monitoring of free-swimming fishes post-release (Donaldson et al., 2008). For example, Cooke et al. (2000) used electromyogram telemetry to determine fine-scale post-release behaviour of nest-guarding male largemouth bass. Another study conducted by Lee and Bergesen (1996) evaluated the influence of oxygen levels on mortality in lake trout (Salvelinus namaycush). Bettoli et al. (2000) studied the postrelease survival of saugers (Stizostedion canadense) using radio transmitters equipped with mortality sensors that, after an $8 \mathrm{~h}$ period of inactivity, transmitted signals at a different pulse rate. Similarly, Stokesbury et al. (in review) affixed pop-up satellite transmitters, equipped with pressure sensors, to Atlantic bluefin tuna (Thunnus thynnus) that detached from the fish after no changes in pressure were noted for a period of $24 \mathrm{~h}$, indicating the fish had died and sunk to the bottom. Hightower et al. (2001) manually radio-tracked striped bass (Morone saxatilis) and concluded that if fish were repeatedly 
tracked to the same locations, then the fish were likely dead or moribund. Biotelemetry offers several advantages over other methods including more reliable survival estimates, the ability to integrate multiple disciplines (e.g., physiology, behavioural ecology). and address several $C \& R$ issues at once (Donaldson et al., 2008).

\section{Biotelemetry and Tagging Techniques}

A recent review of Great Lakes fish movement studies indicated that the use of biotelemetry within the last 20 years has increased (Landsman et al., 2011 b). The ability to locate (Lucas and Baras, 2000) and assess the physiology and behaviour (Cooke et al., 2004b; Ropert-Coudert and Wilson, 2005) of free-swimming fishes has greatly improved with the advent of tools such as: passive integrated transponder (PIT) tags; electromyogram, heart-rate, radio, and acoustic telemetry; satellite tags; and archival, biologging devices (Lucas and Baras, 2000; Cooke et al., 2004a,b; Ropert-Coudert and Wilson, 2005; Wilson et al., 2008). Capture independent methods of studying fish behaviours include hydroacoustics and visual observation, which minimize disturbance and allows for a more accurate representation of normal behaviour (Lucas and Baras, 2000). Capture dependent strategies (e.g., electrofishing, netting, angling) may impose additional stressors that could affect fish physiology and behaviour (e.g., Barton and Iwama, 1991), particularly after the attachment or implantation of transmitters or other remote sensing devices (Bridger and Booth, 2003). Furthermore, biologgers require that

the device be retrieved from the fish, which can be a particularly difficult task (Lucas and Baras, 2000). Still, the potential information gained from electronic telemetry tags is enormous. With such an assortment of methods to observe fish in their natural 
environments, the type of research question addressed should dictate what method is used. For example, the capacity to incorporate several sensors into a single transmitter or logger makes biotelemetry an attractive method of studying the behavioural ecology of a species relatively little is known about.

\section{Muskellunge Biology}

The muskellunge is endemic to North America and is a highly prized sport fish. Approximately $80 \%$ of water bodies containing muskellunge are limited to Wisconsin, Ontario, Michigan, West Virginia, and Minnesota, though their range extends throughout the Midwestern United States and a number of water bodies in Québec, Canada (Scott and Crossman, 1973; Kerr, 2011). Muskellunge are likely most noted for their size, easily capable of exceeding total lengths of $120 \mathrm{~cm}$ (Casselman et al., 1999; Cassleman, 2007) and weighing up to $32 \mathrm{~kg}$. In Canada, the only other freshwater fishes that grow larger are sturgeons (Acipenser spp., Scott and Crossman, 1973). Surveys of almost 100 lakes in Wisconsin indicate density estimates of less than 1.0 adult individual per hectare (Jennings et al., 2010). In addition, catch-per-unit-effort for some water bodies in Ontario suggests it may take nearly 100 hours to catch an adult muskellunge (Kerr, 2007a). Growth rates are rapid in the first few years of development, but taper as muskellunge age (Scott and Crossman, 1973). Spawning occurs in the spring at water temperatures ranging from 9 to $15^{\circ} \mathrm{C}$ when females and males broadcast eggs and milt along the shallow, littoral zones of lakes and rivers (Scott and Crossman, 1973). Sexual maturity occurs at approximately five years of age, and lifespans may reach an estimated 24 years (Casselman et al., 1999; Casselman, 2007). Muskellunge consume a wide array 
of prey including, where present, minnows (Cyprinidae), bass (Micropterus spp.). walleye (Sander vitreus), yellow perch (Percaflavescens), mice (Rodentia), frogs (Ranidae), and even small waterfowl and muskrats (Ondatra zibethicus; Anderson, 1948; Bozek et al.. 1999). Ritchie and Johnson (2009) identify apex predators as "largebodied... specialized hunters" that "occupy the top trophic position in a community." Such characteristics are exemplified by muskellunge, which certainly solidifies them as apex freshwater predators.

Historically, muskellunge populations have faced many challenges. Commercial fishing (Crossman, 1986) and the loss of spawning habitat (Dombeck, 1986) in the early $20^{\text {th }}$ century have been cited as major contributing factors to declines of natural populations. Furthermore, a catch-and-kill mentality among muskellunge anglers reigned supreme until the mid-1900s (Crossman, 1986). Over time, however, anglers began recognizing that killing their catches was contributing to the issue of overharvest. In response, C\&R angling practices were adopted (Graff, 1986). Early handling procedures consisted of a variety of methods for landing fish including hand-landing. cradles, and gaffs (hooked through the lower jaw; Gasbarino, 1986). Recent technological advancements in angling gear (e.g., rods, reels, line) and landing equipment (e.g., coated, knotless mesh nets) have enabled anglers to greatly improve handling practices (Landsman, 2008). Today, over $97 \%$ of muskellunge are voluntarily released (Fayram, 2003; Margenau and Petchenik, 2004; Kerr, 2007a), but the sub-lethal and lethal effects that current handling procedures may have on released muskellunge has never been examined. Scientists now have the ability to monitor post-release survival using biotelemetry and, when combining other research tools, can reveal behavioural and 
physiological (i.e., sub-lethal) disturbances related to the C \&R process.

\section{Research Objectives and Expectations}

The overall objective of this thesis is to further our understanding of muskellunge biology in the context of C\&R angling and behavioural ecology. Most emphasis on muskellunge research has been placed on culture and propagation with little understanding of physiology and behaviour (Crossman, 1986). Although Beggs et al. (1980) assessed the physiology of angled muskellunge in a laboratory setting, no evaluation has been done in the field or with regard to release practices. Relatively little is known about the fine-scale behavioural patterns of muskellunge, with most behavioural assessments being conducted on coarse-scales (e.g., $3 \mathrm{~h}$ intervals) employing manual radio tracking methods (e.g., Miller and Menzel, 1986). Two separate studies were conducted to address these issues.

The objective of Chapter 2 was to combine non-lethal physiology and radio telemetry to evaluate the sub-lethal and lethal effects of current $C \& R$ handling practices, as well as an alternative procedure, on muskellunge. Given the specialized nature of muskellunge anglers and their handling practices, it was expected that physiological and behavioural disturbances would be minimal and not significantly different between angling treatments. Furthermore, mortality would also be minimal and far below the $30 \%$ rate suggested by Beggs et al. (1980).

The objective of Chapter 3 was to evaluate the fine-scale diel (i.e., 24 hour) activity and depth patterns of muskellunge using novel tri-axial acceleration and pressure sensing acoustic transmitters. In addition, biologically-relevant variables such as fish 
size, time of day (i.e., dawn, day, dusk, night), temperature, and moon phase were assessed to quantify their impact on activity and depth. It was expected that higher levels of activity and shallower depths would be noted during the day than at other time periods. It was also expected that activity and depth would be affected by fish size, water temperature, and moon phase. Specifically, activity would be highest for smaller fish, during periods of warm water temperatures, and during new and full lunar phases. Depth was also expected to be shallowest for smaller fish, during warm water temperatures, and at new and full lunar phases.

In Chapter 4, I summarize the findings of these studies and places the results of this thesis in the context of our overall understanding of muskellunge biology. In addition, I provide suggestions for fisheries managers and future research initiatives. The final component of this thesis is Appendix I, in which I detail a small study designed to evaluate the viability of alternative methods to using J-hook swallow rigs when angling muskellunge with live-bait. 


\title{
Chapter 2: Evaluation of the physiology, behaviour, and survival of adult muskellunge (Esox masquinongy) captured and released by specialized anglers
}

\begin{abstract}
Angling for muskellunge (Esox masquinongy) is a specialized endeavour involving species-specific equipment and handling procedures. Anglers developed the latter with little influence from fisheries managers or the scientific community. Today, release rates approach $100 \%$ for specialized anglers; therefore, a formal evaluation of these procedures was warranted. Using two handling treatments - one to mimic current handling procedures with a period of air exposure and another gentler alternative without a period of air exposure - we assessed the physiological and behavioural disturbances as well as mortality associated with the catch-and-release process. Seventy-seven muskellunge were angled and blood sampled during the 2009 and 2010 muskellunge angling seasons. An additional 18 muskellunge were electrofished and immediately blood sampled to obtain baseline physiology data. A subsample $(N=30,15$ per treatment) of the 77 angled individuals were fitted with external radio transmitters to assess behaviour and survival. Glucose and lactate concentrations were found to be significantly lower for controls, and glucose and potassium concentrations increased significantly with increasing surface water temperatures. No differences in physiology were noted between angling treatments. Muskellunge treated with normal and alternative handling procedures exhibited similar post-release behaviour, and no angling related mortalities were observed across a range of water temperatures $\left(17.5-26.0^{\circ} \mathrm{C}\right)$. We demonstrated the effectiveness of current handling procedures at minimizing
\end{abstract}


physiological and behavioural disturbances, particularly when compared with a gentler alternative. A fishery in which no angling mortality exists is not possible, but our study provides support for the notion that angling related mortality for muskellunge captured and released by specialized anglers using handling procedures evaluated in this study may indeed be negligible.

\section{Introduction}

The muskellunge (Esox masquinongy) is one of the most prized sport fishes in North America. Within the past 50 years, muskellunge angling has undergone paradigm shifts away from catch-and-kill to that of catch-and-release (C\&R) angling. Today, release rates among specialized muskellunge anglers exceed $97 \%$ in both the United States and Canada (Fayram, 2003; Margenau and Petchenik, 2004; Kerr, 2007a). Specialized angler groups commonly release more of their catches and urge more stringent $C \& R$ regulations (e.g., increased minimum length limits) to improve the quality of a fishery (Chipman and Helfrich, 1988; Quinn, 1996). Fisheries management agencies often manage populations to produce trophy-size individuals through high minimum length and low bag limits (Hanson et al., 1986; Wingate, 1986; Quinn, 1996), which can be hampered by poor survival rates of released fishes (Brousseau and Armstrong, 1987). Nevertheless, C\&R represents an important management tool for conserving muskellunge populations because individuals can live upwards of 30 years (Casselman and Crossman, 1986), population densities are relatively low (Jennings et al., 2010), and populations have suffered from historical overfishing (Crossman, 1986). The attitudes and actions by 
both anglers and managers, however, suggests both parties rely on the assumption that released fishes will survive, a concept fundamental to C\&R angling (Wydoski, 1977).

Survival assessments can be complicated and mortalities may not be immediately apparent (Muoneke and Childress, 1994). Duration of air exposure, handling time, water temperature, and hooking location can significantly affect the survival of released fishes (see Bartholomew and Bohnsack, 2005; Cooke and Suski, 2005). Sub-lethal effects of angling (e.g.. behaviour, physiology) can also affect overall welfare of angled fishes (e.g.. Suski et al., 2003a,b; Suski et al., 2007; Klefoth et al., 2008), including potential fitnessrelated consequences ranging from mortality to reduced reproductive output (reviewed in Arlinghaus et al., 2007a). Although anglers may not be able to control such factors as hooking location, particularly when using active angling methods, strategies to minimize the accumulation of sublethal endpoints could reduce delayed mortality.

Evaluating handling procedures used by angler groups offers the potential to increase survival among angled fishes (Cooke and Suski, 2005). However, species often differ in their responsiveness to various stressors, and where one set of handling procedures may be appropriate for a particular species a wholly different set may be needed for another (Cooke and Suski, 2005). Muskellunge anglers have made considerable efforts to develop and refine handling procedures as the sport's popularity increased (Gasbarino, 1986; Saric and Heiting, 1999; Kerr, 2007b; Landsman, 2008). Thus far, no scientific input has been used to create these handling procedures. Nevertheless, even a slight increase in annual harvest rates of muskellunge would necessitate large increases in recruitment rates to maintain trophy fisheries (Casselman and Crossman, 1995). Improved C\&R practices would curb harvest and greatly benefit 
the fishery (Casselman and Crossman, 1995). Therefore, validating the appropriateness of current handling procedures used by specialized anglers is of interest for anglers. managers, and researchers alike.

The objectives of this study were to 1) quantify the post-release mortality rates of C\&R muskellunge, 2) quantify the physiological and behavioural consequences associated with the $C \& R$ process for muskellunge, and 3 ) determine if alternative handling techniques (designed to minimize handling disturbances) would ameliorate physiological or behavioural disturbances and reduce mortality rates. This study was conducted in a natural, field setting, using a combination of radio telemetry and bloodbased physiological analyses.

\section{Methods}

2.1. Study sites. Angling took place in eastern Ontario, Canada on the Ottawa River $\left(45^{\circ} 34^{\prime} 27.35 \mathrm{~N}, 75^{\circ} 7^{\prime} 42.01 \mathrm{~W}\right.$; Figure $\left.2-1 \mathrm{a}\right)$ and two reaches of the Rideau River: the "Long Reach" $\left(45^{\circ} 4{ }^{\prime} 23.84\right.$ "N, $75^{\circ} 38^{\prime} 34.53$ "W; Figure 2-Ib) and the "Eccolands Reach" (45'18'53.38"N, 75'41'50.11"W: Figure 2-Ic). When and where angling occurred depended on regulations (e.g., closed angling seasons), local angler information, and weather. All research activities were conducted in accordance with guidelines from the Canadian Council on Animal Care as administered by Carleton University and under a scientific collection permit obtained from the Ontario Ministry of Natural Resources.

2.2. Angling. Volunteer specialized muskellunge anglers aided in capturing fish throughout the study. Although the vast majority of muskellunge were captured from one primary research boat (equipped for muskellunge angling), multiple boats were 
occasionally used to aid in fish collection. Additional boats remained either within eyesight or radio contact of the primary research boat, which would motor to a group of volunteers that had successfully captured a muskellunge to finish the sampling protocol described below. Anglers employed conventional muskellunge angling methods including the use of muskellunge-specific rods, reels, and terminal tackle (e.g., $36-45 \mathrm{~kg}$ braided line, fluorocarbon or steel leaders). A variety of artificial lures were used at the anglers' discretion. ranging in size from $15.2-45.7 \mathrm{~cm}$ with $1-9$ barbed hook points (Figure 2-2), and presented using both casting and trolling methods. All muskellunge were angled from less than $5 \mathrm{~m}$ of water. Lastly, live-bait was not used in this study because of its use during the months of fall, which were not included during the study period, are typically when anglers employ live-bait (Margenau, 2007). Furthermore. anglers generally do not prefer using live-bait to artificial lures, regardless of their degree of specialization (Margenau and Petchenik, 2004).

Unedited online video footage, personal observation, and informal angler surveys were used to determine typical handling procedures used by specialized muskellunge anglers to develop handling protocols; these handling procedures were combined to define the "normal" handling treatment used in this study. This treatment group consisted of the following: muskellunge were angled as quickly as possible; large, knotless nets were used to restrain fish that were left submerged in the water; de-hooking with pliers began with fish still submerged, and continued for no more than $2 \mathrm{~min}$, with hook cutters employed if de-hooking took longer than $2 \mathrm{~min}$; fish were removed from the water for an admiration period (e.g., photos, measurements) of no more than $90 \mathrm{~s}$ and immediately returned to the water for release. As an alternative, a gentler handling 
procedure was compared to the procedures currently used by specialized anglers. In an effort to reduce handling time, the alternative treatment used hook-cutters only. In addition, the admiration period was removed from the alternative handling procedure to eliminate the consequences associated with air exposing angled fishes (Ferguson and Tufts, 1992: reviewed in Cooke and Suski, 2005). For both treatments, at least one angler used a stopwatch to time the duration of the angling events. At the onset of the study a dice was rolled to randomly assign the first angled muskellunge a particular handling treatment, after which treatments were alternated with each consecutive individual. Following the capture of each muskellunge, surface water temperature was recorded using a hand-held thermometer.

2.3. Sampling protocol. Following capture and de-hooking according to the treatment described above, muskellunge were transferred to a flow-through holding trough $(300 \mathrm{~L})$ where a non-lethal blood sample was collected for quantification of physiological disturbances. Approximately $1.5 \mathrm{~mL}$ of blood was extracted from the caudal vasculature using a $3 \mathrm{~mL}$ lithium-heparinized vacutainer and 21 gauge, $30 \mathrm{~mm}$ needle (Cooke et al., 2005). Whole blood was used to analyze glucose and lactate concentrations in the field with portable glucose (ACCU-CHEK glucose meter; Roche Diagnostics, Basel, Switzerland) and lactate (Lactate Pro LT-1710 portable lactate analyzer; Arkray Inc., Kyoto, Japan) meters. These field diagnostic tools have been previously verified for use on fish by comparing data obtained in the field to laboratoryderived data (Venn Beecham et al., 2006; Cooke et al., 2008). After using a centrifuge to separate the plasma and red blood cells, a ruler was used to assess hematocrit levels by measuring the volume of plasma to whole blood. Transfer pipettes were used to separate 
plasma from red blood cells, and samples were flash-frozen in liquid nitrogen for laboratory analysis. In the laboratory, cortisol concentrations were quantified using an enzyme linked, immunosorbent assay (i.e., ELISA: Kit \# 900-071; Assay Designs, Ann Arbor, MI, USA). ELISA kits were ranked on their abilities (e.g., accuracy, precision, variability) to generate cortisol concentrations similar to those obtained from more common, but more expensive, radioimmunoassays (Sink et al., 2008). Of four ELISA kits tested, the kit used in the present study made by Assay Designs scored highest (Sink et al., 2008). Plasma sodium and potassium concentrations were determined using a flame photometer (model 2655-00; Cole-Parmer Instrument Company, Chicago, IL, USA); whereas plasma chloride concentrations were quantified using a digital chloridometer (Labconco, model 4425000, Kansas City, MO, USA).

To obtain baseline physiological data, the same physiological sampling procedures described above were applied to electrofished (2.5 Generator Powered Pulser; Smith-Root, Inc., Vancouver, WA, USA) muskellunge (Schreck, 1976). This method of fish capture is preferred over other methods, such as netting, because of the short period of time following capture that fish can be blood sampled resulting in more accurate measurements of baseline physiology (Harrell and Moline, 1992). Electrofishing efforts were conducted at discrete time periods coinciding with water temperatures similar in range to that of the angling period (i.e., $6.5-25.5^{\circ} \mathrm{C}$ ). All electrofishing took place on the Rideau River at both the Eccolands Reach and the Long Reach. Pulsed direct-current (rate: 60 pulses per second) was used to reduce the risk of injuring captured muskellunge (Snyder, 2003). The electrical current was set at 7-8 amps and maximum output voltage 
was 500 Volts. Fish were sampled within 1 min of netting. Physiological measurements. therefore, were regarded as baseline values.

In 2009, a random sub-sample ( $N_{\text {total }}=30, N=15$ per handling treatment) of muskellunge used for our physiological analyses were externally affixed with individually-coded, external radio transmitters (Holohil Systems. Ltd.: Carp, ON, Canada) that weighed $3.2 \mathrm{~g}$ in air $(138-235 \mathrm{MHz}$, pulse rate $40 \mathrm{p} / \mathrm{min}$, pulse width 22 ms). Two needles were pushed through the dorsal musculature near the soft dorsal fin and stainless steel wires were passed through the lumen of the needles. A small rubber backing plate made from gasket material served to secure the tag on the opposite side of the fish (see Figure 1 of Bridger and Booth, 2003). Though weights were not recorded for tagged muskellunge, length-weight relationships of muskellunge reported by Casselman and Crossman (1986) indicated that even the smallest radio-tagged muskellunge was estimated to weigh approximately $3.0 \mathrm{~kg}$, almost 1,000 times more than the in-air weight of the transmitters (i.e., $3.2 \mathrm{~g}$ ). Given the size of radio-tagged muskellunge, issues associated with a fish's ability to carry the transmitter were avoided. A 3-element yagi antenna (AF Antronics, Urbana, IL) and receiver (Biotracker; Lotek Engineering, Inc.; Newmarket, ON, Canada) were used to manually track individuals and assess survival as well as behavioural alterations immediately post-release (i.e., $10 \mathrm{~min}$, $30 \mathrm{~min}, 1 \mathrm{~h}, 2 \mathrm{~h}$ ), at $24 \mathrm{~h}$ post-release, $48 \mathrm{~h}$, once every third day for $1 \mathrm{wk}$, and weekly or bi-weekly thereafter. Global positioning system (GPS; Garmin E-Trex; Garmin International, Inc.; Olathe, KS, USA) coordinates were taken at each location.

Hightower et al. (2001) outlined methods for determining mortality of radio tagged fish and suggested that repeatedly tracking an individual at the same location 
indicated mortality. This criterion was used for the current study, though particular attention was paid to upstream movements since dead or moribund muskellunge cannot swim upstream. Furthermore, because most post-angling mortality occurs in less than 48 h (Muoneke and Childress. 1994) survival was determined if fish exhibited continued movements, both upstream and downstream, for at least $48 \mathrm{~h}$ (i.e., sum of distance moved up to $48 \mathrm{~h}$ and the number of upstream movements between sequential tracking points). Locations could not be ascertained if muskellunge moved into water deeper than $10 \mathrm{~m}$. Local weather conditions, boat traffic, and macrophyte cover may also have impaired our abilities to locate fish. Repeated attempts - multiple times per day or daily visits - to contact fish were made until contact was reestablished. Finally, recaptures were also used to assess survival, though local anglers were often able to supply only a photograph and unable to supply individual tag numbers because the accumulation of algae covered the tag numbers and anglers were instructed not to remove the tags from the fish. Therefore, identifications were made based on size, location, and individual markings. Reflex impairment was also quantified for angled muskellunge in an attempt to correlate loss of reflex(es) with mortality. At the site of release. each fish's ability to 1) maintain equilibrium, 2) burst away, and 3) swim downward was observed and recorded. The absence and presence of these reflexes were scored on a $0-1$ scale $(0=$ absent, $1=$ present) and a composite score was created for each muskellunge. This method, also known as "reflex action mortality predictor" (RAMP), was strongly correlated (i.e., $P$ "s $<$ 0.01 ) with mortality for several species of flatfish and roundfish (Davis and Ottmar, 2006). 
2.t. Statistical Analyses. Water temperatures were grouped into low (6.5-13.5 C), moderate $\left(14.0-21.0^{\circ} \mathrm{C}\right)$, and high $\left(21.5-28.0^{\circ} \mathrm{C}\right)$ to account for temperature-induced differences in baseline and post-angling physiological disturbances (Gustaveson et al., 1991). Blood data were tested for normality and homogeneity of variance using ShapiroWilk and Levene's tests (Sokal and Rohlf, 1995), but several transformations could not satisfy these assumptions. Data were rank transformed to allow the application of a parametric two-way ANOVA under nonparametric conditions (i.e., non-normal data, heterogeneity of variance; Conover and Iman, 1981). This method of analysis permitted the evaluation of physiological differences between treatments (including controls), temperature, and treatment $\times$ temperature. Movement data, defined as distances swum between sequential tracking points (i.e., time intervals) were log-transformed (Zar, 1984) and post-release behaviour was evaluated using a two-way repeated measures ANOVA (main effects: time interval, treatment, time interval $\times$ treatment; individual fish number entered as a random effect) because the same individuals were sampled more than once, thus violating the assumption of independence (Girden, 1992). Behaviour was evaluated at $10 \mathrm{~min}, 30 \mathrm{~min}, 1 \mathrm{~h}$, and $2 \mathrm{~h}$ post-release. Reflex impairment was evaluated between treatments using a t-test. When a main effect(s) or interaction term was significant, a Tukey-Kramer HSD post hoc test was used to compare means. All statistical tests were carried out using JMP 7.0 (SAS Institute, Cary, North Carolina), significance levels set at $\alpha \leq 0.05$, and means are reported as \pm standard error (S.E.) where appropriate. Correction factors for multiple comparisons were not applied because while the probability of committing Type I errors decreases, the probability of increasing Type II errors increases and statistical power decreases (Zar, 1984; Nakagawa, 2004). 


\section{Results}

3.1. Angling and Electrofishing. Over the 2009 and 2010 angling seasons, 77 muskellunge were successfully angled. The total length $\left(L_{T}\right)$ of fish that were blood sampled in our normal and alternative treatments averaged $102.0 \pm 3.0 \mathrm{~cm}(N=34$, range $63.5-131.0)$ and $98.2 \pm 2.8 \mathrm{~cm} \mathrm{~L} \mathrm{~L}_{\mathrm{T}}(N=33$, range 57.2-132.1), respectively. Blood sampling occurred over periods where surface water temperatures ranged from 6.5 to $27.5^{\circ} \mathrm{C}$. Radio tagged muskellunge in our normal treatment group had a mean $\mathrm{L}_{\mathrm{T}}$ of $110.5 \pm 3.8 \mathrm{~cm}\left(\right.$ range $\left.80.8-131.0 \mathrm{~cm} \mathrm{~L}_{\mathrm{T}}\right)$ and $103.9 \pm 3.4 \mathrm{~cm}\left(\right.$ range $\left.81.3-132.1 \mathrm{~cm} \mathrm{~L}_{\uparrow}\right)$ for our alternative treatment group. Water temperatures ranged from 17.5 to $26.0^{\circ} \mathrm{C}$ during radio tagging periods. Mean $\mathrm{L}_{\mathrm{T}}$ of electrofished muskellunge was $88.5 \pm 3.9 \mathrm{~cm}$ $\mathrm{L}_{\mathrm{T}}\left(N=18\right.$; range $\left.62.2-124.5 \mathrm{~cm} \mathrm{~L} \mathrm{~L}_{\mathrm{T}}\right)$ and water temperatures during electrofishing ranged from 6.5 to $25.5^{\circ} \mathrm{C}$.

\subsection{Mortality and Recaptures. All 30 radio-tagged muskellunge exhibited} continued movements following release (Table 2). These movements included at least two upstream movements during the period they were tracked (Table 2). In the summer of 2009 , six radio-tagged muskellunge were recaptured, including one individual that was recaptured twice within a 2 wk period. The transmitter from fish \# 151.460 was found on shore and assumed to be an unreported recapture given the state in which the transmitter was recovered. For the 2010 angling season, two radio-tagged muskellunge were recaptured as well as an additional non-radio tagged (Floy tag only) muskellunge that was originally captured for physiological analyses. At least $23 \%(N=7)$ of radio-tagged individuals were recaptured and reported during the study. 
3.3. Physiological Disturbances. Treatment had a significant affect on blood glucose (two-way ANOVA, $F_{2.53}=9.2, P=0.0004$; Table 1: Figure 2-3a) and lactate concentrations (two-way ANOVA, $F_{2.53}=14.7, P<0.0001$; Table 1; Figure 2-3b) where angling caused the two parameters to increase relative to controls (Tukey-Kramer HSD, $P<0.05$; Figures $2-3 a$ and $2-3 b$ ). More specifically for angled muskellunge, blood glucose and lactate concentrations increased over 1.3 and 1.8 times to maximums of $3.6 \pm$ $0.2 \mathrm{mmol} / \mathrm{L}$ and $6.9 \pm 0.6 \mathrm{mmol} / \mathrm{L}$, respectively (Figures $2-3 \mathrm{a}$ and $2-3 \mathrm{~b}$ ). Nevertheless, no differences were observed between the two handling treatments themselves for any parameter (Tukey-Kramer HSD, P's $>0.05$; Figures 2-3a-e and 2-4a-e). Plasma potassium had a significant treatment $\times$ temperature interaction term (two-way ANOVA, $F_{2,53}=3.1, P=0.02$; Figure 2-4b). For normally treated muskellunge, an increase of more than two-fold between low and high temperatures was noted as well as an increase of more than 1.5 times between controls and normally handled muskellunge at high temperatures (Figure 2-4b). Temperature also significantly affected blood glucose concentrations (two-way ANOVA, $F_{2.53}=14.9, P<0.0001$; Table $2-1$ ). Mean glucose concentrations at high temperatures increased significantly by over 1.5 times relative to low temperatures (Tukey-Kramer HSD, $P<0.05$; Figure 2-3a). Temperature and treatment effects, however, were not shown for any other parameter (Table 2-1; Figure 2-4a-e). For non-significant effects, statistical power was low $(<0.5)$ for many parameters and the least significant number of samples needed to attain a power of at least 0.5 ranged from 73 to 1,924 (Table 2-1). Finally, plasma chloride ions and cortisol were analyzed without control data due to technical difficulties associated with transportation and analyses. 


\subsection{Behaviour and Reflex Impairment. Angled muskellunge moved similar}

distances irrespective of treatment (two-way repeated measures ANOVA, $F_{1.26}=0.5, P=$ 0.5 ; Figure 2-5) and traveled a maximum of $45 \mathrm{~m}$ at any given period up to $120 \mathrm{~min}$ post-release (Figure 2-5). Mean distance traveled per time interval increased consecutively until $2 \mathrm{~h}$ post-release, but this trend was not significant (two-way repeated measures ANOVA, $F_{3.77}=2.2, P=0.1 ;$ Figure $2-5$ ). More specifically, muskellunge handled gently moved almost twice as far between 10 and 60 min post-release, but decreased movement by more than half from 60 to $120 \mathrm{~min}$ post-release (Figure 2-5). Similarly for muskellunge handled normally, movement increased over two-fold from 10 to $60 \mathrm{~min}$ post-release and also decreased by more than half between 60 and $120 \mathrm{~min}$ post-release (Figure $2-5$ ). Finally, the treatment $\times$ time interval interaction effect had no significant impact on muskellunge post-release behaviour (two-way repeated measures ANOVA, $\left.F_{3.77}=0.05, P=1.0\right)$.

Reflex impairment could not be correlated with mortality because all tagged fish survived. In general, tagged and non-tagged fish from both treatments showed similar responses to reflex testing ( $\mathrm{T}$-test, $F=0.2, P=0.6$ ). The mean transformed proportion of reflexes present for muskellunge handled with alternative $(N=34)$ and normal $(N=34)$ procedures was $0.7 \pm 0.04$ and $0.7 \pm 0.04$, respectively. All but two muskellunge (i.e.. $N$ $=66 ; 97 \%)$ were able to maintain equilibrium. Upon release, $69 \%\left(N_{\text {total }}=47\right)$ of angled muskellunge did not burst away from the handlers. In addition, $19 \%(N=12)$ did not swim downward, but remained on the surface for upwards of approximately 5-10 $\mathrm{min}$. 


\section{Discussion}

We used radio telemetry to estimate mortality of caught-and-released muskellunge, an approach that has been identified as being particularly robust for generating field-relevant post-release mortality estimates (Donaldson et al., 2008). Based on radio tracking muskellunge in this study, none of the 30 radio-tagged muskellunge died as a result of the angling event. Our finding of a $0 \%$ mortality rate contradicts the $30 \%$ figure reported by Beggs et al. (1980). Their estimate, however, was made in a laboratory setting and may have introduced handling and confinement-related stressors resulting in an elevated mortality rate (Pollock and Pine, 2007; Donaldson et al., 2008). Moreover, Frohnauer et al. (2007) and Strand (1986) observed a 4.1\% and 0\% mortality rate of angled muskellunge from Shoepack Lake in Voyageurs National Park, Minnesota and Leech Lake, Minnesota, respectively. The C\&R mortality rates reported in the present study, Frohnauer et al. (2007), and Strand (1986) are markedly lower than those reported for other freshwater species (see Muoneke and Childress, 1994; Bartholomew and Bohnsack, 2005), but are consistent with mortality rates in specialized fisheries that are often less than $5 \%$ and sometimes below $0.1 \%$ (Policansky, 2002). Although no mortalities were observed in this study, it should be acknowledged that zero risk of angling mortality is never achievable in a fishery (Arlinghaus et al., 2007a).

Muskellunge angling mortality, therefore, may be negligible and management decisions should reflect this. For example. if creating trophy fisheries is a management agency's objective and employing high minimum length limits are used (Casselman, 2007), then angling mortality should be low to obtain the intended results (Brousseau and Armstrong, 1987). Indeed, the present study shows low angling mortality of muskellunge released by 
specialized anglers and provides support for increasing minimum length limits if the goal is to create trophy fisheries. However, it is uncertain what mortality rates are when nonspecialized anglers handle muskellunge. We encourage future studies to address the possibility that muskellunge captured by non-specialized anglers (e.g., those using lighter gear and targeting smaller species) may exhibit higher levels of mortality (Gasbarino, 1986).

Angling inevitably causes some level of physiological disturbance for fish (Cooke and Sneddon, 2007). Indeed, the results of this study indicate that angling events cause significant physiological disturbances relative to control fish, though no significant differences between either handling treatments (i.e., normal vs. alternative) were noted. More specifically, blood glucose, blood lactate, and plasma potassium were the only parameters to display significant differences. Angling is a form of exhaustive exercise (Wood, 1991; Kieffer, 2000) that causes a cascade of physiological responses in fishes including the release of glucose into the bloodstream - providing fuel for tissues such as the heart, liver, and gills - and the production of lactate anions (Pagnotta and Milligan, 1991; Moyes and West, 1995; Wendelaar Bonga, 1997). A portion of the lactate produced leaks into the bloodstream, though evidence suggests the majority remains within white muscle tissue (Pagnotta and Milligan, 1991; Wood, 1991; Schwalme and Mackay, 1985). Previous work by Beggs et al. (1980) showed lactate levels of angled muskellunge reaching $4.0 \mathrm{mmol} / \mathrm{L}$, but the present study indicates lactate levels exceeding $6.0 \mathrm{mmol} / \mathrm{L}$. One potential explanation for this discrepancy could be related to size (Kieffer et al., 1996; Kieffer, 2000; Meka and McCormick, 2004), as the maximum size of fish used by Beggs et al. (1980) was $91.8 \mathrm{~cm} \mathrm{~L}_{\mathrm{T}}$ compared to $132.1 \mathrm{~cm} \mathrm{~L}$ in this 
study. This relationship. however, was not explored in the present study because anglers cannot control for the size of fish that strike their lures. Though statistical power was low for many non-significant effects, this is likely explained by the short period of time from capture to blood sampling that may not have allowed some parameters to peak. For example, muskellunge lactic acid concentrations peaked $\mathrm{I}$ h into recovery (Beggs et al., 1980) and plasma cortisol concentrations for juvenile Chinook salmon (Oncorhynchus tshawytscha) also peaked $1 \mathrm{~h}$ after the final stressor (Barton et al., 1986). The large number of samples needed to obtain significant results indicates that many of the parameters tested are highly conserved between individuals immediately following capture. Regardless, the current study demonstrates that the angling event causes significant physiological disturbances relative to non-angled muskellunge.

Despite changes in muskellunge physiology following angling events, no significant differences in physiological status were noted between fish handled with and without $90 \mathrm{~s}$ of air exposure. Physiological disturbances resulting from air exposure can be large and result from collapsing gill lamellae, which prevents gas exchange (Boutilier, 1990; Ferguson and Tufts, 1992). However, the severity and duration of a stressor may have profound effects on the stress response in fishes (Barton and Iwama, 1991; Schreck, 2000). We demonstrated that $90 \mathrm{~s}$ of air exposure may not be long enough to cause significant physiological disturbances.

Suski et al. (2007) found that physiological differences among bonefish (Albula vulpes) were exacerbated as the duration of both angling time and air exposure increased to a maximum of $240 \mathrm{~s}$ of exercise and $180 \mathrm{~s}$ of air exposure. Additional studies on largemouth bass (Micropterus salmoides, Gustaveson et al., 1991), smallmouth bass 
(Micropterus dolomieu. Kieffer et al.. 1995). and Atlantic salmon (Salmo salar. Thorstad et al., 2003) identify angling time as a significant stressor. The current study used handling procedures that minimized angling times in all cases, largely through the use of heavy lines and stout rods (i.e., standard muskellunge angling equipment). Extended angling durations often observed with long-line and down-rigger trolling (Beggs et al., 1980; Dedual, 1996; Bartholomew and Bohnsack, 2005) as well as inexperienced anglers (Storck and Newman, 1986) may cause greater physiological disturbances for muskellunge. We demonstrated that muskellunge subject to normal handling procedures did not exhibit significantly different physiological responses compared to an alternative. suggesting current handling procedures are adequate for minimizing physiological disturbance. Anglers are, however, advised to minimize air exposure as much as possible to ensure fish welfare. Moreover, no mortality was observed which suggests that these fish are indeed able to recover from the level of physiological disturbance incurred in the present study.

Muskellunge angling occurs across a broad range of temperatures, typically spanning late spring through late fall. This time period encompasses warm summer months, particularly in the muskellunge's northern portions of its range, where water temperatures may become excessively high, which could increase physiological disturbances (Cooke and Suski, 2005). Anglers in latitudes extending into the southern portion of the specie's range (e.g., Illinois, Kentucky, Tennessee) typically cease angling for muskellunge when water temperatures rise above $27^{\circ} \mathrm{C}$ (personal observation). The present study revealed that increases in water temperature caused significant increases in blood glucose and plasma potassium concentrations for muskellunge relative to angling 
at cooler temperatures. though temperatures rarely exceeded the optimal thermal preference (i.e., $25.6^{\circ} \mathrm{C}$ : Scott and Crossman, 1973). Our findings agree with several other studies demonstrating increased glucose concentrations at higher temperatures (Gustaveson et al., 1991; Meka and McCormick, 2005). The observed glucose concentration increases may be attributed to increased standard metabolic rates that rise as water temperatures warm (Dickson and Kramer, 1971; Cooke et al., 2001). In turn, production of liver glycogen rises resulting in an increase in glucose as glycogen is catabolized (Kieffer, 2000). Such energy demands are necessary for fish to recover following intense activity (Kieffer, 2000). Explanations for the observed increases in plasma potassium with water temperature are relatively unclear. However, potassium has been shown to enter plasma following exercise due to intercellular metabolic waste (Wang et al., 1994), red blood cell sodium-potassium pumps (Borgese et al., 1987), or intracellular gill uptake (Wood and Lemoigne, 1991), and elevated plasma potassium concentrations at higher water temperatures may result from increases in membrane fluidity (Cossins and Prosser, 1978; Gerner et al., 1980). This particular response is of interest because potassium cations influence nerve function (Hidaka and Toida, 1969; Abe and Oka, 1999) and elevated potassium levels (i.e., hyperkalemia) can contribute to cardiac failure in mammals (Guyton, 1981; Lindinger, 1995). Interestingly, Beggs et al. (1980) observed markedly higher plasma potassium concentrations in muskellunge that died compared to those fish that survived through the experimental period. Because most muskellunge angling occurs in the warm summer months (Kerr, 2007a), the potentially lethal effects of increased potassium concentrations and their relation to cardiac failure is of concern. Evidence from this study clearly indicates the propensity for physiological 
disturbance to increase with increasing water temperatures. Therefore, it is advisable to be cautious of the magnitude of stress imposed on muskellunge (e.g., severely limit air exposure and angling durations) when angling during periods of high water temperatures.

A failure of the different handling treatments to induce different physiological responses can likely be partially related to the immediate blood sampling procedure following angling. Serial sampling has revealed that physiological measures of stress may not peak until well after the onset of the initial stressor (e.g., Soivio and Oikari. 1976; Pickering et al., 1982; Barton et al., 1986; Young and Cech, Jr., 1993). Future studies should consider serial sampling to determine how much time elapses before concentrations of parameters such as blood glucose, blood lactate, and plasma cortisol peak and then return to basal levels. Another potential explanation for the minimal physiological differences across handling treatments in this study is the condition of angled muskellunge. Hematocrit can provide a measure of the overall condition for a fish (Barton, 2002) and the uniformity of hematocrit levels between treatments and controls suggests relatively good health for all fish in this study. Taken together, minimal responses for the physiological parameters tested may be attributed to the apparent good health of the muskellunge sampled and the immediate blood sampling procedures used to collect data.

As with the lack of physiological disturbances between handling treatments, we further demonstrated that handling procedures with and without air exposure (within the limits used in this study) do not significantly affect post-release behaviour. Muskellunge moved an average of $45 \mathrm{~m}$ at $1 \mathrm{~h}$ post-release. Arlinghaus et al. (2009) found that total movement of northern pike (Esox lucius) post-release did not differ significantly with 
varying levels of air exposure. They also showed that with 60 and $180 \mathrm{~s}$ of air exposure. northern pike moved approximately $30 \mathrm{~m}$ in the first hour post-release, which was similar with the distances noted in this study. Predation following angling is a concern for some species of fishes such as bonefish (Cooke and Philipp, 2004; Danylchuk et al., 2007) and red snapper (Lutjanus campechanus; Campbell et al.. 2010), but predation of adult muskellunge is a non-issue because the size of adults precludes them as prey items for other species of fish. Behaviour of muskellunge pre-capture was not determined so it is unclear whether the patterns noted here conform to typical behaviour of non-angled muskellunge. Future studies on muskellunge should evaluate pre- and post-release behaviour and attempt to elucidate the duration necessary to fully recover from angling. It is unclear what affects, if any, the external tagging procedure had on muskellunge. However, because anesthetics were not used and muskellunge length-weight data suggests that even the smallest tagged individual $(80.8 \mathrm{~cm} \mathrm{~L})$ weighed several hundred times more than the transmitter weight (3.2 $\mathrm{g}$ in air; Casselman and Crossman, 1986) it is likely tagging effects were minimal (Ross and McCormick, 1981; Bridger and Booth, 2003). Nevertheless, we acknowledge the possibility that biofouling and tag abrasions could have caused behavioural disturbances, but these issues and others associated with external tagging are often manifest in juvenile or small sized fishes (see Bridger and Booth. 2003). Furthermore, some muskellunge may have tried to avoid the research boat as has been suggested for other fishes, particularly at distances less than $10 \mathrm{~m}$ away (Drašik and Kubečka, 2005). Regardless, the present study clearly demonstrates that angled muskellunge exhibit similar post-release behaviour despite air exposure in one 
handling method. but more fine-scale behavioural analyses could benefit our understanding of the recovery dynamics of muskellunge.

Another metric used to assess the effects of $C \& R$ angling on muskellunge was examining the degree of reflex impairment. Reflexes are tested as a rapid measure of fish condition and health (Davis and Ottmar, 2006). To date, reflex impairment has been used to predict mortality in several commercial species (Davis and Parker, 2004; Davis, 2005; Davis and Ottmar, 2006), but little has been done with recreationally important fishes. However, in the present study no mortality for angled fish was observed, therefore, no conclusions could be drawn for correlations between mortality and the absence of particular reflexes. Nevertheless, reflex impairment can still be used by anglers to assess the condition of their catch. For instance, we observed $19 \%$ of angled muskellunge remaining on the surface for a period of time and $69 \%$ that did not burst away following release. Anglers could potentially use these types of observations to adapt handling procedures accordingly, such as remaining in the vicinity of the catch to ensure no boats collide with released fish. Further validation of reflex impairment tests is needed to confirm its applicability in recreational fisheries.

\section{Conclusions}

Until now, formal evaluation of the handling procedures used by specialized muskellunge anglers has never been accomplished. These procedures were created with little science-based influence and as voluntary release rates approach $100 \%$ it becomes necessary to establish guidelines for proper handling procedures. The present study shows that current $C \& R$ handling procedures used by specialized muskellunge anglers 
maximize survival and minimize physiological and behavioural disturbances. The conscious decision to voluntarily release legal-sized muskellunge and employ methods that, as evidenced in this study, maximize survival is a testament to the conservation mindset of many specialized muskellunge anglers. Rarely are these types of specialized fisheries seen in recreational angling. Analogous to North American muskellunge anglers are specialized carp (Cyprinus carpio) anglers in Europe. These anglers employ similar handling procedures, advocate voluntary $C \& R$ to conserve the resource, and continually refine handling procedures to include new developments in the angling industry (Arlinghaus, 2007b). Although mortality is minimal in both European specialized carp (Raat, 1985) and muskellunge fisheries, species-specific impacts of handling should be evaluated in other specialized fisheries to ensure proper handling practices are employed (Cooke and Suski, 2005). The effectiveness of C\&R and its value to fisheries management is only as good as the procedures used by anglers and promoted by managers. We advise managers to account for the low degree of angling-associated mortality evidenced in this study, particularly when developing management goals for muskellunge fisheries, and advocate promotion of these handling procedures to the general angling public. 


\section{Tables}

Table 2-1. Results of the rank-transformed two-way ANOVA test examining the effects of treatment, temperature. and treatment $\times$ temperature on seven physiological parameters for control and angled muskellunge. Significant effects are denoted by bolded $P$ values. t† signifies parameters without control data and excluding 2010 data from angled muskellunge.

\begin{tabular}{|c|c|c|c|c|c|c|c|c|}
\hline Parameter & $N$ & Effect & $\mathrm{df}$ & SS & $F$ & $P$ & $\begin{array}{l}\text { Power } \\
(1-\beta)\end{array}$ & $\begin{array}{c}\text { Least } \\
\text { Significant } N \\
\end{array}$ \\
\hline \multirow{5}{*}{$\begin{array}{l}\text { Sodium } \\
(\mathrm{Meq} / \mathrm{L})\end{array}$} & \multirow{5}{*}{67} & Whole Model & 8 & 227.79 & 0.58 & 0.8 & & \\
\hline & & Treatment & 2 & 87.58 & 0.89 & 0.4 & 0.24 & 170 \\
\hline & & Temperature & 2 & 24.65 & 0.25 & 0.8 & 0.07 & 1.924 \\
\hline & & Treatment $\times$ Temperature & 4 & 105.87 & 0.54 & 0.7 & 0.16 & 314 \\
\hline & & Error & 53 & 2.828 .47 & & & & \\
\hline \multirow{5}{*}{$\begin{array}{l}\text { Potassium } \\
\text { (Meq/L) }\end{array}$} & \multirow{5}{*}{67} & Whole Model & 8 & 123.63 & 3.00 & 0.007 & & \\
\hline & & Treatment & 2 & 11.19 & 1.08 & 0.3 & 0.29 & 137 \\
\hline & & Temperature & 2 & 42.77 & 4.16 & 0.02 & - & - \\
\hline & & Treatment $\times$ Temperature & 4 & 63.09 & 3.07 & 0.02 & - & - \\
\hline & & Error & 53 & 272.64 & & & & \\
\hline \multirow{5}{*}{$\begin{array}{c}\text { Chloride }^{+\dagger} \\
(\text { Meq/L) }\end{array}$} & \multirow{5}{*}{33} & Whole Model & 3 & 9.87 & 1.50 & 0.2 & & \\
\hline & & Treatment & 1 & 4.42 & 2.02 & 0.2 & - & - \\
\hline & & Temperature & 1 & 0.043 & 0.020 & 0.9 & - & 一 \\
\hline & & Treatment $\times$ Temperature & 1 & 6.04 & 2.75 & 0.1 & - & - \\
\hline & & Error & 23 & & & & & \\
\hline \multirow{5}{*}{$\begin{array}{c}\text { Cortisol }^{+\dagger} \\
(\mathrm{ng} / \mathrm{mL})\end{array}$} & \multirow{5}{*}{33} & Whole Model & 3 & 375.58 & 1.85 & 0.2 & & \\
\hline & & Treatment & 1 & 83.77 & 1.24 & 0.3 & - & - \\
\hline & & Temperature & 1 & 244.18 & 3.62 & 0.1 & - & - \\
\hline & & Treatment $\times$ Temperature & 1 & 33.27 & 0.49 & 0.5 & - & - \\
\hline & & Error & 23 & & & & & \\
\hline
\end{tabular}




\begin{tabular}{|c|c|c|c|c|c|c|c|c|}
\hline \multirow{5}{*}{$\begin{array}{c}\text { Glucose } \\
(\mathrm{mmol} / \mathrm{L})\end{array}$} & \multirow{5}{*}{84} & Whole Model & 8 & 969.96 & 8.51 & $<0.0001$ & & \\
\hline & & Treatment & 2 & 262.32 & 9.20 & 0.0004 & - & - \\
\hline & & Temperature & 2 & 424.65 & 14.90 & $<0.0001$ & - & - \\
\hline & & Treatment $\times$ Temperature & 4 & 77.85 & 1.37 & 0.3 & 0.54 & 112 \\
\hline & & Error & 53 & 755.39 & & & & \\
\hline \multirow{5}{*}{$\begin{array}{l}\text { Lactate } \\
(\mathrm{mmol} / \mathrm{L})\end{array}$} & \multirow{5}{*}{84} & Whole Model & 8 & 6.005 .97 & 5.79 & $<0.0001$ & & \\
\hline & & Treatment & 2 & 3799.73 & 14.66 & $<0.0001$ & - & - \\
\hline & & Temperature & 2 & 455.76 & 1.76 & 0.2 & 0.47 & 109 \\
\hline & & Treatment $\times$ Temperature & 4 & 213.04 & 0.41 & 0.8 & 0.18 & 362 \\
\hline & & Error & 53 & 6.866 .50 & & & & \\
\hline \multirow{5}{*}{$\begin{array}{l}\text { Hematocrit } \\
(\% \text { PCV) }\end{array}$} & \multirow{5}{*}{70} & Whole Model & 8 & 339.40 & 1.26 & 0.3 & & \\
\hline & & Treatment & 2 & 178.80 & 2.67 & 0.08 & 0.56 & 73 \\
\hline & & Temperature & 2 & 23.95 & 0.36 & 0.7 & 0.11 & 523 \\
\hline & & Treatment $\times$ Temperature & 4 & 181.95 & 1.36 & 0.3 & 0.45 & 112 \\
\hline & & Error & 53 & 1.766 .14 & & & & \\
\hline
\end{tabular}

Note: Least significant $N$ represents a power of $\beta=0.5$. 
Table 2-2. Movement data for all radio tagged $(N=30)$ muskellunge. Recaptures. the sum of distances moved up to $48 \mathrm{~h}$. and the number of upstream movements for the entire tracking period were used to assess survival. An asterisk denotes individuals tracked after being recaptured.

\begin{tabular}{|c|c|c|c|c|c|c|c|}
\hline Fish \# & $\begin{array}{l}\text { Capture } \\
\text { Location }\end{array}$ & $\begin{array}{c}\text { Capture } \\
\text { Date }\end{array}$ & $\begin{array}{l}\text { Final } \\
\text { Tracking } \\
\text { Date } \\
(2009)\end{array}$ & $\begin{array}{c}\text { Recapture } \\
(\mathrm{Y} / \mathrm{N})\end{array}$ & $\begin{array}{c}\# \\
\text { Locations }\end{array}$ & $\begin{array}{c}\text { Sum of } \\
\text { distance (m) } \\
\text { moved up to } \\
48 \mathrm{~h}\end{array}$ & $\begin{array}{l}\text { \# Upstream } \\
\text { movements } \\
\text { between } \\
\text { sequential } \\
\text { tracking points }\end{array}$ \\
\hline 151.981 & $\begin{array}{c}\text { Rideau R. } \\
\text { (Long) }\end{array}$ & 22-Jun & 28-Oct & $N$ & 19 & 754 & 4 \\
\hline 150.681 & $\begin{array}{c}\text { Rideau R. } \\
\text { (Long) }\end{array}$ & 25-Jun & $28-\mathrm{Oct}$ & $Y$ & 19 & 1019 & 9 \\
\hline 150.920 & $\begin{array}{l}\text { Rideau R. } \\
\text { (Long) }\end{array}$ & 4-Jul & 13-Aug & $N$ & 14 & 569 & 8 \\
\hline 150.359 & Ottawa R. & 8-Jul & 12-Aug & $N$ & 12 & 802 & 6 \\
\hline 150.580 & Ottawa R. & 8-Jul & 23-Nov & $N$ & 18 & 952 & 10 \\
\hline 150.960 & $\begin{array}{l}\text { Rideau R. } \\
\text { (Eccolands) }\end{array}$ & 11-Jul & $3-O c t$ & $N$ & 16 & 562 & 7 \\
\hline 151.479 & $\begin{array}{l}\text { Rideau R. } \\
\text { (Eccolands) }\end{array}$ & 13-Jul & $3-\mathrm{Oct}$ & $\mathrm{Y}$ & 16 & 1655 & 6 \\
\hline 151.121 & Ottawa R. & 16-Jul & 14-Oct & $\mathrm{Y}$ & 17 & 412 & 9 \\
\hline 150.380 & $\begin{array}{l}\text { Rideau R. } \\
\text { (Eccolands) }\end{array}$ & 23-Jul & 3-Oct & $N$ & 15 & 455 & 8 \\
\hline
\end{tabular}




\begin{tabular}{|c|c|c|c|c|c|c|c|}
\hline 150.722 & Ottawa R. & 24-Jul & 23-Nov & $N$ & 16 & 383 & 8 \\
\hline 150.561 & Ottawa R. & 24-Jul & 23-Nov & $\mathrm{Y}$ & 16 & 285 & 7 \\
\hline 150.840 & $\begin{array}{l}\text { Rideau R. } \\
\text { (Long) }\end{array}$ & 29-Jul & 28-Oct & $\mathrm{Y}$ & 14 & 1072 & 6 \\
\hline 151.401 & Ottawa R. & 3-Aug & 23-Nov & $\mathrm{N}$ & 15 & 354 & 7 \\
\hline 150.541 & Ottawa R. & 4-Aug & 14-Oct & $\mathrm{Y}$ & 14 & 2702 & 7 \\
\hline 150.421 & Ottawa R. & 6-Aug & 23-Nov & $N$ & 14 & 266 & 5 \\
\hline 150.341 & Ottawa R. & 7-Aug & 23-Nov & $\mathrm{N}$ & 15 & 191 & 8 \\
\hline 150.821 & Ottawa R. & 10-Aug & 23-Nov & $\mathrm{N}$ & 13 & 483 & 4 \\
\hline 150.300 & Ottawa R. & 10-Aug & 15-Sept & $\mathrm{N}$ & 10 & 1778 & 5 \\
\hline 151.440 & Ottawa R. & 11-Aug & 25-Sept & $\mathrm{N}$ & 11 & 337 & 4 \\
\hline 151.560 & Ottawa R. & 14-Aug & 15-Oct & $N$ & 13 & 680 & 5 \\
\hline 151.460 & Ottawa R. & 15-Aug & 15-Sept & $Y$ & 9 & 514 & 4 \\
\hline 151.579 & Ottawa R. & 7-Sep & $1-\mathrm{Oct}$ & $N$ & 10 & 641 & 5 \\
\hline 151.980 & Ottawa R. & 7-Sep & 15-Sept & $\mathrm{N}$ & 9 & 564 & 3 \\
\hline
\end{tabular}




\begin{tabular}{|c|c|c|c|c|c|c|c|}
\hline 151.059 & Ottawa R. & 12-Sep & 15-Oct & $N$ & 10 & 1415 & 4 \\
\hline 150.200 & Ottawa R. & 18-Sep & 23-Nov & $\mathrm{N}$ & 10 & 250 & 5 \\
\hline 150.041 & Ottawa R. & $20-$ Sep & 23-Nov & $\mathrm{N}$ & 9 & 905 & 4 \\
\hline 150.099 & Ottawa R. & 24-Sep & 23-Nov & $\mathrm{N}$ & 9 & 496 & 2 \\
\hline 151.920 & Ottawa R. & 24-Sep & 14-Oct & $N$ & 8 & 932 & 3 \\
\hline 151.900 & Ottawa R. & 24-Sep & 23-Nov & $N$ & 10 & 881 & 6 \\
\hline 151.880 & Ottawa $R$. & 25-Sep & 23-Nov & $\mathrm{N}$ & 8 & 2300 & 4 \\
\hline
\end{tabular}




\section{Figures}

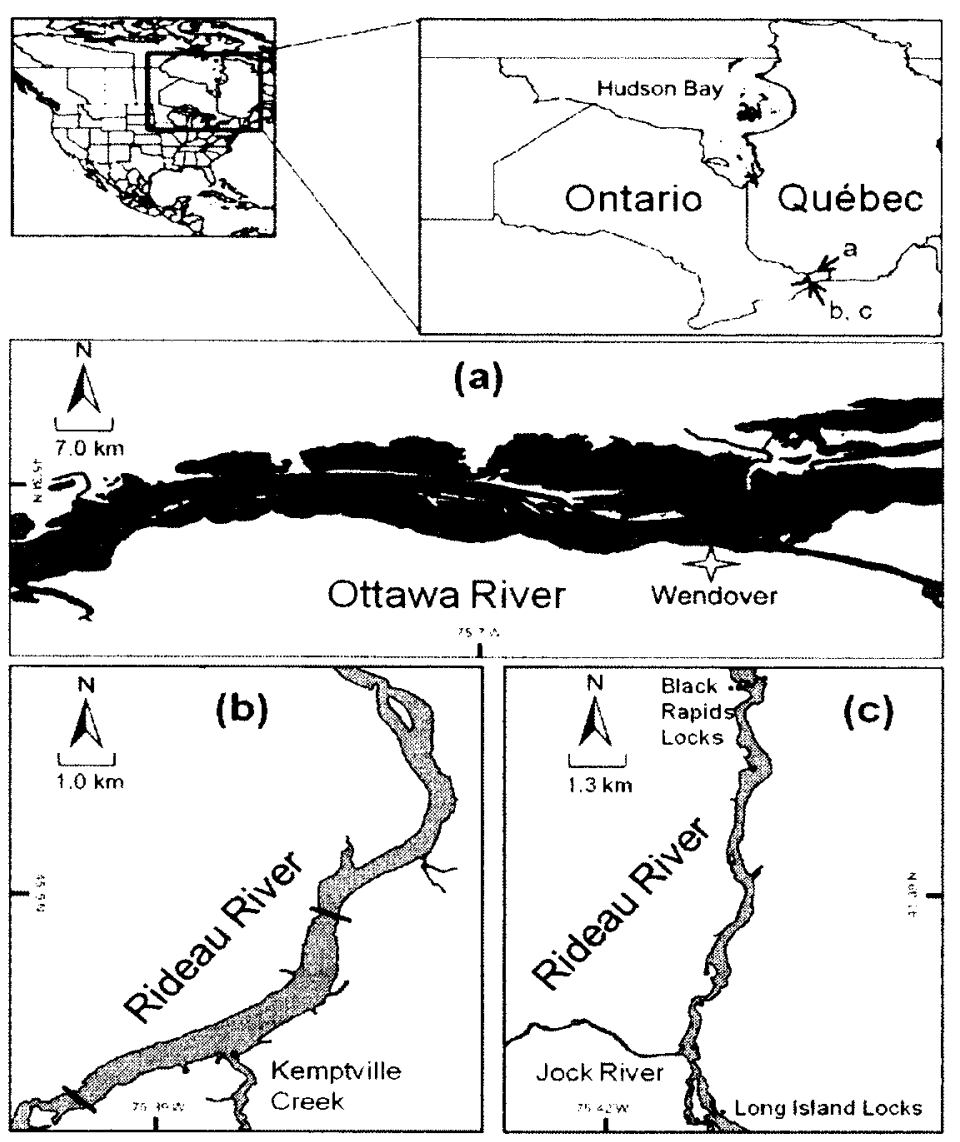

Figure 2-1. Map of the Ottawa River study site (a) east of the city of Ottawa, Ontario and two stretches of the Rideau River south of Ottawa near Kemptville, Ontario (b) and between the Black Rapids and Long Island Locks (c). The thin black line splitting the Ottawa River separates the provinces of Ontario and Québec. For the Rideau River, solid lines indicate bridges and dashed lines indicate dam and lock systems. 


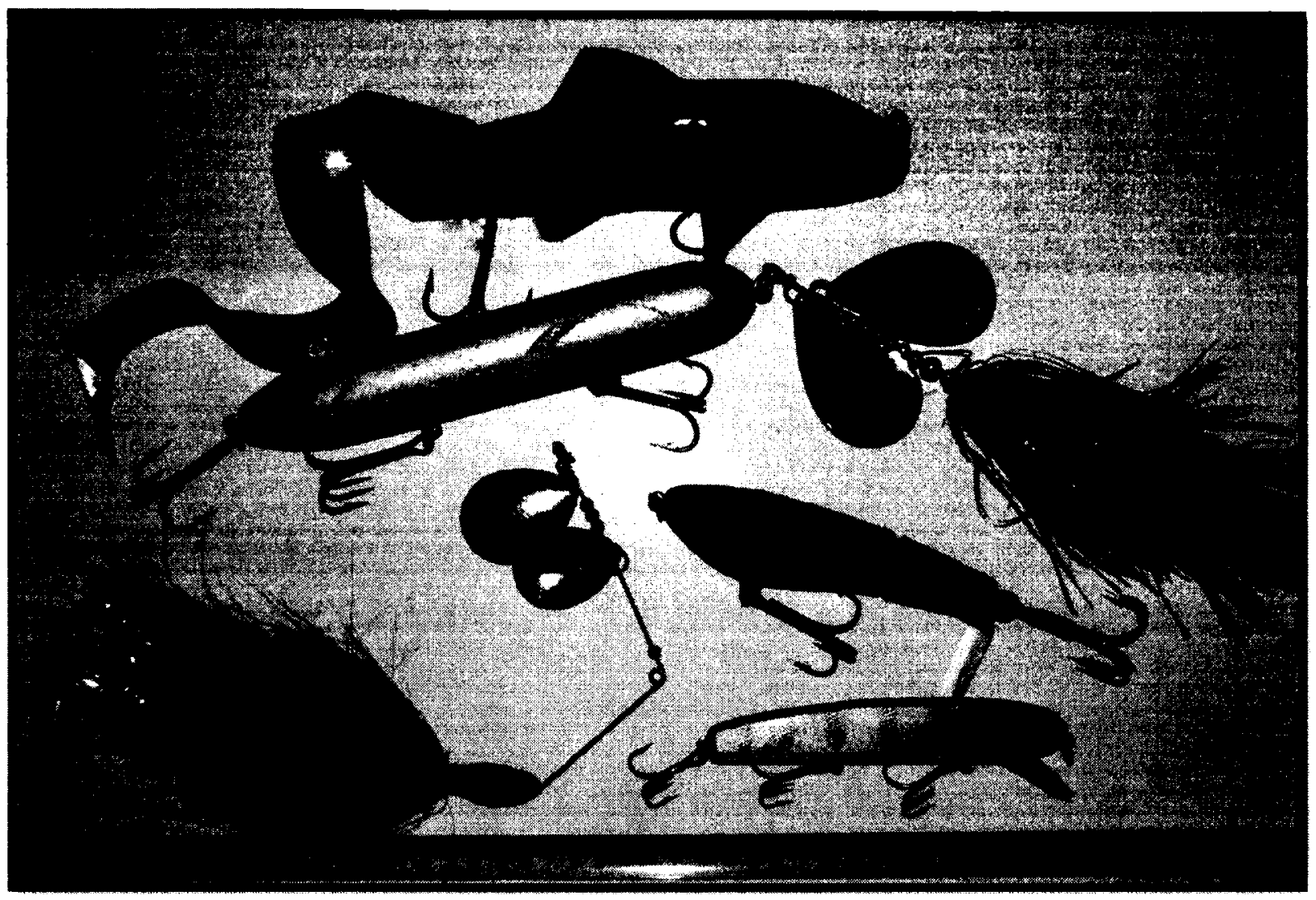

Figure 2-2. A selection of muskellunge-specific artificial lures with up to nine barbed hook points. 

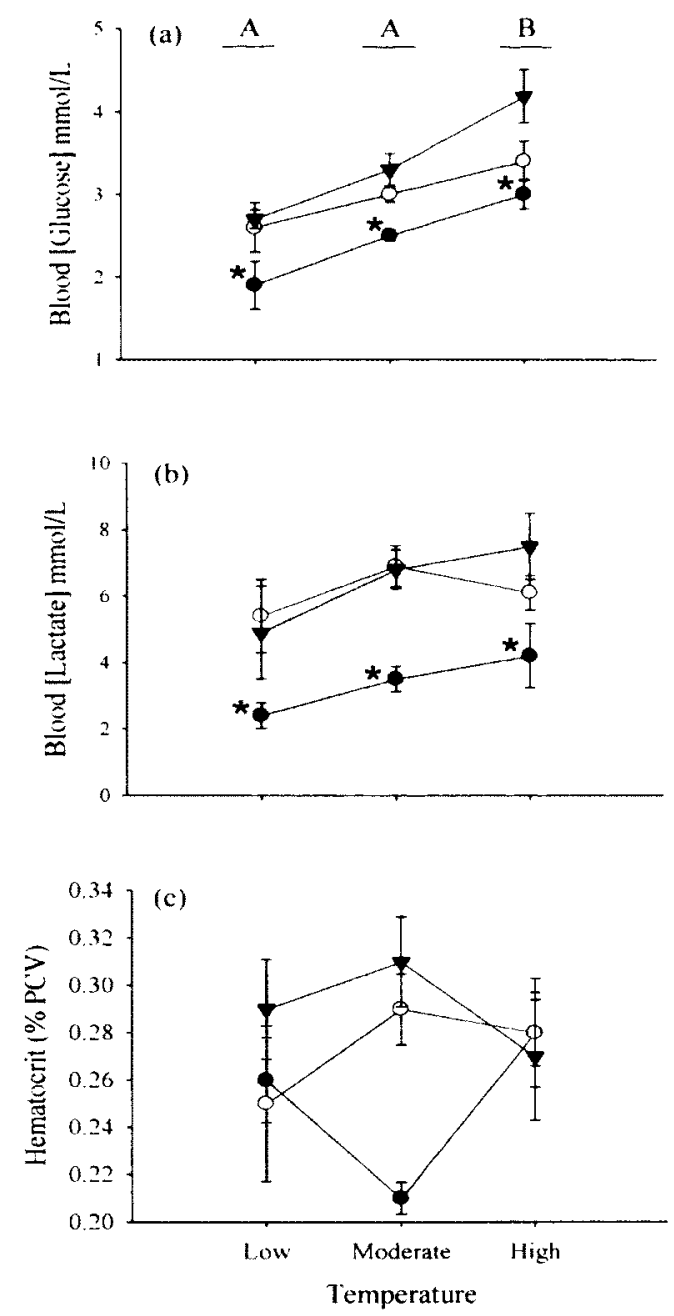

Figure 2-3. Concentrations of blood glucose (a), lactate (b), and hematocrit (c; percent packed cell volume) for control (solid circle) and angled muskellunge subjected to alternative (hollow triangle) and normal (solid square) handling treatments. The sample sizes for glucose and lactate at low, moderate, and high temperatures for the three treatments were as follows: control $(N=8,3,7)$, alternative $(N=4,11,18)$, and normal $(N=4,13,15)$. Samples sizes for hematocrit at low, moderate, and high temperatures for the three treatments were: control $(N=8,3,6)$, alternative $(N=4,10,15)$, and normal $(N$ $=4,8,10)$. An asterisk $\left({ }^{*}\right)$ denotes a significant difference between controls and angled muskellunge. Dissimilar upper case letters joined by horizontal lines denote significant differences between temperature groups. 

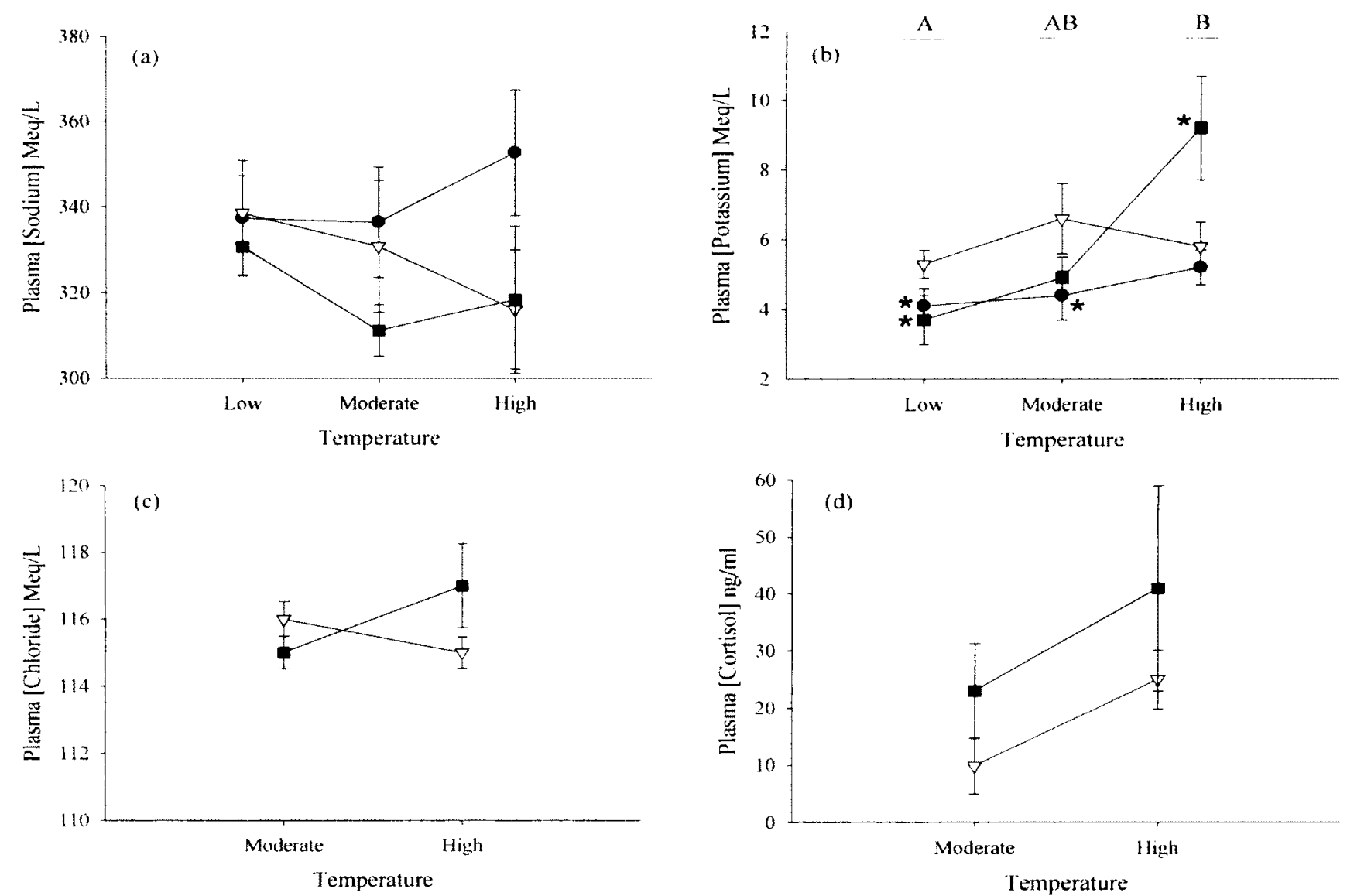

Figure 2-4. Concentrations of plasma sodium (a), potassium (b), chloride (c), and cortisol (d) for control muskellunge (a-b, solid circle) and angled muskellunge subjected to gentle (hollow triangle) or normal (solid square) handling treatments. The samples sizes for plasma sodium and potassium ions at low, moderate, and high temperatures for the three treatments were as follows: control $(N=$ $8,3,6)$, alternative $(N=4,10,14)$, normal $(N=4,9,9)$. Sample sizes for plasma chloride ions and cortisol were: alternative $(N=7$, 9) and normal $(N=7,4)$. Dissimilar upper case letters joined by horizontal lines denote significant differences between temperature groups, and asterisks $\left(^{*}\right)$ indicate treatment groups at given temperatures that are statistically different from each other (i.e., interaction effect). 


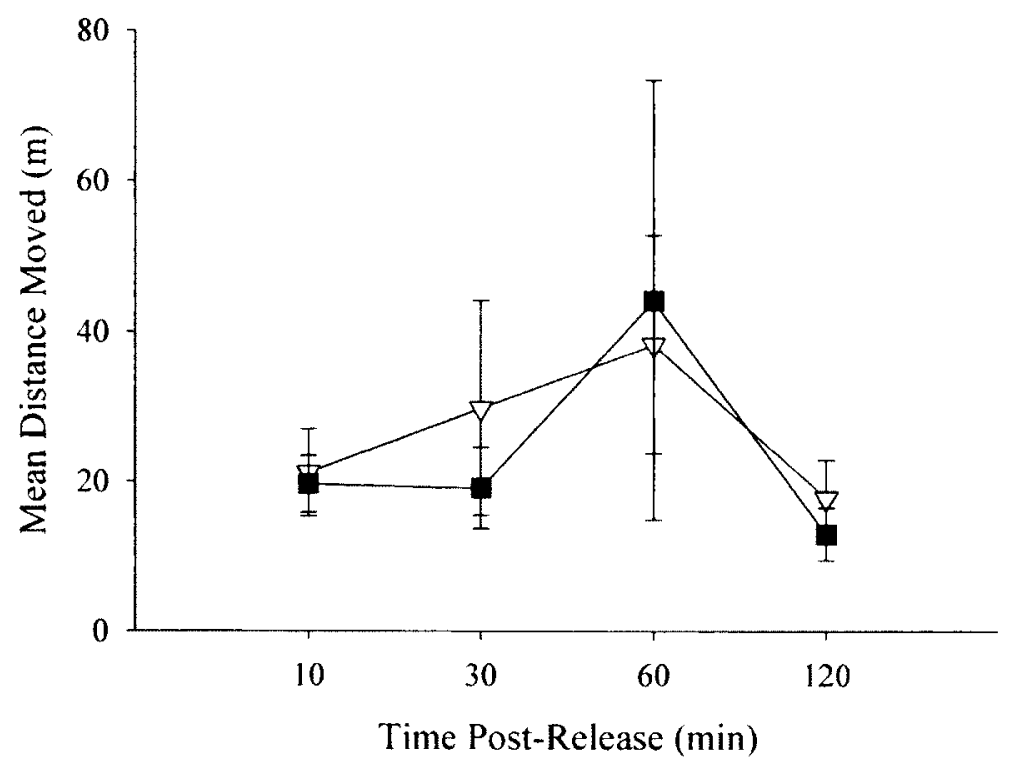

Figure 2-5. Mean distance moved for angled muskellunge subject to normal handling procedures (solid squares) used by specialized anglers as well as an alternative handling procedure (hollow triangles). Sample sizes were $N=15$ for both treatments except at when one individual could not be located (i.e., $N=14$ ) at 120 min post-release for the normal treatment and 10 and $30 \mathrm{~min}$ post-release for the alternative treatment. 


\title{
Chapter 3: Fine-scale behaviour of muskellunge (Esox masquinongy) assessed using tri-axial acceleration and pressure sensing transmitters
}

\begin{abstract}
Tri-axial acceleration and pressure sensing acoustic transmitters measured the activity and depth patterns of free-swimming adult muskellunge (Esox masquinongv) and telemetered signals were recorded by nine underwater hydrophones spread throughout an $8 \mathrm{~km}$ impounded reach of the Rideau River, Ontario between May and October 2010. In general, muskellunge remained inactive over $70 \%$ of the time and depth was primarily limited to less than $3 \mathrm{~m}$. Model selection based on Akaike's Information Criterion (AIC) revealed that activity varied greatly with each factor analyzed, but generally activity was highest during the waxing lunar phase, low during periods of warm water temperatures, relatively constant for larger fish, and highest at dusk. Depth generally increased during the waxing lunar phase, was shallowest for larger fish and at warmer water temperatures, and varied across diel periods depending on water temperature and time of day. Activity and depths of free-swimming muskellunge were compared to individuals that were angled, tagged (externally) and released at hourly intervals over the first $24 \mathrm{~h}$ period following release. Muskellunge activity, regardless of treatment group, was significantly different depending on the hour post-release, but yielded no discernable pattern. Compared to free-swimming muskellunge, angled fish were observed deeper during the first hour post-release, shallower from hours 1-3, and deeper each hour thereafter. In general, this study contributes to our understanding of the activity levels and depth use patterns of an ecologically and recreationally important freshwater apex predator.
\end{abstract}


Furthermore, these findings also have implications for improving angler catch rates and fisheries manager sampling efforts.

\section{Introduction}

The survival of an animal depends on its ability to balance energy allocated to maintenance, growth, reproduction, and activity (Brett and Groves, 1979; Tytler and Calow, 1985). These components of energy budgets, however, can be highly variable among animals. For example, maintenance costs of endotherms compared to ectotherms range widely between taxa (Lavigne, 1982). In fishes, activity levels can vary greatly within populations (Boisclair, 1992; Lucas et al., 1993) and account for a large amount of the energy budget (Boisclair and Leggett, 1989). For juvenile fishes, there are clear tradeoffs between allocating energy to growth versus storing energy to use during periods of limited resources (Post and Parkinson, 2001) and increasing foraging activities at the risk of increased predation (Post and Parkinson, 2001; Lima, 2002). Adult animals that increase foraging activities can gain a competitive advantage over individuals both within and among species (see Werner and Anholt, 1993). Predator-prey interactions may be governed by differences in activity levels and may influence either predatory or antipredator behaviour (Lima, 2002). Nevertheless, the complicated nature of energy budgets, particularly in fishes, can be difficult to assess in the wild (Diana, 1983; Hansen et al., 1993; Ney, 1993). Therefore, the development of technologies capable of accurately measuring energy expenditure in wild animals becomes important (Lucas et al., 1993; Cooke et al., 2004b). 
Activity patterns can be influenced by a myriad of environmental variables. For instance. changing light levels corresponding to day. night. and crepuscular (i.e.. dawn and dusk) periods has varying effects on fish activity (Kelso, 1978: Diana, 1980: Young. 1999: Hanson et al.. 2010). Such cycles of light and dark are most commonly associated with diel (i.e. daily) behaviour, though any pattern over a period of $24 \mathrm{~h}$ can be classified as diel (Reebs, 2002). As ectotherms, water temperature is perhaps one of the most important determinants of activity in fish because changes in temperature directly affect biochemical reactions within the body which govern swimming capacity (Fry. 1971; Brett and Groves. 1979). More specifically, as temperatures increase or decrease. generally, so does activity (Brett, 1971), which is often demonstrated on a seasonal basis (e.g.. Todd and Rabeni, 1988: Hasler et al., 2009; Hanson et al.. 2010). Further still, prey availability, shoal size, parental care, migration, and organismal development have. among other factors. also been shown to affect activity (as reviewed in Reebs, 2002 ). Finally, cyclical patterns in activity relative to lumar phases have been well documented in marine fish literature, particularly with regard to the influence of tides (e.g.. Leatherland et al., 1992). Less is known. however, about the effects of lunar phase on freshwater lishes. In general, the ability to quantify patterns of activity in the wild can be a challenge, but recent technological advancements have made this task much easier.

Field-based biotelemetry has enabled researchers to obtain accurate measurements of the physiology and behaviour of wild animals for use in predictive modeling or to supplement our current understanding of organismal ecology (Lucas et al., 1993; Cooke et al., 2004a,b). Where direct observation was once the standard method of monitoring animals in their natural environments, biotelemetry devices enable researchers to 
continually monitor animals from a distance (Lucas and Baras, 2000). Specialized transmitters used in heart-rate and electromyogram telemetry can provide insight into the physiological and behavioural responses of animals to changing environmental conditions (Cooke et al.. 2004a,b). Various forms of telemetry are also used to quantify post-release behaviour of angled fishes (e.g.. Bettoli and Osborne, 1998; Thorstad et al.. 2003; reviewed in Donaldson et al., 2008; Arlinghaus et al., 2009). Mitigating the negative impacts of angled and released fishes is paramount to increasing survivorship and reducing fitness-related effects. A relatively new suite of sensors used with biologging and biotelemetry devices are tri-axial accelerometers, which record and either $\log$ or transmit information on activity and fine-scale behaviour (e.g., Wilson et al.. 2006; O'Toole et al., 2010). Locomotion in fishes is a function of muscle contraction that enables the creation of thrust and propulsion through water (see Altringham and Ellerby, 1999), while acceleration in fishes is considered a proxy for energy expenditure (Halsey et al., 2009). Field-based estimates of activity have been incorporated into fisheries management most often through bioenergetics models (Hansen et al., 1993). However, understanding how environmental factors affect fish activity could improve sampling efforts. Hubert (1983) notes that the success of passive capture techniques (e.g., nets, traps) is dependent on the interaction of fishes with the sampling gear and poor knowledge of how fishes respond to environmental factors can decrease catch rates. Present understanding of muskellunge (Esox masquinongy) behavioural ecology is limited (Crossman, 1986), despite their popularity with anglers and importance within freshwater ecosystems as apex predators. Most field-based behavioural studies to date employ traditional positional biotelemetry. Indeed, several tracking studies of 
muskellunge have revealed key information regarding seasonal movements (Younk et al., 1996), inter-lake movement (Weeks and Hansen, 2009), and reproductive homing (Crossman, 1990) that have played important roles in muskellunge management.

However, fine-scale behavioural information is lacking and most information regarding activity patterns (e.g., feeding events) emanates from angler-based anecdotal observations (e.g., Saric and Heiting, 1995).

Our objectives for this study were to characterize the general activity and depth patterns of free-swimming muskellunge using field-based telemetry. Muskellunge are generally characterized as sit-and-wait, shallow-dwelling predators (Scott and Crossman, 1973). Therefore, we expected activity to be relatively low, with short periods of increased activity, and depths to be confined largely to the littoral zone of the study site. The effects of time of day (i.e., dawn, day, dusk, night), water temperature, fish size, and lunar phase were incorporated into models used to explain activity and depth. Consistent with angler-based anecdotal observations and findings presented by Miller and Menzel (1986), we expected activity to be highest during dawn and dusk periods at warm water temperatures and depths shallowest during the day and deepest at crepuscular periods. Angler observations suggest muskellunge activity decreases and depths inhabited are deeper at cooler water temperatures, regardless of time of day; we expected activity and depth to resemble these observations. For size, Miller and Menzel (1986) found no effect and we expected similar results in the present study. Many muskellunge anglers are adamant that lunar phase plays a crucial role in influencing activity, citing increased catch rates during the new and full lunar phases. Indeed, many angling publications publish lunar tables predicting the best angling times (i.e., periods of high fish activity) to 
occur near the new and full lunar phases. Thus, activity was expected to be highest at these lunar phases. In addition, to coincide with perceived increases in angler catch rates depths were expected to be shallowest during the new and full lunar phases because muskellunge are suspected to become more vulnerable to angling in shallow water (Miller and Menzel, 1986). Our final objective was to compare the activity and depths of free-swimming individuals with angled, post-release muskellunge. To accomplish these objectives, we used fixed station, acoustic receivers and acoustic transmitters equipped with tri-axial acceleration and pressure sensors.

\section{Methods}

Study site. This study was conducted on the Rideau River, Ontario, Canada between the Long Island and Black Rapids Locks (approximately $8 \mathrm{~km}$ in length, $<400 \mathrm{~m}$ in width; Figure 3-1). It is a relatively shallow, heavily vegetated section of river with mean and maximum depths of approximately 3 and $10 \mathrm{~m}$, respectively. Fish habitats include: shallow, vegetated flats; creek mouths; shallow, rocky riffles; pools; deep river channels; and rock humps.

Nine acoustic receivers (VR2W, Vemco/Amirix Systems, Shad Bay, Nova Scotia, Canada) were deployed throughout the system (Figure 3-1). Each receiver was either attached to a short piece of V-shaped steel bar and tied to three sandbags or hung beneath navigational buoys. Receivers were positioned in areas of expected high fish activity to maximize the number of detections based on an earlier radio telemetry study (i.e., Landsman et al., 2011). However, an abundance of macrophyte vegetation in the shallow littoral zones where many of the receivers were placed probably decreased detection 
efficiency. Range testing was not conducted because individual positions were not addressed in this study.

Thermal loggers (iButton DS1921Z; resolution $\pm 0.1^{\circ} \mathrm{C}$, accuracy $\pm 1^{\circ} \mathrm{C}$; Maxim Integrated Products. Inc., Sunnyvale, California) were used to record water temperatures at $2 \mathrm{~h}$ time intervals. Loggers were deployed along the riverbank to record surface water temperatures. However, a high water temperature alarm was inadvertently set on the thermal logger rendering it incapable of measuring temperatures above $26.4^{\circ} \mathrm{C}$. To keep water temperature as a continuous variable in our analyses, water temperatures, recorded every hour, were obtained from the Smiths Falls Water Treatment Plant (SFWTP) also located on the Rideau River, but approximately $70 \mathrm{~km}$ upstream. Water temperatures ranged from $9.0-29.9^{\circ} \mathrm{C}$.

Transmitters. In this study, we used individually coded acoustic transmitters containing acceleration and pressure sensors, aptly dubbed 'accelerometers' (model V9AP, Vemco/Amirix Systems, Shad Bay, Nova Scotia, Canada). Transmitter dimensions were $46 \mathrm{~mm} \times 9 \mathrm{~mm}$ and weighed $3.3 \mathrm{~g}$ in water and $6.3 \mathrm{~g}$ in air. Data were transmitted, on average every $60 \mathrm{~s}$, acceleration measured for a period of $20 \mathrm{~s}$, and total percent sampling time $17 \%$. All transmitters measured the acceleration of freeswimming fishes by calculating acceleration in three planes - X-, Y-, and Z-axis - and taking a vector average of the three planes to produce a single $\mathrm{g}$-force value. Because acceleration is measured as the instantaneous change in velocity over time, each g-force value was then converted into $\mathrm{m} / \mathrm{s}^{2}\left(1 \mathrm{~g}\right.$-force is equal to $\left.9.8 \mathrm{~m} / \mathrm{s}^{2}\right)$. Maximum acceleration values produced were $48.0 \mathrm{~m} / \mathrm{s}^{2}$ (4.9 g-forces). Hereafter, acceleration is considered a proxy for activity and therefore referred to as activity. Finally, the acoustic 
transmitters were also equipped with pressure (i.e., depth) sensors. Error for these sensors was $\pm 2.5 \mathrm{~m}$ with a resolution of $0.22 \mathrm{~m}$. Negative depth readings were recorded up to $-0.88 \mathrm{~m}$ and depth readings were scaled to reflect this value. Given the transmitter error and locations of the receivers (i.e., predominantly shallow water), depth use could not be inferred. Finally, muskellunge were monitored until the transmitter batteries (approximately $120 \mathrm{~d}$ ) expired or until 13 October 2010 when the receivers were removed from the river.

Capture methods. To assess free-swimming behaviour, eight muskellunge were captured via electrofishing (for settings see Landsman et al., 2011) in late April 2010. The total length $\left(\mathrm{L}_{\mathrm{T}}\right)$ of electrofished muskellunge was $83.0 \mathrm{~cm} \pm 6.0$ standard error (S.E.) and ranging from $53.0-101.2 \mathrm{~cm} \mathrm{LT}$. A second group of muskellunge was angled between 12 June and 5 July 2010 to compare post-release behaviour to behaviour of freeswimming muskellunge. Originally, eight muskellunge were captured, but one individual died and an angler inadvertently removed another's transmitter. Both transmitters were recovered and redeployed. Twenty-four hours after capture and release, angled muskellunge were added to the sample size of the electrofished individuals and used to assess free-swimming behaviours. The $\mathrm{L}_{\mathrm{T}}$ of angled fish averaged $95.8 \mathrm{~cm} \pm 4.5 \mathrm{~S}$.E. (range, 63.5-110.5 $\mathrm{cm} \mathrm{L} \mathrm{L}_{\mathrm{T}}$ ) and after angled muskellunge were added to the pool of freeswimming individuals, average $L_{T}$ of free-swimming muskellunge was $90.1 \mathrm{~cm} \pm 3.8$ S.E. (range $53.0-110.5 \mathrm{~L}_{\mathrm{T}}$ ).

Tagging. Following electrofishing in late April 2010, most muskellunge entered a state of electronarcosis for several minutes, allowing us to surgically implant individually coded transmitters. This procedure is relatively noninvasive and greatly reduces handling 
time (Madden and Houston. 1976; Jennings and Looney. 1998; Sattari et al., 2009). All individuals were held in a $100 \mathrm{~L}$ cooler of water. Not all muskellunge, however, could be electroanesthetized properly and clove oil was used as an anesthetic for several fish (concentration: $15 \mathrm{ppm}$ ). Once anesthetized, either electro or chemical, an incision of approximately $1.5 \mathrm{~cm}$ long was made with a size 15 -blade scalpel along the ventral midline. To close the incision, a reversed curve needle and two simple interrupted absorbable monofilament sutures were used (PDS II 3/0, Ethicon Ltd., New Jersey; Cooke et al., 2003b; U.S. Army Corps of Engineers, 2010). Electroanesthetized fish were revived alongside the boat and chemically anesthetized fish were flushed with fresh river water to aid in recovery. Muskellunge were released when equilibrium was gained and strong swimming actions were observed. All muskellunge were released at the site of capture. This process took approximately 5 and 10 minutes for electroanesthetized and chemically anesthetized individuals, respectively. All surgeries were conducted by the same trained individual and in accordance with standard operating procedures set forth by the Canadian Council for Animal Care issued through Carleton University, Ottawa, Canada.

In contrast to these procedures, transmitters for angled muskellunge were affixed externally beneath the dorsal fin as described in Bridger and Booth (2003). External attachment procedures were used with angled muskellunge to reduce post-release behavioural effects (Donaldson et al., 2008). For those animals, no anesthesia was used but the fish were held in a water-filled trough during tagging.

Statistical analysis. Data collection commenced on 6 May 2010, at least 7 days following surgical implantation of transmitters, and data recorded on the receivers were 
downloaded on 13 October 2010. Two muskellunge were excluded from all analyses because of a disproportionately low number of detections signaling mortality, transmitter detachment, transmitter failure, or movement of fish beyond the study reach via the navigation locks (see Gillis et al., 2010). A repeated measures ANOVA was used to compare post-release activity and depth between treatment groups (i.e., angled vs. freeswimming; Zar, 1984). Data transmitted at the same time - with resolutions to the minute - for both angled and free-swimming muskellunge were evaluated to ensure equal comparison. This analysis was carried out in JMP 8.0 (SAS Inc., Cary, NC, USA) and significance levels were set at $\alpha \leq 0.05$.

Mixed effects models were used to assess the effects of several biotic (i.e. fish size) and abiotic (i.e., time of day, lunar phase, water temperature) variables on activity and depth. Total length of each muskellunge was used to assess the effect of size on activity and depth. Time of day was separated into periods of dawn (one hour before and after sunrise), day, dusk (one hour before and after sunset), and night using historical records provided by the National Research Council Canada - Herzberg Institute of Astrophysics. Following methodologies described in deBruyn and Meeuwig (2001), the percent illuminated disk of the moon was converted into a continuous scale between 0 and $2 \pi$ radians (i.e., $\theta$ ) to account for the cyclical nature of lunar cycles (i.e., 29.5 days per lunar cycle). $\operatorname{Sin}(\theta)$ and $\cos (\theta)$ transformations coincided with half and new/full lunar phases, respectively. Additional transformations of $\sin (2 \theta)$ and $\cos (2 \theta)$ were used to describe two peaks during one lunar cycle. All lunar data were obtained online from www.timeanddate.com. Lastly, water temperature was analyzed to determine its effect on activity and depth. 
Activity was measured as the proportion of active detections during a given time of day using a binary variable where 1 indicated active fish displaying accelerations $\geq 1$ $\mathrm{m} / \mathrm{s}^{2}$ and 0 indicating inactive fish with accelerations $<1 \mathrm{~m} / \mathrm{s}^{2}$. The response variable proportion of active detections was logit transformed prior to analysis. To account for variation between individuals, fish ID was held as a random effect. Also, the effect of serial autocorrelation presents a potentially confounding issue (Rogers and White, 2007) and was addressed by using mixed effects models with built-in autocorrelation structures. Furthermore, data were grouped into time periods (i.e., dawn, day, dusk, night) and analyzed at these intervals thereby removing some of the bias associated with serial autocorrelation. Time periods with less than five detections were excluded from analysis.

A set of candidate models was constructed to determine which set of variables best explained variation in activity and depth. The models in this set included all possible combinations of the variables time of day, water temperature, $L_{T}$, or moon phase (separated into half-moon and new/full moon periods) and second-order interactions among them. Over 100 models were fit to the data. In all cases, the intercept was modeled as random on fish ID and models ranged from containing one fixed variable to as many as 14. The bias-corrected Akaike's Information Criterion (AICc) was used to determine the 'best approximating model' for activity and depth (Bozdogan, 1987; Burnham and Anderson, 2002). The model with the lowest AICc value was deemed the best approximating model and models with $\mathrm{AICc}$ values differing from this one by less than 2 units (i.e., $\triangle \mathrm{AICc}<2.00$ ) were also considered to have strong support from the data (Bozdogan, 1987; Burnham and Anderson, 2002). Model-averaged estimates of activity and depth were computed based on the models with $\triangle \mathrm{AICc}<2.00$ (Burnham and 
Anderson, 2002). Models were fit and selected using packages 'Ime4' (Bates et al., 2011) and 'AlCcmodavg' (Mazerolle, 2011), respectively, in R 2.12.2 (R Core Development Team, 2011). We present estimates of activity and depth for small (i.e.. $50 \mathrm{~cm}$ ). medium (i.e., $80 \mathrm{~cm}$ ), and large (i.e., $110 \mathrm{~cm}$ ) muskellunge as well as estimates at cool (i.e., $10^{\circ}$ C) and warm (i.e., $30^{\circ} \mathrm{C}$ ) water temperatures.

\section{Results}

General activity and depth. Over 100,000 detections were recorded for both activity and depth. Muskellunge were inactive (i.e., $0-1 \mathrm{~m} / \mathrm{s}^{2}$ ) $71 \%$ of the time (Figure $3-2 a)$, with periodic increases in activity. A steady decline in the frequency of activity $>1 \mathrm{~m} / \mathrm{s}^{2}$ was observed with relatively few observations recorded above $10 \mathrm{~m} / \mathrm{s}^{2}$ (Figure $3-$ 2a). An accumulation of detections at $48 \mathrm{~m} / \mathrm{s}^{2}$ was noted at the upper end of the transmitter's calculation range. Muskellunge occupied a range of depths from 0.0 to 9.5 $\mathrm{m}$, but $70 \%$ of transmissions occurred in shallow water $<3.0 \mathrm{~m}$ (Figure $3-2 \mathrm{~b}$ ). Depths between 3.0 and $5.5 \mathrm{~m}$ were frequented $28 \%$ of the time (Figure $3-2 \mathrm{~b}$ ).

Activity and depth models. In total, several variables were identified as explaining activity: time of day, $\mathrm{L}_{\mathrm{T}}$, time of day $\times \mathrm{L}_{\mathrm{T}}$, water temperature, time of day $\times$ water temperature, water temperature $\times L_{T}, \cos (\theta), \cos (2 \theta)$, and $\sin (\theta)$ (Table $3-1$ ). Four models had $\triangle \mathrm{AICc}$ values less than 2.00 and variables in all four models were used to explain activity. The first model differed from the other top three models with inclusion of the interaction term time of day $\times$ water temperature and exclusion of the term $\cos (2 \theta)$, which was found in the third best model (Table $3-1$ ). This lunar effect was likely 
minimal as no observable pattern was noted in the estimated activity levels (Figures 3$3 a-c)$. Despite the top model consisting of several parameters, simpler models were not well supported by the analyses; models with only one of the variables had $\triangle \mathrm{AICC}$ values of at least 130 and the null model's $\triangle A I C c$ value was over 600 .

Despite penalizing models with many parameters, results of the AICc analysis indicated several parameters that explained depths inhabited by muskellunge, including several interactions: time of day, water temperature, $L_{T}, \sin (\theta), \cos (\theta)$, time of day $x$ water temperature, time of day $\times \mathrm{L}_{\mathrm{T}}$, water temperature $\times \mathrm{L}_{\mathrm{T}}$, water temperature $\times \sin (\theta)$, and water temperature $\times \cos (\theta)$ (Table $3-2)$. Two models had $\triangle \mathrm{AICc}$ values less than 2.00. The AICc weight of the first model was almost 2.5 times greater than the second best model, which differed from the top model by containing the interaction term water temperature $\times \mathrm{L}_{\mathrm{T}}$. In comparison to these multi-parameter models, those with only one of the variables had $\triangle \mathrm{AICc}$ of at least 168 and the null model had a $\triangle \mathrm{AlCc}$ value of 191.

Estimates for larger fish (i.e., $110 \mathrm{~cm}$ ) showed approximately constant activity across all times of the day (Figure 3-3a). whereas activity for smaller individuals (i.e., 50 $\mathrm{cm}$ ) was highest at dusk and during the day, relatively moderate at night, and the lowest at dawn (Figure 3-3b). In fact, activity was least during dawn, regardless of size (Figure $3-3 \mathrm{c}$ ). Estimates of activity at cooler water temperatures (i.e., $10^{\circ} \mathrm{C}$ ) revealed a pattern of activity whereby smaller muskellunge were more active than larger fish, but the pattern switched at warmer water temperatures (i.e., $30^{\circ} \mathrm{C}$ ) where larger fish were more active than smaller individuals (Figure 3-3a). Finally, activity was highest during the waxing phase of the lunar cycle, declining to a low during the waning phase (Figures 3$3 a-c)$ 
Like activity, depths inhabited by muskellunge were highly variable and changed depending on the interaction between factors. For instance, the interaction between fish size and water temperature was the only term that differed between the top and second best model, but the data do not indicate a strong interaction; a slightly narrower range of depths was noted at warmer water temperatures (i.e., estimates at $30^{\circ} \mathrm{C}$; Figure $3-4 \mathrm{a}$ ). At cool water temperatures (i.e., estimates at $10^{\circ} \mathrm{C}$ ) muskellunge were the shallowest at dusk and deepest at dawn, but during periods of warmer water temperatures muskellunge were shallowest during the day and deepest at dusk (Figure 3-4b). In addition, over the course of one lunar cycle at cooler temperatures depth would increase to a maximum during the waxing moon phase and decrease to a low in the waning phase (Figure $3-4 a-$ b). In contrast, depths gradually increased to a maximum just after the full lunar phase and decreased to a minimum shortly after the new lunar phase (Figure 3-4a-b). Depth changes also varied depending on the interaction between size of fish and time of day. Smaller fish (i.e., $50 \mathrm{~cm} \mathrm{~L}_{T}$ ) were the shallowest at night and increased depth at dawn, day, and dusk, while larger fish (i.e., $110 \mathrm{~cm} \mathrm{~L}$ ) were shallowest at day and increasing depth during dusk, dawn, and night periods (Figure 3-4c).

Post-release behaviour. Behaviours were analyzed at hourly intervals over $24 \mathrm{~h}$ periods, but no significant differences were observed between post-release activity of angled muskellunge and activity of free-swimming individuals (repeated measures ANOVA, $F_{1,11}=0.006, P=0.9$ ). However, significant differences in hourly activity were noted (repeated measures ANOVA, $F_{23.3914}=2.0, P=0.004$ ), though activity was erratic and yielded no discernable pattern (Figure 3-5a). Also, there was no effect of the 
interaction between treatment and hour (repeated measures ANOVA, $F_{23.3914}=1.3, P=$ 0.2). For depth, there were significant differences for both treatment group (repeated measures ANOVA, $F_{1.8869}=136.4, P<0.0001$ ) and post-release hour (repeated measures ANOVA, $\left.F_{23.8961}=9.8, P<0.0001\right)$. The interaction between post-release hour and treatment group was also statistically significant (repeated measures ANOVA. $\left.F_{23.8961}=29.3, P<0.0001\right)$. Compared to free-swimming individuals, angled muskellunge were deeper during the first hour post-release, shallower from hour 1 to 3 , and deeper at all other hours post-release (Figure 3-5b).

\section{Discussion}

Activity. Esocids, including northern pike and muskellunge, are considered sedentary, sit-and-wait predators (Scott and Crossman, 1973; Diana, 1980; Hart, 1997; New et al., 2001). Indeed, Diana (1980) demonstrated that northern pike were inactive $80 \%$ of the time and muskellunge in the present study were inactive (i.e., acceleration $<1$ $\mathrm{m} / \mathrm{s}^{2}$ ) over $70 \%$ of the time. Maximum acceleration was measured at $48 \mathrm{~m} / \mathrm{s}^{2}$, coinciding with the highest measurement the transmitters were capable of recording. In contrast. Harper and Blake (1991) surgically implanted piezoelectric accelerometers to record maximum acceleration of laboratory-held northern pike, which they measured at $95 \mathrm{~m} / \mathrm{s}^{2}$. The limitations of the transmitters used in the present study prevented us from recording true maximum acceleration, but these results clearly indicate that muskellunge have the capability of accelerating greater than $48 \mathrm{~m} / \mathrm{s}^{2}$. Furthermore, these findings add credence to the notion that esocids, muskellunge included, are relatively sedentary fishes spending much of their time holding position in the water and substantially less moving actively. 
Conflicting levels of activity were noted for muskellunge of different sizes at different times of the day. Muskellunge ranging from $53.0-110.5 \mathrm{~cm} \mathrm{~L} \mathrm{~L}_{\mathrm{T}}$ were sampled and although no extremely small or large muskellunge were tagged, there was still an effect of size on activity. More specifically, activity was relatively constant for larger fish over $24 \mathrm{~h}$ periods, whereas smaller fish were more active during the day and dusk than larger conspecifics. Bozek et al. (1999) examined the stomachs of over 1,000 muskellunge and found that the percentage of muskellunge with food items present in their stomachs decreased as size increased. This suggests that larger muskellunge do not feed as heavily as smaller individuals, supporting the findings in the current study that smaller fish were more active than larger individuals who had relatively constant activity. Yellow perch, a species that occurs in the Rideau River system (Walker et al., 2010), are a common food source of muskellunge (Bozek et al., 1999) and activity of yellow perch also increases during the day (Radabaugh, 2006). By increasing their movement, yellow perch become more vulnerable to predation, which likely triggers muskellunge to also become active at these time periods. Another potential explanation for this relationship is that smaller muskellunge may be more active during the day and dusk because they are searching for suitable foraging habitat. Northern pike, for instance, may sample a variety of habitats before settling on an acceptable area to forage in (Hart, 1997). The optimal foraging theory (OFT), too, likely explains at least some of the observed dichotomy between activity over $24 \mathrm{~h}$ periods and fish size. The basis of the OFT indicates that prey is selected based on expected energetic returns given an amount of energy invested (see Diana, 1995). Larger fishes consume larger prey (Schindler and Eby, 1997), which maximizes their energetic intake, but smaller fishes have reduced handling efficiencies 
that limit the size of prey consumed (Mittelbach, 1981). Therefore, consuming larger prey may require less energy than consuming smaller prey more often. Also, because muskellunge are visually oriented predators (New et al., 2001) vision may be a factor for smaller muskellunge that must balance prey detection with predator avoidance. Such tradeoffs are evidenced by greater activity during the day and at dusk, compared to less activity at night and towards dawn when larger fish are more active. Overall, the results of this study demonstrate that activity varies as a function of both fish size and time of day.

Miller and Menzel (1986) found that muskellunge were most active during dusk with high activity levels also present at dawn. The latter observation conflicts with the findings in the current study that, irrespective of size, activity was lowest at dawn. Miller and Menzel (1986), however, did not find an effect of size on activity. For northern pike, Diana (1980) found little evidence of crepuscular (i.e., dawn/dusk) activity; instead, most activity occurred during the day. Results of the present study and those from Miller and Menzel (1986) failed to categorize muskellunge as solely diurnal, nocturnal, or crepuscular. Instead, variation in $24 \mathrm{~h}$ activity levels was demonstrated. Indeed, Reebs (2002) suggests that freshwater fishes are more generalists than marine species, further noting that activity is a function of foraging success.

Water temperature is considered one of the most important factors affecting behaviour (Fry, 1971). Indeed, the interaction between water temperature and time of day as well as fish size were shown to affect muskellunge activity. Data were recorded across a wide range of water temperatures $\left(9.0-29.9^{\circ} \mathrm{C}\right)$ and the variation in activity was generally narrower at warmer water temperatures than at cooler water temperatures. 
These findings concur with our present understanding of muskellunge behavioural ecology, which indicates that muskellunge are least active during periods of warm water temperatures (Dombeck, 1979). This lack of activity coincides with the establishment of summer home ranges, while more activity at cooler water temperatures is associated with movements away from spawning grounds in the spring and toward over-wintering areas in the fall (Dombeck, 1979; Younk et al., 1996). In addition, smaller fish were more active at cooler water temperatures while larger fish were more active at warmer water temperatures. The differences in activity at cooler water temperatures may reflect competition for suitable habitats, as vegetation is just beginning to grow in the spring and decreasing in abundance during the fall. One potential explanation for the suppressed activity of smaller fish during warmer water temperatures (i.e., summer) is another form of competition described as 'interference competition' (Persson, 1985). Here, larger animals can inhibit the ability of smaller animals to successfully forage (Schoener, 1983; Persson, 1985). Further speculation of the specific mechanisms triggering these observed differences in activity are not supported by the data. Nevertheless, the findings of this study clearly indicate an influence of water temperature on activity.

It is difficult to discern whether some of the accelerations noted in the present study were feeding events as opposed to other non-foraging behaviours (e.g., startle responses to boating activity, conspecific interactions, burst-glide swimming). Indeed, Diana (1980) notes that recording feeding events in the field is particularly difficult and that, for sit-and-wait predators, periods of inactivity may actually be foraging events. Therefore, although muskellunge appear to be sitting stationary over $70 \%$ of the time, some of these activity measurements may actually be a manifestation of sit-and-wait 
foraging behaviours. However, feeding events have been successfully recorded in the field. Accelerometers were surgically implanted in tigerfish (Hydrocynus brevis) and manual tracking enabled researchers to observe specific behaviours including foraging and hunting (Baras et al., 2002). Similarly, manual tracking combined with heart-rate telemetry was used to examine foraging behaviours of free-swimming northern pike, revealing that most foraging occurred during daylight hours (Lucas et al., 1991). For the transmitters used in this study, a priori calibrations would have been necessary to associate a range of acceleration values with feeding events, something not possible given the size and relative rarity of these fish. Despite strong anecdotal evidence relating environmental factors to feeding, it remains unclear as to what specifically influences feeding activities of muskellunge and could provide the basis for future studies of muskellunge behavioural ecology.

Lunar tables have long been used to predict the best angling times such as those often centered near new and full lunar periods. Indeed. Kuparinen et al. (2010) demonstrated that increased northern pike catch rates were associated with new and full lunar periods. The specific mechanism is unclear, particularly when considering the lack of tidal influences in inland freshwater systems (Kuparinen et al., 2009). However, it is possible that behavioural changes may result with shifts in zooplankton abundance triggered by variations in ambient light levels (Gliwicz, 1986). Zooplankton density was least during the last quarter of the lunar cycle, presumably following predation during full lunar periods as a result of increased ambient light, and increased exponentially during the new, first quarter, and up to the full lunar phase (Gliwicz, 1986). These patterns of zooplankton density match the patterns in activity of muskellunge noted in the present 
study, perhaps demonstrating an indirect response of muskellunge to shifts in prey behaviour. Contrary to these findings, Hanson et al. (2008) calculated the activity. measured as mean daily distance travelled, of largemouth bass and found no effect of lunar phase. The present study suggests that muskellunge activity is affected by lunar phase, with increased activity displayed during waxing phases. These results are at least partially similar to those shown by Kuparinen et al. (2010) with northern pike, a closely related member of the same family.

Several studies indicate specific patterns of seasonal behaviour for muskellunge (Dombeck, 1979; Miller and Menzel, 1986; Younk et al., 1996; Weeks and Hansen, 2009) as well as other warm-water species such as largemouth bass (Hasler et al., 2009; Hanson et al., 2010). The current study indicates an impact of water temperature on activity, with activity higher during periods of cool water temperatures than warmer water temperatures. However, the effect is likely quite small given the low $\mathrm{AICc}$ weight of the model that included water temperature as a factor. This is likely due to the relatively narrow range of dates encompassed in the study: late spring, summer, and early fall. Increases in muskellunge activity are typically noted following migrations away from spawning areas in the spring and again in autumn as fish move toward overwintering areas (Dombeck, 1979; Younk et al., 1996). Had data been recorded for longer periods, a more pronounced effect of water temperature may have been observed.

Depth. Muskellunge are considered shallow-dwelling predators that often associate with vegetation or other cover in the littoral zone (Scott and Crossman, 1973; Porter, 1977; Miller and Menzel, 1986). Indeed, this study confirms that muskellunge 
spend the majority of their time in relatively shallow water; $70 \%$ of detections recorded fish in $<3.0 \mathrm{~m}$ of water, which is considerably shallower than the approximate maximum depth of $10 \mathrm{~m}$. Eilers (2008) and Miller and Menzel (1986) tracked muskellunge in shallow water, despite greater depth variation in the lakes used for those studies. Eilers (2008) noted some movement to offshore areas, but the duration of these movements was short and muskellunge quickly returned to inshore areas. A preference for these shallow littoral areas may be reflected in the diet of muskellunge, which also consist of littoralassociating fishes including yellow perch and catostomids as well as, to a lesser degree. centrarchids (Bozek et al., 1999). Study site characteristics likely influenced depths inhabited, too. In the Rideau River, vegetation extends from the shoreline toward approximately $3 \mathrm{~m}$ of water. Muskellunge prefer vegetated areas (Scott and Crossman, 1973; Miller and Menzel, 1986) and because most detections occurred in depths $<3.0 \mathrm{~m}$ this suggests a strong association with vegetated areas. It should also be noted that receiver placement may also have affected observed depth patterns because many receivers were placed in $<3.0 \mathrm{~m}$ of water, including several that were found surrounded by vegetation months after initial deployment. Range testing was not conducted, but could have provided valuable information into what areas fish could have traveled to without being detected. Because of these limitations, depth use could not be evaluated, but this study does provide support for the long-held belief that muskellunge are shallowdwelling predators.

The interaction between temperature and lunar phase partially explained depth shifts, but while the thermal ecology of muskellunge is well understood the effects of lunar phase are not. Over the range of water temperatures data were recorded in, the 
current study showed that at cooler water temperatures muskellunge were deepest during the waxing lunar phase (i.e., transition from new to full) and shallowest during the waning phase (i.e.. transition from full to new). In warmer water, muskellunge were shallowest during the waxing lunar phase and deepest at the waning phase. These findings conflict with those of Hanson et al. (2008) who showed that largemouth bass inhabited greater depths during the spring and summer at waxing lunar periods. Similar patterns of shallow depth use during warm summer months were observed in radiotracked muskellunge from West Okoboji Lake, Iowa (Miller and Menzel, 1986). Zooplankton abundance increases during the waxing phase to a high at the full moon before tapering off to a low at the end of the lunar cycle (Gliwicz, 1986; Hernández-León et al., 2002). Zooplankton rise vertically at night, but become vulnerable to predators during nights of the full lunar phase when ambient light levels are high (Gliwicz, 1986). Shifts in depth of zooplankton likely cause a cascading effect throughout the food chain where baitfish move shallower to follow the zooplankton food sources and predators follow. However, this explanation does not hold during periods of cool water temperatures when muskellunge are shallowest at waning lunar phase periods. A diet shift away from pelagic species to benthivores is likely not a plausible explanation because muskellunge were shown to feed on yellow perch (i.e., pelagic species) and catostomids (i.e., benthivores) equally throughout the year (Bozek et al., 1999). Overall, this study demonstrates the complexity between depth and the interactions of water temperature and lunar phase.

Diel depth patterns were previously documented only during the summer months, but varied greatly depending on the specific month (Miller and Menzel, 1986). For 
instance. muskellunge were shallowest from late morning through late afternoon in June, but were deepest during this time frame in July and remained at a relatively constant depth during August (Miller and Menzel, 1986). Indeed. the present study demonstrated that muskellunge inhabit similar depths during diel periods in the warm summer months. Light levels diminish with depth and as visual predators muskellunge rely on their eyesight to initiate the strike sequence (New et al., 2001). Therefore, foraging may occur predominantly in shallow water, though specific feeding behaviours could not be determined in this study. Although these patterns were evident during the summer months, detections in shallow water were noted at dusk and night at cooler temperatures coinciding with periods in late spring and early fall. The scope of the data do not allow us to make further inferences about what might cause this shift in depth between warm and cool water temperatures. Nevertheless, our findings indicate that muskellunge indeed display clear patterns of depths inhabited both during warm and cool water temperatures.

Muskellunge size was previously not found to influence diel behaviour, including both movement and depth (Miller and Menzel, 1986). However, this study contradicts the findings of Miller and Menzel (1986) by demonstrating that, of the sizes sampled, larger muskellunge inhabited shallower water than smaller individuals. Furthermore, smaller fish were the shallowest at night and dawn while larger individuals were shallower during the day and dusk. The effect of the interaction between time of day $x$ fish size may be related to competition for resources. Larger size confers a competitive advantage both in terms of the ability to capture prey (Schoener, 1983) and preventing smaller individuals from successfully foraging, such as by defending an area or forcibly 
attacking an individual (Schoener, 1983: Persson, 1985). Furthermore, although the second best $\mathrm{AICc}$ model indicated an interaction between water temperature and fish size, larger fish continued to remain shallower than smaller fish regardless of water temperature.

Post-release behaviour of angled muskellunge. Little activity following exercise is common in fishes where the goal is to minimize the metabolic costs of restoring basal metabolism (Wood, 1991). Indeed, the results of this study demonstrated that activity of angled muskellunge for $24 \mathrm{~h}$ post-release was low, though not significantly different from free-swimming individuals during the same time frame. Differences in activity may have been masked because free-swimming muskellunge already remain quite inactive across $24 \mathrm{~h}$ periods. However, low activity of angled muskellunge, as compared to hyperactivity (e.g., Cooke and Philipp, 2004), indicates the animal's attempt to restore physiology to pre-exercise levels (Wood, 1991). Klefoth et al. (2008) made a similar finding after determining that movements of northern pike were significantly reduced following angling and release, suggesting that recovery is a significant contributor to suppressed movement. Although several studies suggest that various physiological parameters return to baseline levels after less than $24 \mathrm{~h}$, and in many cases less than $12 \mathrm{~h}$ (e.g., Soivio and Oikari, 1976; Gustaveson et al., 1991; Kieffer, 2000; Arlinghaus et al., 2009 ), it is possible that behavioural alterations may extend longer as a response to perceived negative stimuli such as an angling event (Klefoth et al., 2008). Together, this study illustrates that activity of angled individuals differs little from free-swimming 
muskellunge, and that the recovery dynamics of exercised fish may explain the observed patterns.

Several behavioural metrics have been used to assess the degree of post-release behavioural impairment including minimum displacement per hour (Klefoth et al., 2008), swimming speed (Cooke and Philipp, 2004), percent time resting (Arlinghaus et al., 2008), and dispersal distance (Bettoli and Osborne, 1998; Thorstad et al., 2003).

Characterizing depths inhabited by post-release fishes is less common and appears limited mainly to the marine environment (e.g., Domeier et al., 2003; Horodysky et al., 2007). As such, this study represents one of the first to document depth patterns of a freshwater fish species following angling and incorporates comparisons of depth patterns between angled and free-swimming individuals. Compared to free-swimming individuals, angled muskellunge were observed deeper during the first hour post-release, shallower at hours 1,2, and 3 post-release, and deeper for the duration of the $24 \mathrm{~h}$ monitoring period. The external transmitter attachment methods used were incorporated to minimize post-release behavioural disturbances, and given the size of the transmitters relative to the size of the fish it was assumed that there was little effect on post-release behaviour. One plausible explanation for the difference in behavioural patterns between treatment groups is that detections of angled muskellunge in greater depths reflects postrelease recovery. Muskellunge were found to move very little post-release (Landsman et al., 2011 a) and many fish could be seen descending to the bottom for a period of time (personal observation). It should be mentioned that free-swimming muskellunge were not necessarily located in the same areas as angled muskellunge; therefore, observed differences in depth use may be attributed to habitat characteristics at a given location, 
although this is unlikely given the relative homogeneity of this reach of the Rideau River. However, depths are relatively homogenous throughout the study site and may account little for discrepancies in depths inhabited. This study is one of the first to characterize post-release depth patterns for a freshwater species. clearly demonstrating differences in depths occupied by angled and free-swimming individuals.

Management and angling implications. The results of this study have implications for maximizing the successful capture of muskellunge. Understanding the factors that affect behaviour can lead to increased catch-per-unit-effort for anglers (Kuparinen et al., 2010) and fisheries managers (Hubert, 1983; Jennings et al., 2011). For example, managers looking to assess muskellunge populations should focus sampling efforts during the waxing lunar phase and to encompass daylight and dusk periods when muskellunge activity was noted to increase, regardless of size and temperature. Muskellunge activity was shown to be highest and depths shallowest during the waxing lunar phase, suggesting heightened vulnerability to angling. Anglers have made similar observations that catch rates increase around the new and full lunar periods (M. Lazarus, personal communication), also coinciding with predictions made by most lunar tables published in angling magazines. Miller and Menzel (1986) suggest that muskellunge inhabiting shallow depths are more vulnerable to angling than fish in deeper water. Indeed, most muskellunge angling occurs in shallow water during the warm summer months of June through August (Kerr, 2007a). Anglers also report catching muskellunge in deeper water during the months of fall (i.e., cool water temperatures; M. Clay, personal communication). Muskellunge inhabited greater depths during periods of cool water 
temperatures and were located in deeper water at night. Overall, this study adds credibility to lunar table predictions and behavioural observations made by anglers. 


\section{Tables}

Table 3-1. Summary table of AICc candidate models for factors describing activity patterns of free-swimming muskellunge. Models $(N=130)$ with $\triangle \mathrm{AICc}$ values $>5.00$ are not shown. The abbreviations TOD. TL, TEMP, $\sin (\theta)$, and $\cos (\theta)$ were used for time of day, total length (i.e., fish size), temperature, half lunar, and new/full lunar phases, respectively.

\begin{tabular}{|c|c|c|c|c|}
\hline Model Structure & K & $\mathrm{AICc}$ & $\triangle \mathrm{AICc}$ & $\begin{array}{l}\text { AlCc } \\
\text { Weight }\end{array}$ \\
\hline$A_{\text {TOD }+T E M P+T L}+\operatorname{SiN}(\theta)+\operatorname{COS}(\theta)+$ TOD TEMP $\cdot$ TOD $\cdot T L+T E M P \cdot T L+$ ID & 17 & 1495.91 & 0.00 & 0.21 \\
\hline$A_{T O D}+T E M P+T L+\operatorname{SiN}(\theta)+\operatorname{COS}(\theta)+T O D \cdot T L+T E M P \cdot T L+1 D$ & 14 & 1496.47 & 0.56 & 0.16 \\
\hline$A_{T O D}+T E M P+T L \cdot S N(H)+\operatorname{COS}(2 \theta)+T O D \cdot T E M P+T O D \cdot T L+T E M P \cdot T L+1 D$ & 17 & 1497.36 & 1.44 & 0.10 \\
\hline$A_{T O D}+T E M P+T_{L}+S I N(\theta)+\operatorname{COS}(\theta)+T O D-T E M P+T O D \cdot T L+I D$ & 16 & 1497.75 & 1.83 & 0.080 \\
\hline 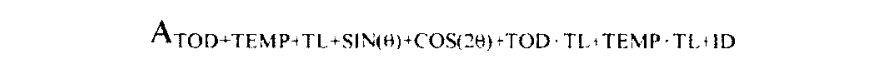 & 14 & 1497.94 & 2.02 & 0.080 \\
\hline$A_{T O D+T E M P}+T L+S I N(H)+\operatorname{COS}(\theta)+T O D \cdot T L+1 D$ & 13 & 1498.69 & 2.78 & 0.050 \\
\hline$A_{\text {TOD }}+T_{E M P}+T L+\operatorname{SIN}(\theta)+\operatorname{COS}(2 \theta)+T O D^{*} \cdot T E M P-T O D \cdot T L+I D$ & 16 & 1499.01 & 3.10 & 0.040 \\
\hline 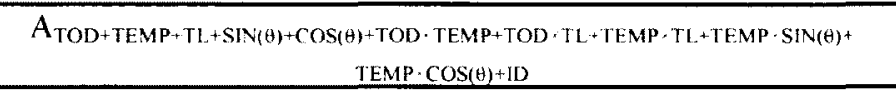 & 19 & 1499.39 & 3.48 & 0.040 \\
\hline$A_{\text {TOD }}+\mathrm{TEMP}+\mathrm{TL}+\mathrm{TOD} \cdot \mathrm{TEMP} \cdot \mathrm{TOD} \cdot \mathrm{TL}+\mathrm{TEMP} \cdot \mathrm{TL}+\mathrm{ID}$ & 15 & 1499.69 & 3.78 & 0.030 \\
\hline$A_{\operatorname{TOD}}+\operatorname{TEM} P+\mathrm{TL}+\operatorname{SIN}(\theta) \cdot \operatorname{Cos}(\theta)+\operatorname{TOD} \cdot \mathrm{TL}+\mathrm{THMP} \cdot \mathrm{TL}+\mathrm{TEMP} \cdot \operatorname{SIN}(\theta)+\operatorname{TEMP} \cdot \cos (\theta)+1 \mathrm{D}$ & 16 & 1499.95 & 4.03 & 0.030 \\
\hline$A_{T O D}+T E M P+T L+\operatorname{Sin}(\theta)+\operatorname{COS}(2 \theta)+T O D \cdot T L+R D$ & 13 & 1499.97 & 4.05 & 0.030 \\
\hline
\end{tabular}


Table 3-2. Summary table of AICc candidate models for factors describing depth patterns of free-swimming muskellunge. Models $(N=132)$ with $\triangle \mathrm{AICc}>30.00$ are not shown. The abbreviations TOD, TL, TEMP, $\sin (\theta)$, and $\cos (\theta)$ were used for time of day, total length (i.e., fish size), temperature. half lunar, and new/full lunar phases, respectively.

\begin{tabular}{|c|c|c|c|c|}
\hline Model Structure & K & $\mathrm{AlCc}$ & $\triangle \mathrm{AICc}$ & $\begin{array}{l}\text { AlCc } \\
\text { Weight }\end{array}$ \\
\hline 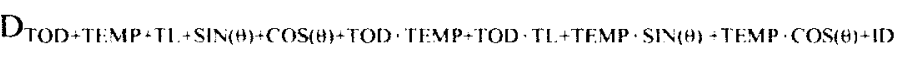 & 18 & 2407.33 & 0.00 & 0.70 \\
\hline 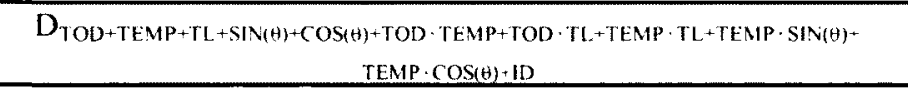 & 19 & 2409.07 & 1.74 & 0.29 \\
\hline 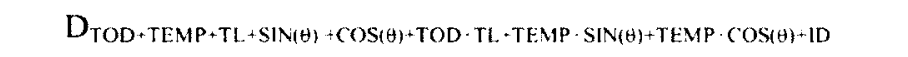 & 15 & 2418.22 & 10.89 & 0.00 \\
\hline 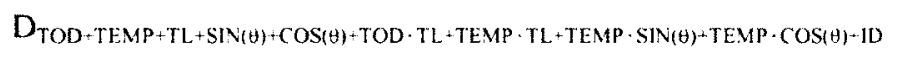 & 16 & 2419.92 & 12.59 & 0.00 \\
\hline 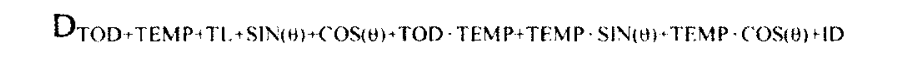 & 15 & 2427.07 & 19.75 & 0.00 \\
\hline 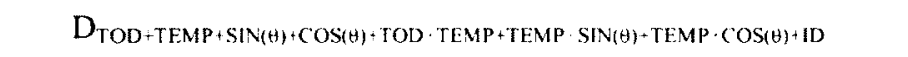 & 14 & 2427.11 & 19.78 & 0.00 \\
\hline 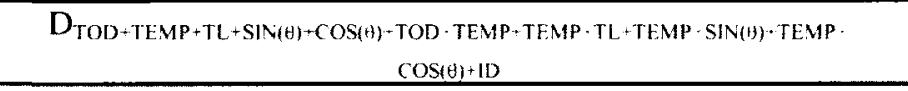 & 16 & 2428.84 & 21.51 & 0.00 \\
\hline$D_{\text {TOD }+T E M P+T L}+\operatorname{SIN}(H)+\operatorname{COS}(H)+T O D \cdot T E M P+T O D \cdot T L+I D$ & 16 & 2429.98 & 22.65 & 0.00 \\
\hline$D_{\text {TOD }+T E M P+T L}+\operatorname{SIN}(\theta)+\operatorname{COS}(\theta) \cdot T O D \cdot T E M P+T O D<T L-T E M P \cdot T L+1 D$ & 17 & 2431.50 & 24.18 & 0.00 \\
\hline 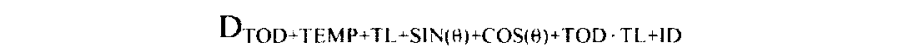 & 13 & 2436.95 & 29.62 & 0.00 \\
\hline
\end{tabular}


Figures

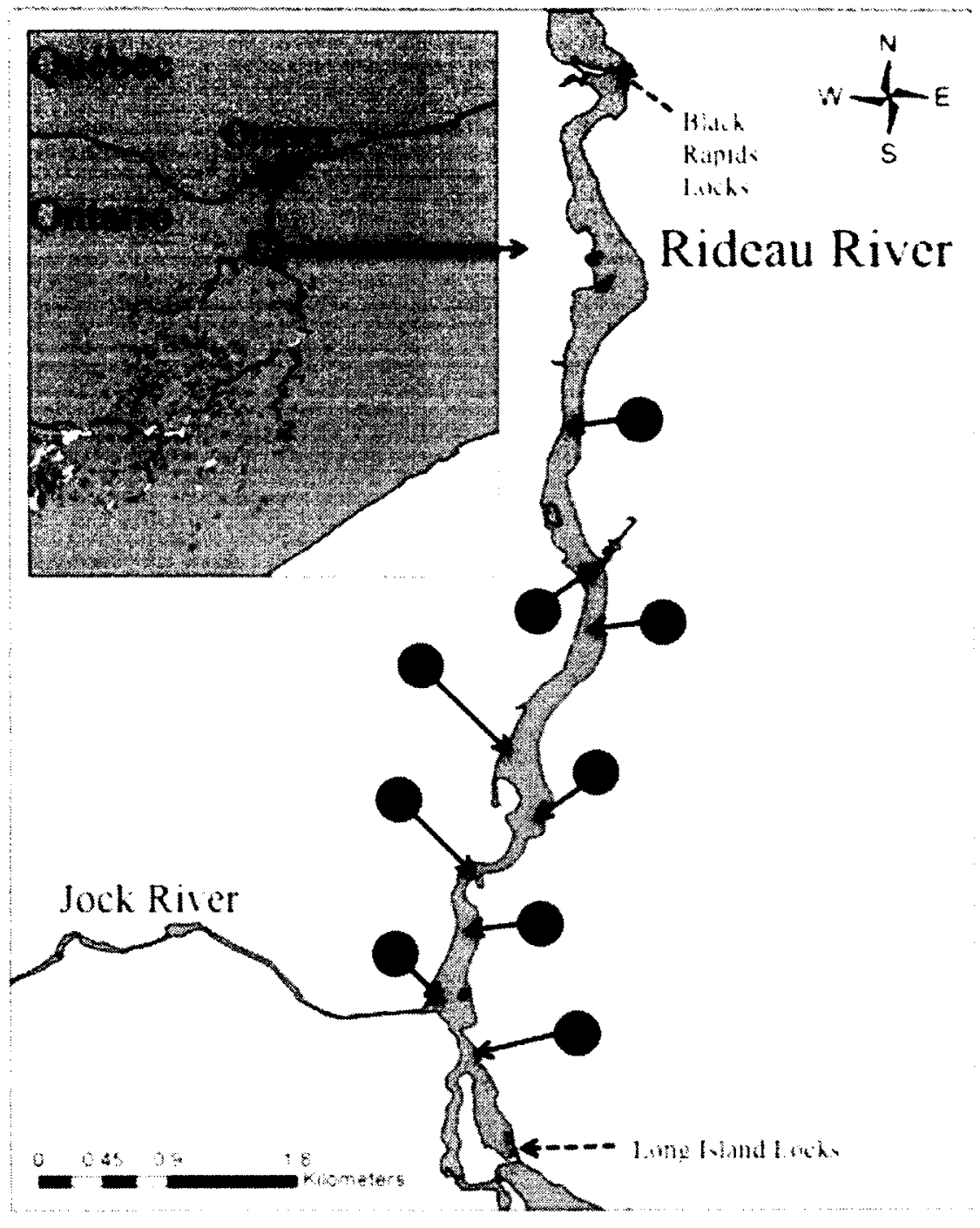

Figure 3-1. Map of the Rideau River between the Black Rapids and Long Island Locks. Dashed lines point to the lock systems and solid circles indicate acoustic receiver positions. 

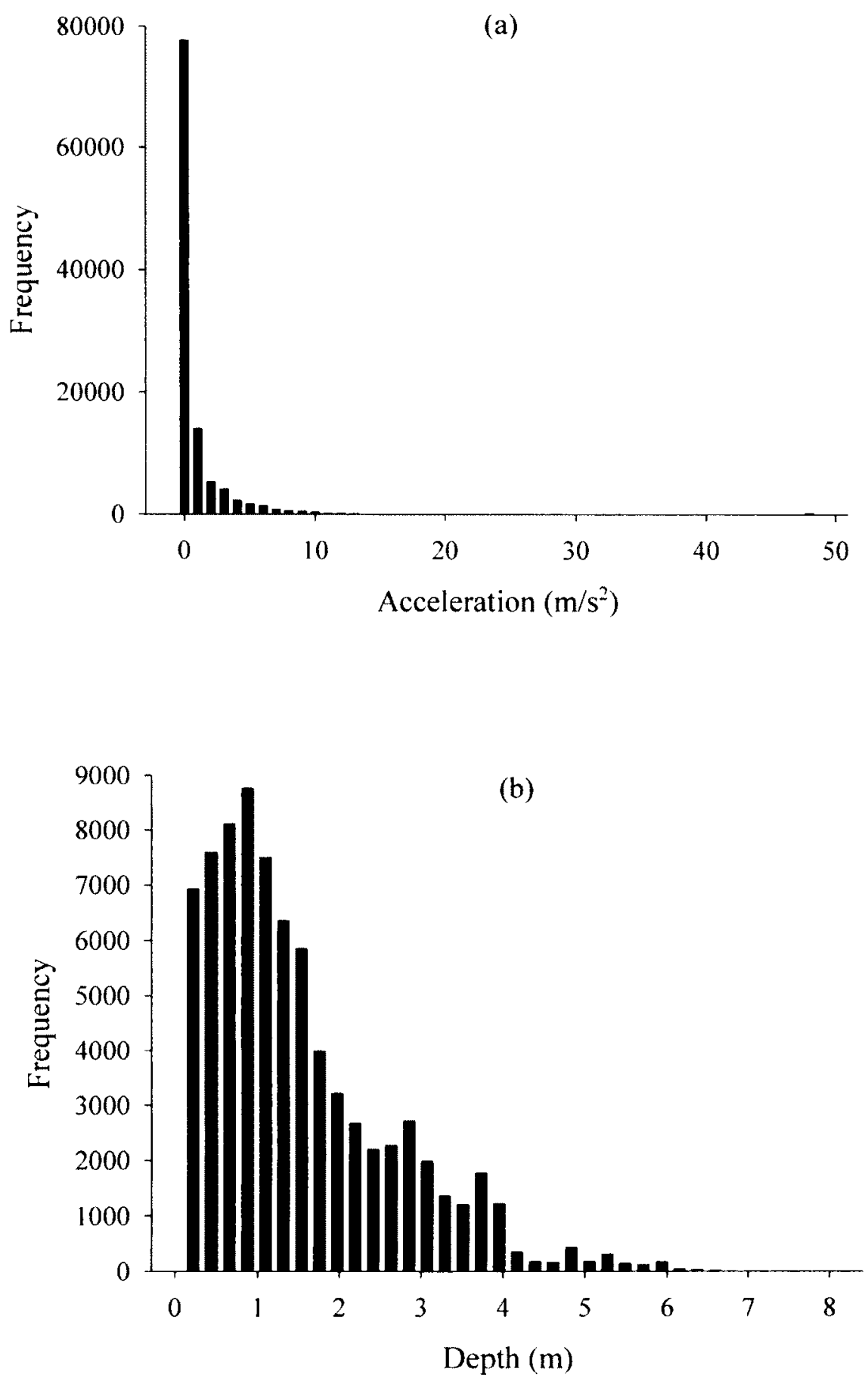

Figure 3-2. Frequency histogram for the number of detections at a given acceleration (a) and depth (b). 

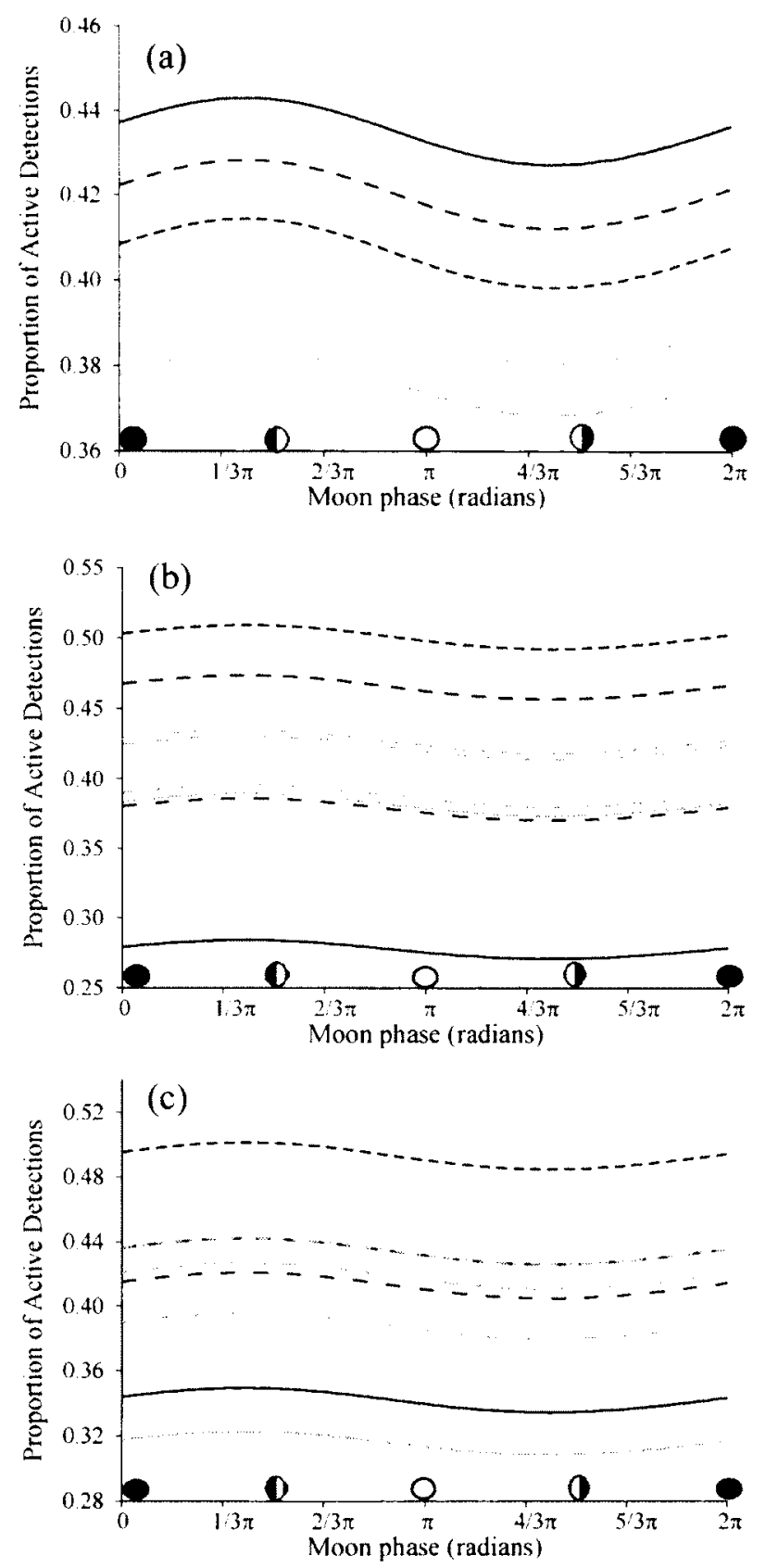

Figure 3-3. The proportion of active detections at cool (black lines, $10^{\circ} \mathrm{C}$ ) and warm (grey lines, $30^{\circ} \mathrm{C}$ ) water temperatures for small (solid, $50 \mathrm{~cm} \mathrm{~L}$ ), medium (dash-dot, 80 $\mathrm{cm} \mathrm{L}_{\mathrm{T}}$ ), and large (dash, $110 \mathrm{~cm} \mathrm{~L}$ ) sized muskellunge and across diel periods (a). Panel (b) demonstrates activity for small (black) and large (grey) muskellunge during dawn (solid), day (dash-dot), dusk (dashed), and night (dash-dot-dot) across all water temperatures. Panel (c) illustrates diel patterns of activity at cool (black) and warm (grey) during dawn (solid), day (dash-dot), dusk (dashed), and night (dash-dot-dot) for all sizes of fish. All panels show patterns across the lunar month. 

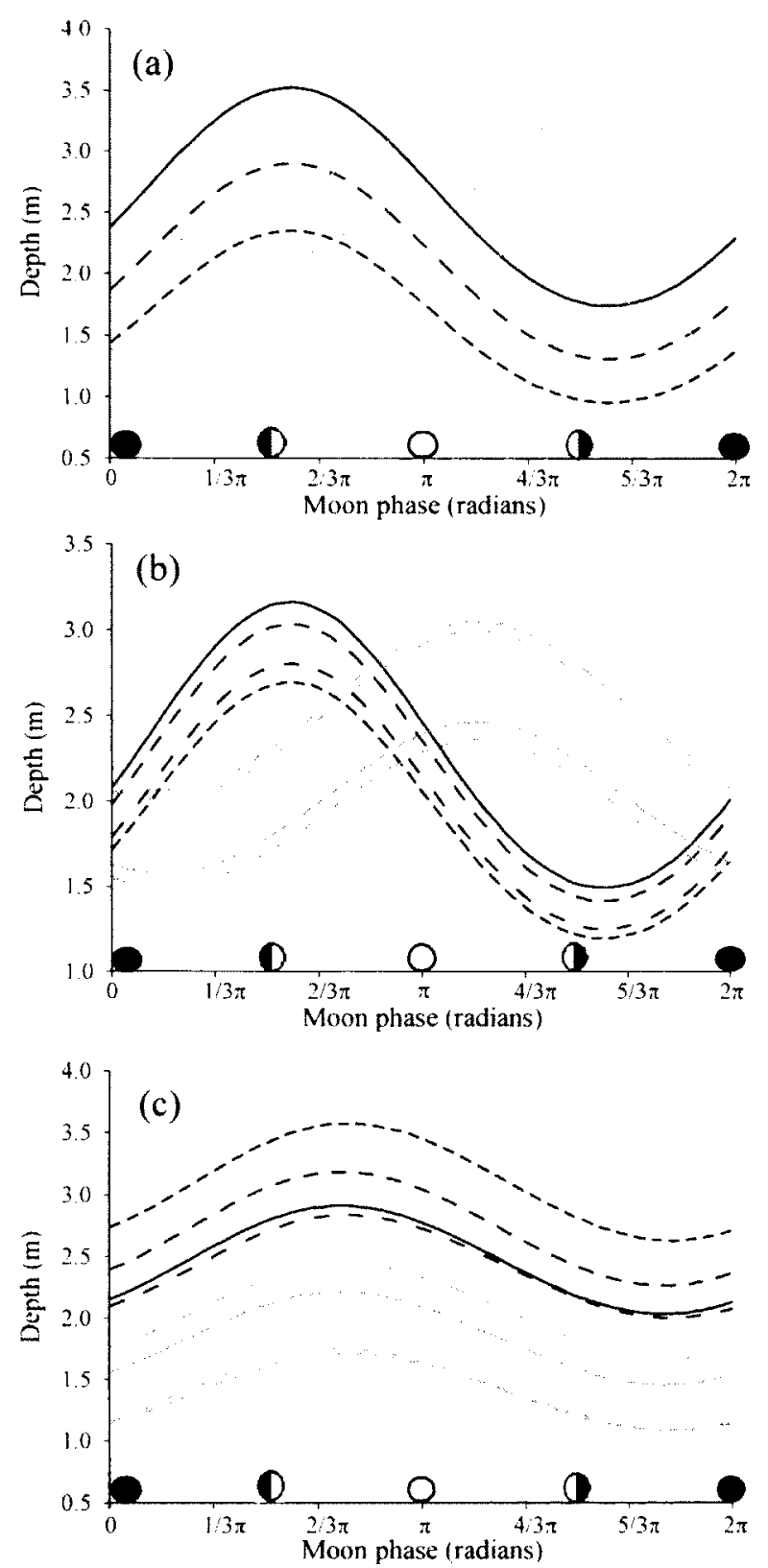

Figure 3-4. Depth at cool (black lines, $10^{\circ} \mathrm{C}$ ) and warm (grey lines, $30^{\circ} \mathrm{C}$ ) water temperatures for small (solid, $50 \mathrm{~cm} \mathrm{~L}_{\mathrm{T}}$ ), medium (dash-dot, $80 \mathrm{~cm} \mathrm{~L} \mathrm{~L}_{\mathrm{T}}$ ), and large (dashed, $110 \mathrm{~cm} \mathrm{~L}_{1}$ ) sized muskellunge across diel periods (a). Panel (b) illustrates depths inhabited at cool (black lines) and warm (grey lines) water temperatures during dawn (solid), day (dash-dot), dusk (dash), and night (dash-dot-dot) for all sizes of fish. Panel (c) demonstrates patterns of depth measurements for small (black) and large (grey) sized muskellunge at dawn (solid), day (dash-dot), dusk (dash), and night (dash-dot-dot) across all water temperatures. All panels show patterns throughout the lunar month. 

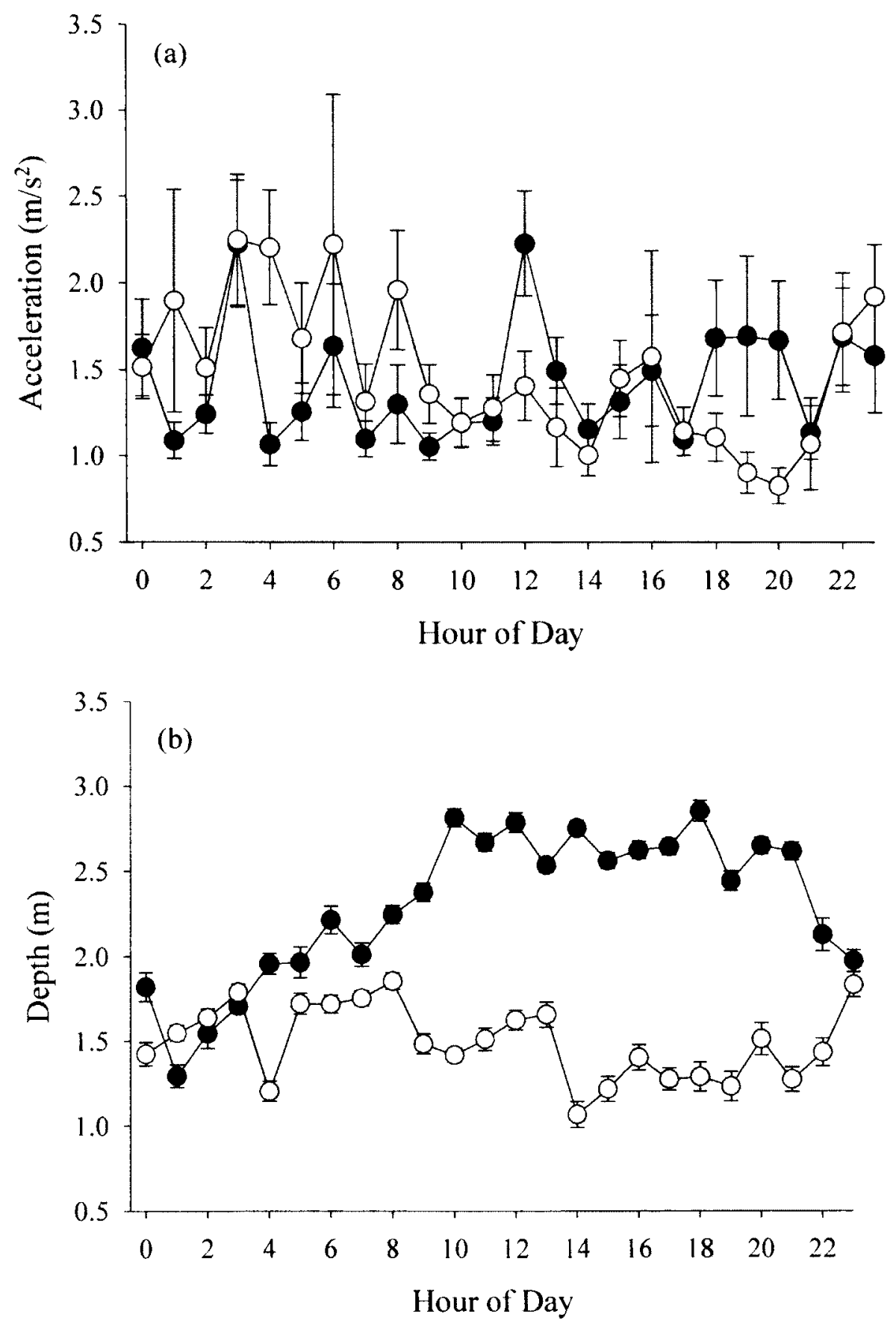

Figure 3-5. Acceleration (a) and depth (b) of post-release angled (black) muskellunge compared to free-swimming (white) individuals over $24 \mathrm{~h}$ periods. 


\section{Chapter 4: General Discussion}

The goal of this thesis was to address both applied and fundamental issues related to the biology of muskellunge. This large game fish is sought by an increasing number of specialized anglers employing very specific handling procedures (Kerr. 2007a). In

Chapter 2 I combined physiology and radio telemetry to evaluate the physiological and behavioural disturbances as well as survival of angled muskellunge. Previous studies suggested mortality rates as high as $30 \%$ for this species (Beggs et al., 1980), but with the advent of new angling and fish handling equipment (e.g., rods, reels, landing nets) coupled with voluntary release rates approaching 100\% (Fayram, 2003; Kerr, 2007a) it was deemed necessary to re-evaluate the effects of $C \& R$ angling on muskellunge (Chapter 2). An additional applied component of this thesis is Appendix I which presents my recommendations to the Ontario Ministry of Natural Resources (OMNR) regarding the viability of alternative live-bait rigging methods to potentially replace single-hook swallow rigs used to target muskellunge. Margenau (2007) presented evidence of high hooking mortality and severe injury when single-hook swallow rigs were used to capture muskellunge. Issues regarding sustainable angling practices were raised by the OMNR, which prompted this short paper. Questions regarding fine-scale activity and depth patterns of muskellunge were addressed in Chapter 3 using novel multi-sensor (acceleration and pressure) acoustic transmitters. Crossman (1986) identified muskellunge behaviour as a poorly understood aspect of their biology. Furthermore, very few studies have addressed muskellunge diel behaviour as we have in Chapter 3 and certainly none have done it on the scale that was accomplished in this thesis. Together, 
this thesis combines one of the most comprehensive examinations of the muskellunge's response to $C \& R$ angling and its fine-scale behavioural ecology.

\section{Findings and Implications}

Prior to the research presented in this thesis, only one study examined the physiological impacts of angling on muskellunge, but that study was conducted in a laboratory setting (Beggs et al., 1980). This study is the first to quantify not only the physiological effects of $C \& R$ angling, but also behavioural disturbances and survival of muskellunge in a field setting. A handling treatment was designed to mimic those employed by specialized muskellunge anglers - dubbed 'normal' - and another was created as a gentler alternative. No significant differences in physiology between these handling procedures were observed, although significant decreases in blood glucose and lactate concentrations were noted for control fish only. Also, plasma potassium concentrations showed a treatment $\times$ temperature affect where high temperatures and normally handled individuals displayed increased concentrations compared to gently handled muskellunge and control fish. Handling treatment had no effect on behaviour up to 2 hours post-release. Finally, all radio-tagged individuals from both handling treatments survived the $C \& R$ event, indicating a $100 \%$ survival rate. These findings contrast a previous estimate of $30 \%$ mortality for angled muskellunge (Beggs et al., 1980) and although zero mortality can never be achieved in a hook-and-line fishery (Arlinghaus et al., 2007a) efforts to maximize survival are paramount to sustainable recreational fisheries. These findings have important implications for the development of species-specific handling procedures (Cooke and Suski, 2005) and support the concept of 
$C \& R$ angling as a management tool to establish and maintain fisheries throughout the world.

Several studies describe various aspects of muskellunge behaviour including general movements (e.g. Younk et al., 1986; Weeks and Hansen, 2009), homing (Crossman. 1990), and spawning habits (e.g., Strand, 1986), but only two have examined diel behaviour (Miller and Menzel, 1986; juveniles, Wagner and Wahl, 2007). The majority of muskellunge behavioural studies have been conducted using radio telemetry, but with the advent of fixed station acoustic arrays and multi-sensor acoustic transmitters, tagged individuals can be continuously monitored and data can be collected on scales much finer than traditional radio tracking enables. In Chapter 3, I describe the fine-scale behaviour of muskellunge. In general, muskellunge were found to spend the vast majority of time stationary interspersed with periodic bursting events. Activity varied depending on the size of fish, with larger fish displaying constant activity throughout the day and smaller fish more active during the day and at dusk. Activity decreased slightly at warmer water temperatures and was highest during the waxing phase of the lunar cycle. How fishes distribute energy is important to understanding the costs of various behaviours. Similar activity patterns were revealed for northern pike in which activity was deemed a relatively unimportant aspect of their energy budget (Diana, 1980; Diana, 1983). Therefore, muskellunge may be allocating a large amount of energy to other processes such as maintenance, growth, and reproduction as was shown in northern pike (Diana, 1983). This may have important implications for protecting spawning muskellunge from anthropogenic disturbances (e.g., angling, shoreline development) that may shift energy expenditure away from critical gonadal development before and during 
the spawning period. Furthermore, shifts in muskellunge energy expenditure may reflect ecosystem change and act as a warning system to fisheries managers. With a timely and appropriate response, fisheries managers could prevent irreversible ecosystem change and conserve muskellunge populations as well as the communities they belong to.

In Chapter 3, I also revealed clear depth patterns for muskellunge. Overall, muskellunge remained in $<3.0 \mathrm{~m}$ of water $70 \%$ of the time. Larger fish remained shallower than smaller fish, regardless of size. Muskellunge remained shallower during the waxing phase of the lunar cycle at warmer temperatures, but were shallower during the waning phase of the lunar cycle at cooler temperatures. At warmer water temperatures, muskellunge were shallowest at dawn and during the day, while at cooler water temperatures muskellunge were shallower at dusk and during nighttime. In the context of a fisheries management framework, knowledge of what depths muskellunge inhabit and general behavioural patterns could improve capture efficiency by fisheries managers (Jennings et al., 2011), particularly when using passive capture techniques that require the interaction of fish with sampling gears (Hubert, 1983). For example, very few muskellunge are sampled in the Ottawa River because net sets are placed at unsuitable depths and habitats (T. Baker, OMNR, personal communication). Inadequate sampling could lead to improper regulations or management schemes and misrepresentation of the species assemblage for a given water body. Programs designed to monitor changes in fish community dynamics with changing environmental conditions can use the findings of Chapter 3 (both activity and depth) as a basis for comparison. 


\section{Future Research Directions}

In Chapter 2 . I showed that handling procedures used by today's specialized muskellunge anglers minimize physiological and behavioural disturbances and maximize survival. However, this study did not simulate how inexperienced anglers handle muskellunge and it has been suggested that inexperience may influence injury rates (Meka, 2004) and air exposure durations (Storck and Newman, 1992), which could impact successful releases. Muskellunge are bycatch for many anglers pursuing other species and are often angled, albeit unintentionally, with inadequate equipment and without proper handling tools (e.g., large landing nets, hook cutters, large pliers). Photo sessions, too, are often much longer with muskellunge (personal observation), likely because these fish are the largest a generalist angler will ever catch. Further studies should evaluate the effect of prolonged fight times and air exposure durations on muskellunge similar to how inexperienced anglers might handle muskellunge. In addition, anecdotal evidence suggests that angled muskellunge may be particularly susceptible to temperatures above $27^{\circ} \mathrm{C}$. Although individuals in Chapter 2 were radiotagged as high as $26^{\circ} \mathrm{C}$, sample sizes were low. It remains unclear what level of mortality may have been revealed if more individuals were tagged at this perceived critical temperature.

Reflex impairment testing was conducted in Chapter 2 with a goal of linking the absence of certain reflexes to mortality. However, because no mortality was observed this could not be accomplished. Nevertheless, the ability of quickly assessing relative health or condition in the field has interesting implications for anglers (Davis and Ottmar, 2006). If anglers can incorporate reflex testing in their handling procedure 
methodologies and adjust individual handling procedures accordingly. then the benefit to captured fish could be great. Future work should aim to validate reflex impairment testing for a variety of recreational fisheries and assess the feasibility of this approach in the field.

Depths inhabited by muskellunge remains a relatively unknown aspect of their biology. Angler-based anecdotal observations have indicated that some populations of muskellunge such as those found in the St. Lawrence River may never go shallower than $6 \mathrm{~m}$ of water. In other more oligotrophic systems with less macrophyte cover, anglers have also suggested that muskellunge use deep water structure and open basins to forage. following large schools of baitfish as they move throughout the system. With less macrophyte cover, a sit-and-wait predator such as muskellunge may be spotted by potential prey easier, thus forcing the predator to either increase active foraging or utilize greater depths to ambush prey. Chapter 3's study site had little variation in depth and thus a wide range of depths was not recorded. A more complete understanding of muskellunge biology would be accomplished by tagging muskellunge in deep riverine systems or oligotrophic lakes using accelerometers.

Assigning specific behaviours to a particular set of measurements without prior verification is difficult to justify and could not be done in Chapter 3. Murchie et al. (2011) tagged bonefish and related behaviours observed in holding tanks with acceleration recordings. Adult muskellunge, however, are too big to confine in most laboratories, making the determination of natural behaviours difficult to assess. One potential method is to use heart-rate telemetry, though this method would still require $a$ priori calibrations in a net pen or similarly large enclosure. Monitoring the behaviour 
(e.g.. underwater video, snorkeling/diving) of free-swimming muskellunge and relating these behaviours to the data gathered using heart-rate telemetry would provide the basis for comparing telemetered data in the wild to data collected in a controlled setting. For instance, tachycardias occurring in free-swimming northern pike were similar to the heart rates displayed by feeding northern pike held in a laboratory (Lucas et al., 1991). The authors were thus able to assign specific behaviours to free-swimming northern pike. The data gathered from this type of study would enable researchers to 1) assess the allocation of energy to processes such as general locomotion and feeding and 2) the interaction between environmental variables and behaviour.

\section{Afterword and Summary}

The goal of this thesis was to explore issues related to 1) specialized catch-andrelease angling practices, with specific focus on muskellunge, and 2) the behavioural ecology of muskellunge. This thesis is unique because it offers information useful to a variety of audiences. For example, anglers have long maintained that muskellunge can be caught and released multiple times, an observation confirmed in Chapter 2. Anglers may also appreciate the behavioural patterns discussed in Chapter 3 because of their potential to help anglers increase catch rates through improved understanding of their behavioural ecology. Fisheries managers were another target audience in Chapter 2 because accounting for the impacts, or lack thereof, of specialized $C \& R$ muskellunge angling could affect management practices (e.g., the decision to implement more restrictive regulations). Similarly, knowledge of when muskellunge alter depths, such as the information presented in Chapter 3, may improve capture efficiency by fisheries managers when conducting population assessments or community index netting. Finally, 
academics whose research interests exist within the field of recreational angling and the biological impacts of this endeavor on target species could use the information provided in Chapter 2 to supplement existing knowledge and guide future research. Academics can look to Chapter 3 for an example of how accelerometers, a relatively new biotelemetry device, can be applied to studying the behavioural ecology of fishes. Furthermore, many questions were raised in Chapter 3, which academics may choose to explore further.

Although the focus of Chapter 2 was on muskellunge, the implications of this study extend beyond muskellunge fisheries and can be applied to popular sport fisheries worldwide. Similarly, the findings presented in Chapter 3 not only contribute to our understanding of the fine-scale activity and depth patterns of muskellunge, but also demonstrate the utility of accelerometers for studying the behaviour of free-swimming fishes. Overall, there are several significant findings presented in this thesis that include: 1) Handling procedures developed by specialized anglers have the potential to create sustainable $\mathbf{C} \& \mathbf{R}$ fisheries. Compared to a gentler alternative handling procedure, current handling practices yielded no significant differences in physiological and behavioural disturbances, despite air exposure durations of $90 \mathrm{~s}$ in current handling practices. Most importantly, however, no mortality was observed regardless of handling treatment.

\section{2) Water temperature significantly affects muskellunge physiology following}

angling. Glucose and potassium concentrations were significantly elevated in both handling treatments compared to controls. Of concern are increased potassium levels as such elevations have been known to cause cardiac arrest in mammals. Care should be 
taken to minimize the stress imposed on angled fishes, including muskellunge, during periods of warm water temperatures.

\section{3) Descriptions of the general activity and depth patterns of muskellunge.}

Muskellunge were inactive over $70 \%$ of the time, displaying periodic increases in activity, and generally inhabited shallow (i.e., $<3.0 \mathrm{~m}$ ) water. These findings support prior research that indicate muskellunge are a shallow dwelling, relatively sedentary fish species employing sit-and-wait foraging strategies.

\section{4) Validation of lunar table activity predictions and confirmation of angler}

observations. Lunar tables published in angling magazines often predict the best angling times (i.e., high fish activity) near the new and full lunar phases. Although muskellunge are primarily inactive, periods of inactivity were interrupted by increased activity during the waxing lunar phase (i.e., transition from the new to full lunar phase). In addition, muskellunge inhabited shallower depths during periods of warm water temperatures during summer months. Indeed, most muskellunge angling occurs during the months of June through August when water temperatures are typically at their highest. 


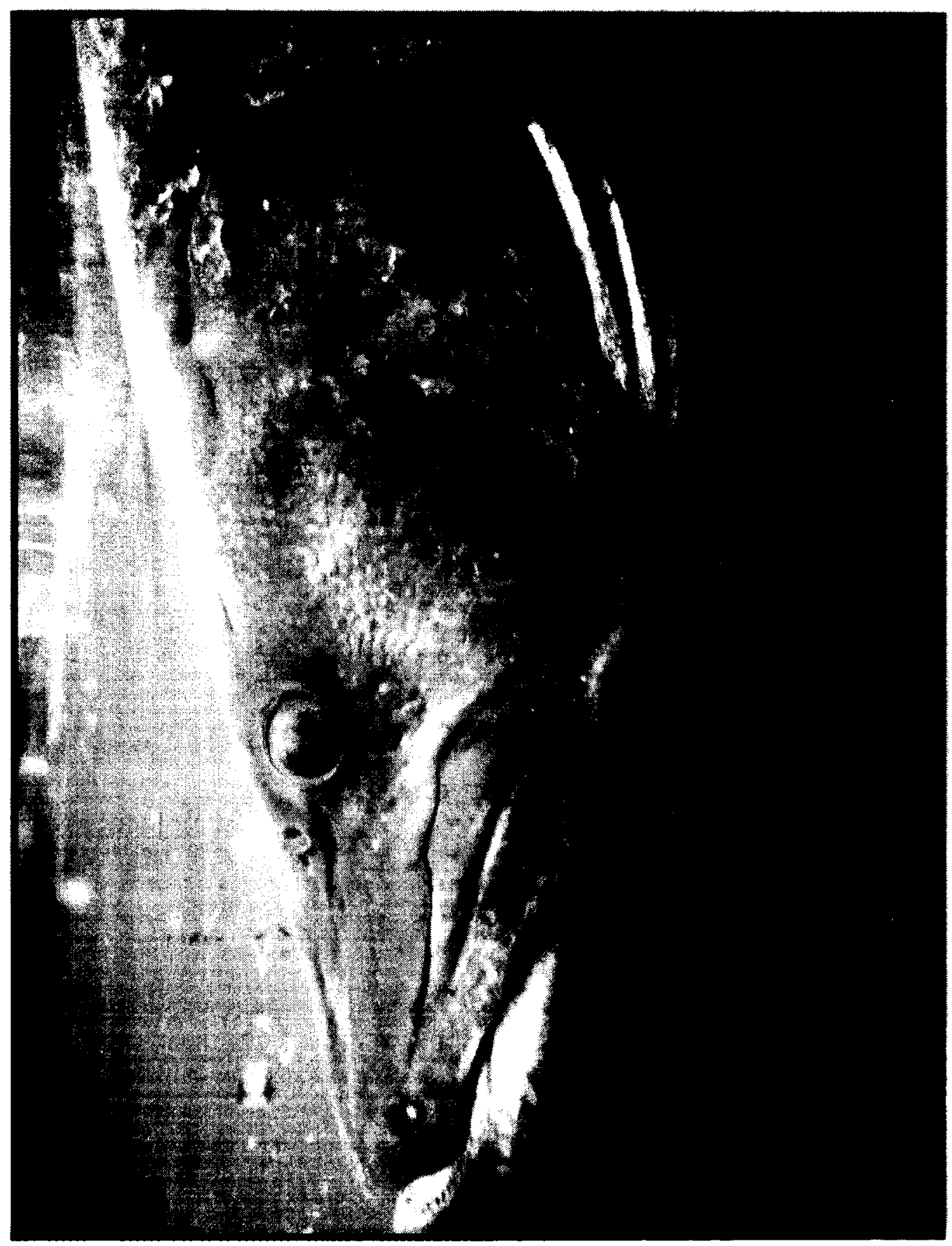




\section{References}

Abe, H., Oka, Y., 1999. Characterization of $\mathrm{K}^{+}$currents underlying pacemaker potentials of fish gonadotoprin-releasing hormone cells. J. Neurophysiol. 81, 643-653.

Alós, J., 2009. Mortality impact of recreational angling techniques and hook types on Trachynotus ovatus (Linnaeus, 1758) following catch-and-release. Fish Res. 95. 365-369.

Altringham, J.D., Ellerby, D.J., 1999. Fish swimming: patterns in muscle function. J. Exp. Biol. 202, 3397-3403.

Anderson, L.R., 1948. Unusual items in the diet of the northern muskellunge (Esox masquinongy immaculatus). Copeia 1948, 63.

Arlinghaus, R., Klefoth, T., Cooke, S.J., Gingerich, A., Suski, C., 2009. Physiological and behavioural consequences of catch-and-release angling on northern pike (Esox lucius L.). Fish. Res. 97, 223-233.

Arlinghaus, R., Klefoth, T., Kobler, A., Cooke, S., 2008. Size selectivity, injury, handling time, and determinants of initial hooking mortality in recreational angling for northern pike: the influence of type and size of bait. N. Am. J. Fish. Manage. 28 , $123-134$.

Arlinghaus, R., Cooke, S.J., Lyman, J., Policansky, D., Schwab, A., Suski, C., Sutton, S.G., Thorstad, E.B., 2007a. Understanding the complexity of catch-and-release 
in recreational fishing: an integrative synthesis of global knowledge from historical, ethical, social, and biological perspectives. Rev. Fish Sci. 15. 75-167.

Arlinghaus, R., 2007b. Voluntary catch-and-release can generate conflict within the recreational angling community: a qualitative case study of specialised carp, Cyprinus carpio, angling in Germany. Fish. Manage. Ecol. 14, 161-171.

Arlinghaus, R., Cooke, S.J., Schwab, A., Cowx, I.G., 2007c. Fish welfare: a challenge to the feelings-based approach, with implications for recreational fishing. Fish Fish. $8,51-71$.

Baras, E., Togola, B., Sicard, B., Bénech, V., 2002. Behaviour of tigerfish Hydrocynus brevis in the River Niger, Mali, as revealed by simultaneous telemetry of activity and swimming depth. Hydrobiologia 483, 103-110.

Bartholomew, A., Bohnsack J. A., 2005. A review of catch-and-release angling mortality with implications for no-take reserves. Rev. Fish Biol. Fish. 15, 129-154.

Barton, B.A., 2002. Stress in fishes: a diversity of responses with particular reference to changes in circulating corticosteroids. Integr. Comp. Biol. 42, 517-525.

Barton, B.A., Iwama, G.K., 1991. Physiological changes in fish from stress in aquaculture with emphasis on the response and effects of corticosteroids. Integr. Comp. Biol. 42, 517-525.

Bates. D.. Maechler, M.. Bolker, M., 2011. Ime4: Linear mixed-effects models using S4 classes. R package version $0.999375-38$. http://CRAN.R- 
projectorg/package 1 met

Barton B.A., Schreck C.B.. Sigismondi, L.A., 1986. Multiple acute disturbances evoke cumulative physiological stress responses in juvenile Chinook salmon. Trans. Am. Fish. Soc. 115, 245-251.

Beggs, G.L., Holeton, G.F., E.J. Crossman, 1980. Some physiological consequences of angling stress in muskellunge, Esox masquinongy Mitchell. J. Fish. Biol. 17, 649659.

Bettoli, P., Vandergoot, C.. Horner, P., 2000. Hooking mortality of saugers in the Tennessee River. N. Am. J. Fish. Manage. 20, 833-837.

Bettoli, P., Osborne, R., 1998. Hooking mortality and behavior of striped bass following catch and release angling. N. Am. J. Fish. Manage. 18, 609-615.

Boisclair, D., 1992. Relationship between feeding and activity rates for actively foraging juvenile brook trout (Salvelinus fontinalis). Can. J. Fish. Aquat. Sci. 49, 25662573.

Boisclair, D., Leggett, W.C., 1989. Importance of activity in bioenergetics models applied to actively foraging fishes. Can. J. Fish. Aquat. Sci. 46, 1859-1867.

Borgese F., Garcia-Romeu, F., Motais, R., 1987. Control of cell volume and ion transport by b-adrenergic catecholamines in erythrocytes of rainbow trout, Salmo gairdneri. J. Physiol. 382: 123-144. 
Boutilier, R.G., 1990. Control and co-ordination of gas exchange in bimodal breathers. In: Boutilier, R.G. (Ed.), Advances in Comparative \& Environmental Physiology. Springer Verlag: New York, New York. pp. 280-346.

Bozdogan, H., 1987. Model selection and Akaike's Information Criterion (AIC): the general theory and its analytical extensions. Psychometrika 52, 340-375.

Bozek, M., Burri. T., Frie, R., 1999. Diets of muskellunge in northern Wisconsin lakes. N. Am. J. Fish. Manage. 19, 258-270.

Braithwaite, V.A., Huntingford, F.A., 2004. Fish and welfare: do fish have the capacity for pain perception and suffering? Anim. Welfare 13, 87-92.

Brett, J.R., Groves, T.D.D., 1979. Physiological energetics. In W.S. Hoar, Randall, D.J., Brett, J.R. (Eds.), Fish Physiology. Volume 8. Bioenergetics and Growth. Academic Press: New York. pp. 279-352.

Brett, J.R., 1971. Energetic responses of salmon to temperature: a study of some thermal relations in the physiology and freshwater ecology of sockeye salmon (Oncorhynchus nerka). Amer. Zool. 11, 99-113.

Bridger, C.J., Booth, R.K., 2003. The effects of biotelemetry transmitter presence and attachment procedures on fish physiology and behaviour. Rev. Fish. Sci. 11, 1334.

Brousseau, C.S., Armstrong, E.R., 1987. The role of size limits in walleye management. Fisheries 12, 2-5. 
Brown, R.S., Cooke, S.J., Wagner, G.N., Eppard, M.B., 2010. Methods for surgical implantation of acoustic transmitters in juvenile salmonids: a review of literature and guidelines for technique. U.S. Army Corps of Engineers (contract DE-AC0576RL01830).

Bryan, H., 1977. Leisure value systems and recreation specialization: the case of trout fishermen. J. Leisure Res., 9, 174-187.

Burnham, K.P., Anderson, D.R., 2002. Model selection and multimodel interface, a practical information-theoretic approach, 2nd Edn. Springer-Verlag: New York.

Campbell, M.D., Tolan, J., Strauss, R., Diamond, S.L., 2010. Relating angling-dependent fish impairment to immediate release mortality of red snapper (Lutjanus campechanus). Fish. Res. 106, 64-70.

Casselman, J. M., 2007. Determining minimum ultimate size, setting size limits, and developing trophy standards and indices of comparable size for maintaining quality muskellunge (Esox masquinongy) populations and sports fisheries. Env. Biol. Fish. 79, 137-154.

Casselman, J., Robinson, C., Crossman, E.J., 1999. Growth and ultimate length of muskellunge from Ontario water bodies. N. Am. J. Fish. Manage. 19, 271-290.

Casselman, J.M., Crossman, E.J., 1995. Assessing sustainability of trophy muskellunge fisheries, in: Kerr, S.J., Oliver, C.H. (Eds.), Managing Muskies in the '90s: Workshop Proceedings. Ontario Ministry of Natural Resources, Southern Region Science \& Technology Transfer Unit, Kemptville, Ontario, pp. 29-39. 
Casselman, J. M.. Crossman, E.J. 1986. Size, age. and growth of trophy muskellunge and muskellunge-northern pike hybrids - the Cleithrum Project, 1979-1983, in: Hall, G.E. (Ed.), Managing Muskies. American Fisheries Society Special Publication (15): Bethesda, Maryland. pp. 93-110.

Chipman, B. D., Helfrich, L.A., 1988. Recreational specialization and motivations of Virginia river anglers. N. Am. J. Fish. Manage. 8, 390-398.

Conover, W.J., Iman, R.L., 1981. Rank transformations as a bridge between parametric and nonparametric statistics. Am. Stat. 35, 124-129.

Cooke, S.J., Suski, C.D., Danylchuk, S.E., Danylchuk, A.J., Donaldson, M.R., Pullen, C., Bulté, O’Toole, A., Murchie, K.J., Koppelman, J.B., Shultz, A.D., Brooks, E., Goldberg, T.L., 2008. Effects of different capture techniques on the physiological condition of bonefish Albula vulpes evaluated using field diagnostic tools. J. Fish Biol. 73, 1351-1375.

Cooke, S.J., Sneddon, L.U., 2007. Animal welfare perspectives on recreational angling. Appl. Anim. Behav. Sci. 104, 176-198.

Cooke, S. J., Suski, C.D., 2005. Do we need species-specific guidelines for catch-andrelease recreational angling to conserve diverse fishery resources? Biodivers. Cons. 14, 1195-1209.

Cooke, S.J., Crossin, G.T., Patterson, D.A., English, K.K., Hinch, S.G., Young, J.L., Alexander, R.F., Healey, M.C., Van der Kraak, Farrell, A.P., 2005. Coupling noninvasive physiological assessments with telemetry to understand inter-individual 
variation in behaviour and survivorship of sockeye salmon: development and validation of a technique. J. Fish Biol. 67, 1342-1358.

Cooke, S.J., 2004. Are circle hooks an effective tool for conserving marine and freshwater recreational catch-and-release fisheries? Aquatic Conserv.: Mar. Freshw. Ecosyst. 14, 299-326.

Cooke, S.J., Cowx, I.G., 2004. The role of recreational fishing in global fish crises. BioScience 54, 857-859.

Cooke, S.J., Philipp, D.P., 2004. Behaviour and mortality of caught-and-released bonefish (Albula spp.) in Bahamian waters with implications for a sustainable recreational fishery. Biol. Conserv. 118, 599-607.

Cooke, S.J., Thorstad, E.B., Hinch, S.G., 2004a. Activity and energetics of freeswimming fish: insights from electromyogram telemetry. Fish Fish. 5, 21-52.

Cooke, S.J., Hinch, S.G., Wikelski, M., Andrews, R.D., Kuchel, L.J., Wolcott, T.G., Butler, P.J., 2004b. Biotelemetry: a mechanistic approach to ecology. Trends Ecol. Evol. 19, 334-343.

Cooke, S.J., Suski, C.D., Siepker, M.J., Ostrand, K.G., 2003a. Injury rates, hooking efficiency and mortality potential of largemouth bass (Micropterus salmoides) captured on circle hooks and octopus hooks. Fisheries Research, 61(1-3), 135144.

Cooke, S.J., Graeb, B.D.S., Suski, C.D., Ostrand, K.G., 2003b. Effects of suture material 
on incision healing. growth and survival of juvenile largemouth bass implanted with miniature radio transmitters: case study of a novice and experienced fish surgeon. J. Fish Biol. 62, 1366-1380.

Cooke, S.J., Schreer, J.F., Wahl, D.H., Philipp, D.P., 2002. Physiological impacts of catch-and-release angling practices on largemouth bass and smallmouth bass. Black Bass 2000. Am. Fish. Soc. Symp. 31, 489-512.

Cooke, S.J., Kassler, T.W., Philipp, D.P., 2001. Physiological performance of largemouth bass related to local adaptation and interstock hybridization: implications for conseration and management. J. Fish Biol. 59, 248-268.

Cooke, S.J., Philipp, D.P., Schreer, J.F., McKinley, R.S., 2000. Locomotory impairment of nesting male largemouth bass following catch-and-release angling. N. Am. J. Fish. Manage. 20, 968-977.

Cossins, A.R., Prosser, C.L., 1978. Evolutionary adaptation of membranes to temperature. P. Natl. Acad. Sci. USA. 75, 2040-2043.

Crossman, E. J., 1990. Reproductive homing in muskellunge, Esox masquinongy. Can. J. Fish. Aquat. Sci. 47, 1803-1812.

Crossman, E.J., 1986. The noble muskellunge: a review. In: Hall, G.E. (Ed.), Managing Muskies. American Fisheries Society Special Publication (15): Bethesda, Maryland. pp. 1-13. 
Danylchuk, A.J., Danylchuk, S.E.. Cooke, S.J., Goldberg, T.L., Koppelman, J.B., Philipp. D.P., 2007. Post-release mortality of bonefish. Albula vulpes, exposed to different handling practices during catch-and-release angling in Eleuthera. The Bahamas. Fish. Manag. Ecol. 14, 149-154.

Davis, M.W., Ottmar, M.L., 2006. Wounding and reflex impairment may be predictors for mortality in discarded or escaped fish. Fish. Res. 82, 1-6.

Davis, M.W., 2005. Behaviour impairment in captured and released sablefish: ecological consequences and possible substitute measures for delayed discard mortality. J. Fish. Biol. 66, 254-265.

Davis, M.W., Parker, S.J., 2004. Fish size and exposure to air: potential effects on behavioural impairment and mortality rates in discarded sablefish. N. Am. J. Fish. Manage. 24, 518-524.

deBruyn, A. M. H., \& Meeuwig, J. J. (2001). Detecting lunar cycles in marine ecology: periodic regression versus categorical ANOVA. Mar. Ecol. Prog. Ser. 214, 307310.

Dedual, M., 1996. Observed mortality of rainbowtrout caught by different angling techniques in Lake Taupo, New Zealand. N. Amer. J. Fish. Manage. 16, 357-363.

Department of Fisheries and Oceans (DFO) Canada, 2005. 2005 Survey of recreational fishing in Canada. http://www.dfo-mpo.gc.ca/stats/rec/can/2005/index-eng.htm 
Diana, J.S., 1995. Biology and Ecology of Fishes. Biological Sciences Press: Carmel, Indiana.

Diana, J.S., 1983. An energy budget for northern pike (Esox lucius). Can. J. Zool. 61, $1968-1975$.

Diana, J.S., 1980. Diel Activity Pattern and Swimming Speeds of Northern Pike (Esox lucius) in Lac Ste. Anne, Alberta. Can. J. Fish. Aquat. Sci. 37, 1454-1458.

Dickson, I.W., Kramer, R.H., 1971. Factors influencing scope for activity and active and standard metabolism of rainbow trout (Salmo gairdneri). J. Fish. Res. Board. Can. $28,587-596$.

Dombeck, M. P. 1979. Movement and behavior of the muskellunge determined by radiotelemetry. Wisconsin Department of Natural Resources Technical Bulletin 113.

Domeier, M.L., Dewar, H., Nasby-Lucas, N., 2003. Mortality rate of striped marlin (Tetrapturus audax) caught with recreational tackle. Mar. Freshwater Res. 54, $435-445$.

Donaldson, M.R., Arlinghaus, R., Hanson, K.C., Cooke, S.J., 2008. Enhancing catch-andrelease science with biotelemetry. Fish Fish. 9, 79-105.

Drašík,V., Kubečka, J., 2005. Fish avoidance of acoustic survey boat in shallow waters. Fish. Res. 72, 219-228.

Eilers, C.D., 2008. Movement, home-range, and habitat selection of muskellunge (Esox masquinongy Mitchell) in Thornapple Lake, Michigan. M.Sc. thesis: Central 
Michigan University. pp. 109.

Fayram, A.H., 2003. A comparison of regulatory and voluntary release of muskellunge and walleyes in northern Wisconsin. N. Am. J. Fish. Manag. 23, 619-624.

Ferguson, R.A., Tufts, B.L., 1992. Physiological effects of brief air exposure in exhaustively exercised rainbow trout (Oncorhynchus mykiss): implications for "catch and release" fisheries. Can. J. Fish. Aquat. Sci. 49, 1157-1162.

Frohnauer, N.K., Pierce, C.L., Kallemeyn, L.W., 2007. Population dynamics and angler exploitation of the unique muskellunge population in Shoepack Lake, Voyageurs National Park, Minnesota. N. Am. J. Fish. Manage. 27, 63-76.

Fry, F.E.J., 1971. The effect of environmental factors on the physiology of fish. In: Hoar, W.S., Randall, D.J. (Eds.), Fish Physiology, Vol. VI. Academic Press: New York. pp. 1-98.

Gasbarino, P.L., 1986. Catch-and-release of muskellunge - philosophy and methods. In: Hall, G.E. (Ed.), Managing Muskies. American Fisheries Society Special Publication (15): Bethesda, Maryland. pp. 300-308.

Gerner, E.W., Cress, A.E., Stickney, D.G., Holmes, D.K., Culver, P.S., 1980. Factors regulating membrane permeability alter thermal resistance. Ann. NY. Acad. Sci. $335,215-233$. 
Gillis. N.C.. Rapp, T., Hasler, C.T., Wachelka, H., Cooke, S.J., 2010. Spatial ecology of adult muskellunge (Esox masquinongv) in the urban Ottawa reach of the historic Rideau Canal, Canada. Aquat. Living Resour. 23, 225-230.

Girden, E.R., 1992. ANOVA repeated measures. SAGE Publications, Inc. Newbury Park, California, pp. 79.

Gliwicz, Z.M., 1986. A lunar cycle in zooplankton. Ecology 67, 883-897. glycogen during recovery from exhaustive exercise in rainbow trout (Oncorhynchus mykiss) and winter flounder (Pseudopleuronectes americanus). J. Exp. Biol. 161, 489-508.

Graff, D.R., 1986. Musky management - a changing perspective from past to present. In: Hall, G.E. (Ed.), Managing Muskies. American Fisheries Society Special Publication (15): Bethesda, Maryland. pp. 195-198.

Gravel, M.A., Cooke, S.J., 2008. Severity of barotrauma influences the physiological status, post-release behaviour, and fate of tournament-caught smallmouth bass. N. Am. J. Fish. Manage. 28, 607-617.

Gustaveson, A.W., Wydoski, R. S., Wedemeyer, G.A., 1991. Physiological response of largemouth bass to angling stress. Trans. Am. Fish. Soc., 120, 629-636.

Gutowsky, L.F.G., Harrison, P.M., Landsman, S.J., Power, M., Cooke, S.J., 2011. Injury and mortality associated with recreational troll capture of bull trout (Salvelinus confluentus) in a reservoir in the Kootenay-Rocky Mountain region of British Columbia. Fish. Res. 109, 379-383. 
Guyton, A.C.. 1981. Textbook of medical physiology: 6th edition. W. B. Saunders Co.: Toronto, Ontario.

Halsey, L.G., Portugal, S.J., Smith, J.A, Murn, C.P., Wilson, R.P., 2009. Recording raptor behavior on the wing via accelerometry. J. Field Ornithol. 80, 171-177.

Hansen, M.J., Boisclair, D., Brandt, S.B., Hewett, S.W., Kitchell, J.F., Lucas, M.C., Ney, J.J., 1993. Applications of bioenergetics models to fish ecology and management: Where do we go from here? Trans. Amer. Fish. Soc. 122, 1019-1030.

Hanson, K. C., Hasler, C.T., Donaldson, M.R., Cooke, S.J., 2010. Stability of swimming performance and activity hierarchies among wild largemouth bass at multiple temporal scales: evidence for context-dependent shuffling between seasons. Can. J. Zool. 88, 324-333.

Hanson, K.C., Arrosa, S., Hasler, C.T., Suski, C.D., Philipp, D.P., Niezgoda, G., Cooke, S.J., 2008. Effects of lunar cycles on the activity patterns and depth use of a temperate sport fish, the largemouth bass, Micropterus salmoides. Fish. Manage. Ecol. 15, 357-364.

Harper, B.Y.D.G., Blake, R.W., 1991. Prey capture and the fast-start performance of northern pike Esox Lucius. J. Exp. Biol. 155, 175-192.

Harrell, R.M., Moline, M.A., 1992. Comparative stress dynamics of brood stock striped bass Morone saxatilis associated with two capture techniques. J. World Aquacult. Soc. $23,58-63$. 
Hart, P.J.B., 1997. Foraging tactics. In: Godin, J.G. (Ed.) Behavioural Ecology of Teleost Fishes. Oxford: Oxford University Press. pp. 102-133.

Hasler, C.T., Suski, C.D., Hanson, K.C., Cooke, S.J., Philipp, D.P., Tufts, B.L., 2009. Effect of water temperature on laboratory swimming performance and natural activity levels of adult largemouth bass. Can. J. Zool. 87. 589-596.

Hernandez-Leon S., Almeida C, Yebra L. \& Aristegui J. (2002) Lunar cycle of zooplankton biomass in subtropical waters: biogeochemical implications. J. Plankton Res 24, 935-939.

Hidaka, T., Toida, N., 1969. Biophysical and mechanical properties of red and white muscle fibres in fish. J. Physiol. 201, 49-59.

Hightower, J.E., Jackson, J.R., Pollock, K.H., 2001. Use of telemetry methods to estimate natural and fishing mortality of striped bass in Lake Gaston, North Carolina. Trans. Am. Fish. Soc. 130, 557-567.

Horodysky, A.J., Kerstetter, D.W., Latour, R.J., Graves, J.E., 2007. Habitat utilization and vertical movements of white marlin (Tetrapturus albidus) released from commercial and recreational fishing gears in the western North Atlantic Ocean: inferences from short duration pop-up archival satellite tags. Fisheries Oceanogr. $16,240-256$.

Hubert, W.A., 1983. Passive capture techniques. In: Nielsen, L.A. and Johnson, D.L. (Eds.), Fisheries Techniques. American Fisheries Society: Bethesda, Maryland. pp. 95-122. 
Huntingford, F.A.. Adams, C., Braithwaite, V.A.. Kadri, S.. Pottinger, T.G., Sandøe, P.. Turnbull, J.F., 2006. Current issues in fish welfare. J. Fish Biol. 68, 332-372.

Isermann, D.A., Willis, D.W., Lucchesi, D.O., Blackwell, B.G., 2005. Seasonal harvest, exploitation, size selectivity, and catch preferences associated with winter yellow perch anglers on South Dakota lakes. N. Am. J. Fish. Manage. 25, 827-840.

Jennings, C.A., Looney, G.L., 1998. Evaluation of two types of anesthesia for performing surgery on striped bass. N. Am. J. Fish. Manag. 18, 187-190.

Jennings, M.J., Hatzenbeler, G.R., Kampa, J.M., 2011. Spring capture site fidelity of adult muskellunge in inland lakes. N. Am. J. Fish. Manage. 31, 461-467.

Jennings, M.J., Sloss, B.L., Hatzenbeler, G.R., Kampa, J.M., Simonson, T.D., Avelallemant, S.P., Lindenberger, G.A., Underwood, B.D., 2010. Implementation of genetic conservation practices in a muskellunge propagation and stocking program. Fisheries, 35, 388-395.

Kelso, J.R.M., 1978. Diel rhythm in activity of walleye (Stizostedion vitreum vitreum). J. Fish Biol. 12, 593-599.

Kerr, S.J., 2011. Distribution and management of muskellunge in North America: an overview. Fisheries Policy Section, Biodiversity Branch. Ontario Ministry of Natural Resources. Peterborough, Ontario. 22 p. + appendices.

Kerr, S.J., 2010. Muskellunge of the Ottawa River. Biodiversity Branch. Ontario Ministry of Natural Resources. Peterborough, Ontario, 21 p. + appendices. 
Kerr, S.J. 2007a. Characteristics of Ontario muskellunge (Esox masquinongy) fisheries based on volunteer angler diary information. Env. Biol. Fish. 79, 61-69.

Kerr, S.J., 2007b. Guidelines for competitive fishing events for muskellunge in Ontario. Ontario Ministry of Natural Resources. Peterborough, Ontario, pp. 11.

Kieffer, J.D., 2000. Limits to exhaustive exercise in fish. Comp. Biochem. Physiol. A $126,161-179$.

Kieffer, J.D., Ferguson, R.A., Tompa, J.E., Tufts, B.L., 1996. Relationship between body size and anaerobic metabolism in brook trout and largemouth bass. Trans. Am. Fish. Soc. 125, 760-767.

Kieffer, J.D., Kubacki, M.R., Phelan, F.J.S., Philipp, D.P., Tufts, B.L., 1995. Effects of catch-and-release angling on nesting male smallmouth bass. Trans. Am. Fish. Soc. $124,70-76$.

Klefoth, T., Kobler, A.. Arlinghaus, R., 2008. The impact of catch-and-release angling on short-term behaviour and habitat choice of northern pike (Esox lucius L.). Hydrobiologia 601, 99-110.

Kuparinen, A., Klefoth, T., Arlinghaus, R., 2010. Abiotic and fishing-related correlates of angling catch rates in pike (Esox lucius). Fish. Res. 105, 111-117.

Kuparinen. A., O'Hara, R.B., Merilä, J., 2009. Lunar periodicity and the timing of river entry in Atlantic salmon Salmo salar. J. Fish Biol. 74, 2401-2408.

Landsman, S.J., Wachelka, H.J., Suski, C.D., Cooke, S.J., 201 la. Evaluation of the 
physiology, behaviour, and survival of adult muskellunge (Esox masquinongy) captured and released by specialized anglers. Fish. Res. 110, 377-386.

Landsman, S.J., Nguyen, V.M., Gutowsky, L.F.G., Gobin, J., Cook, K.V., Binder, T.R.. Lower, N., McLaughlin, R.L., Cooke, S.J., 2011 b. Fish movement and migration studies in the Laurentian Great Lakes: research trends and knowledge gaps. J. Great Lakes Res. 37, 365-379.

Landsman, S.J., 2008. Blending science and proper handling practices for a better release. Muskie $42,15-17$.

Lavigne, D.M., 1982. Similarity in energy budgets of animal populations. J. Anim. Ecol. $51,195-206$.

Leach, G.J., Taylor, M.H., 1980. The role of cortisol in stress-induced metabolic changes in Fundulus heteroclitus. Gen. Comp. Endocrinol. 42, 219-227.

Leatherland, J.F., Farbridge, K.J., Boujard, T., 1992. Lunar and semi-lunar rhythms in fishes. In: Ali, M.A. (Ed.), Rhythms in Fishes. Plenum Press: New York. pp. 83107.

Lee, W.C., Bergesen, E.P., 1996. Influence of thermal and oxygen stratification on lake trout hooking mortality. N. Am. J. Fish. Manage. 16, 175-181.

Lewin, W.C., Arlinghaus, R., Mehner, T., 2006. Documented and potential biological impacts of recreational fishing: insights for management and conservation. Rev. Fish. Sci. 14, 305-367. 
Lima, S.L., 2002. Putting predators back into behavioral predator-prey interactions. Trends Ecol. Evol. 17, 70-75.

Lindinger, M.I., 1995. Potassium regulation during exercise and recovery in humans: implications for skeletal and cardiac muscle. J. Mol. Cell. Cardiol. 27, 10111022.

Loomis, D.K., Holland, S., 1997. Specialization and sport fishing: angler support for rules and regulations. Proc. Gulf. Carib. Fish. Inst. 49, 398-410.

Lucas, M.C., Baras, E., 2000. Methods for studying spatial behaviour of freshwater fishes in the natural environment. Fish Fish. 1, 283-316.

Lucas, M.C., Johnstone, A.D.F., Priede, I.G., 1993. Use of physiological telemetry as a method of estimating metabolism of fish in the natural environment. Trans. Am. Fish. Soc. 122, 822-833.

Lucas, M.C., Priede, I.G., Armstrong, J.D., Gindy, A.N.Z., DeVera, L., 1991. Direct measurements of metabolism, activity and feeding behaviour of pike, Esox lucius L., in the wild, by the use of heart rate telemetry. J. Fish Biol. 39, 325-345.

Madden, J., Houston, A.H., 1976. Use of electroanesthesia with freshwater teleosts: some physiological consequences in the rainbow trout, Salmo gairdneri Richardson. J. Fish. Biol. 9, 457-462.

Margenau, T.L., 2007. Effects of angling with a single-hook and live bait on muskellunge survival. Environ. Biol. Fish 79, 155-162. 
Margenau. T.L., Petchenik, J.P., 2004. Social aspects of muskellunge management in Wisconsin. N. Am. J. Fish. Manage. 24, 82-94.

Mazerolle. M.J.. 2011. AlC cmodavg: Model selection and multimodel inference based on (Q)AIC(c). R package version 1.14. http://CRAN.Rproject.org/package $=\mathrm{AIC}$ cmodavg

Meka, J.M., 2004. The influence of hook type, angler experience, and fish size on injury rates and the duration of capture in an Alaskan catch-and-release rainbow trout fishery. N. Am. J. Fish. Manage. 24, 1309-1321.

Meka, J.M., McCormick, S.D., 2004. Physiological response of wild rainbow trout to angling: impact of angling duration, fish size, body condition, and temperature. Fish. Res. 72, 311-322.

Mezzera, M., Largiadèr, C.R., 2001. Evidence for selective angling of introduced trout and their hybrids in a stocked brown trout population. J. Fish Biol. 59, 287-301.

Miller, M.L., Menzel, B.W., 1986. Movement, activity, and habitat use patterns of muskellunge in West Okoboji Lake, Iowa. In: Hall, G.E. (Ed.), Managing Muskies. American Fisheries Society Special Publication (15): Bethesda, Maryland. pp. $51-61$.

Mittelbach, G.G., 1981. Foraging efficiency and body size: a study of optimal diet and habitat use by bluegills. Ecology 62, 1370-1386. 
Moyes. C.D.. West. T.G.. 1995. Exercise metabolism of fish. In: Hochachka, P.W.. Mommsen. T. P. (Eds.), Biochemistry and Molecular Biology of Fishes. Elsevier: Amersterdam. pp. 367-392.

Muoneke. M.I., Childress, W.M., 1994. Hooking mortality: a review for recreational fisheries. Rev. Fish. Sci. 2, 123-156.

Murchie, K. J., Cooke. S. J., Danylchuk, A. J., \& Suski, C. D. (2011). Estimates of field activity and metabolic rates of bonefish (Albula vulpes) in coastal marine habitats using acoustic tri-axial accelerometer transmitters and intermittent-flow respirometry. J. Exp. Mar. Biol. Ecol. 396, 147-155.

Nakagawa, S.. 2004. A farewell to Bonferroni: the problems of low statistical power and publication bias. Behav. Ecol. 15, 1044-1045.

New, J. G., Alborg Fewkes, L., \& Khan. a N. (2001). Strike feeding behavior in the muskellunge, Esox masquinongy: contributions of the lateral line and visual sensory systems. J. Exp. Biol. 204, 1207-1221.

Ney, J.J., 1993. Bioenergetics modeling today: growing pains on the cutting edge. Trans. Amer. Fish. Soc. 122, 736-748.

Nilsson, P.A., Brönmark, C., 2000. Prey vulnerability to a gape-size limited predator: behavioural and morphological impacts on northern pike piscivory. Oikos 88 , $539-546$.

O’Toole. A.C., Murchie, K.J., Pullen C.. Hanson, K.C., Suski. C.D., Danylchuk, A.J., Cooke, S.J., 2010. Locomotory activity and depth distribution of adult great 
barracuda (Sphyraena harracuda) in Bahamian coastal habitats determined using acceleration and pressure biotelemetry transmitters. Mar. Freshwater Res. 61, $1446-1456$.

Pagnotta, A., Milligan, C.L., 1991. The role of blood glucose in the restoration of muscle glycogen during recovery from exhaustive exercise in rainbow trout (Oncorhynchus mykiss) and winter flounder (Pseudopleuronectes americanus). J. Exp. Biol. 161, 489-508.

Persson, L., 1985. Asymmetrical competition: are larger animals competitively superior? Amer. Nat. 126, 261-266.

Philipp, D.P., Cooke, S.J., Claussen, J.E., Koppelman, J.B., Suski, C.D., Burkett, D.P., 2009. Selection for vulnerability to angling in largemouth bass. Trans. Amer. Fish. Soc. 138, 189-199.

Pickering, A.D., Pottinger, T.G., Christie, P., 1982. Recovery of the brown trout, Salmo trutta L., from acute handling stress: a time-course study. J. Fish Biol. 20, 229244.

Policansky, D., 2002. Catch-and-release recreational fishing: a historical perspective. In: Pitcher, T.J., Hollingworth, C.E. (Eds.), Recreational Fisheries: Ecological, Economic and Social Evaluation. Blackwell Science: Oxford, United Kingdom. pp. 74-93.

Pollock, K.H., Pine III, W.E., 2007. The design and analysis of field studies to estimate catch-and-release mortality. Fish. Manag. Ecol. 14, 123-130. 
Porter. L.R., 1977. Review of selected literature of muskellunge life history, ecology. and management. Minnesota Department of Natural Resources Special Publication 119. pp. 81 .

Portz, D.E., Woodley, C.M., Cech, J.J., 2006. Stress-associated impacts of short-term holding on fishes. Rev. Fish Biol. Fisher. 16, 125-170.

Post, J.R., Parkinson, E.A., 2001. Energy allocation strategy in young fish: allometry and survival. Ecology 82, 1040-1051.

Post, J.R., Sullivan, M., Cox, S., Lester, N.P., Walters, C.J., Parkinson, E.A., Paul, A.J., Jackson, L., Shuter, B.J., 2002. Canada's recreational fisheries: the invisible collapse? Fisheries $27,6-17$.

Quinn, S. 1996. Trends in regulatory and voluntary catch-and-release fishing. In: Miranda, L.E., DeVries, D.R. (Eds.), Multidimensional approaches to reservoir fisheries management. American Fisheries Society, Symposium (16): Bethesda, Maryland. Pp. 152-162.

R Development Core Team, 2011. R: A language and environment for statistical computing. R Foundation for Statistical Computing. Vienna, Austria. ISBN 3 900051-07-0. http://www.R-project.org

Raat, A.J.P., Klein Breteler, J.G.P., Jansen, S.A.W., 1997. Effects on growth and survival of retention of rod-caught cyprinids in large keep nets. Fish. Manag. Ecol. 4, 355368. 
Radabaugh, N.B., 2006. Seasonal distributions, movements, and habitat use of adult yellow perch in a simple basin. M.Sc. thesis. South Dakota State University. pp. 80.

Reebs, S.G.. 2002. Plasticity of diel and circadian activity rhythms in fishes. Rev. Fish. Biol. Fisher. 12, 349-371.

Ritchie, E.G., Johnson, C.N., 2009. Predator interactions, mesopredator release and biodiversity conservation. Ecol. Lett. 12, 982-998.

Rogers, K.B., White, G.C., 2007. Analysis of movement and habitat use from telemetry data. In: Brown, M., Guy, C., (Eds.), Analysis and Interpretation of Freshwater Fisheries Data. American Fisheries Society: Bethesda, Maryland. pp. 625-676.

Ropert-Coudert, Y., Wilson, R.P., 2005. Trends and perspectives in animal-attached remote sensing. Front. Ecol. Environ. 3, 437-444.

Rose, J., 2002. The neurobehavioral nature of fishes and the question of awareness and pain. Rev. Fish. Sci. 10, 1-38.

Ross, M.J., McCormick, J.H., 1981. Effects of external radio transmitters on fish. Prog. Fish. Cult. 43, 67-72.

Saric, J., Heiting, S., 1999. The complete guide to musky hunting. Musky Hunter Publications. pp. 252.

Sattari, A., Mirzargar, S., Abrishamifar, A., Lourakzadegan, R., Bahonar, A., Mousavi. H., Niasari, A, 2009. Comparison of electroanesthesia with chemical anesthesia 
(MS222 and clove oil) in rainbow trout (Oncorhynchus mykiss) using plasma cortisol and glucose responses as physiological stress indicators. Asian J. Anim. Vet. Adv., 4, 306-313.

Schindler, D.E., Eby, L.A.. 1997. Stoichiometry of fishes and their prey: implications for nutrient recycling. Ecology 78, 1816-1831.

Schoener, T.W., 1983. Field experiments on interspecific competition. Amer. Nat. 122, 240-285.

Schreck, C.B., 1976. The stress concept in fisheries: Implications in environmental monitoring. Proceedings of the Western Association of State Game and Fish Commissioners 56, 186-188.

Schreck, C.B., 2000. Accumulation and long-term effects of stress in fish. In: Moberg, G.P., Mench, J.A. (Eds.), The Biology of Animal Stress: Basic Principles and Implications for Animal Welfare. CABI Publishing: New York. pp. 147-158.

Schwalme, K.. Mackay, W.C., 1985. The influence of angling-induced exercise on the carbohydrate metabolism of northern pike (Esox lucius L.). J. Comp. Physiol. B $156,67-75$.

Scott, W.B., Crossman, E.J., 1973. Freshwater fishes of Canada. Bull. Fish. Res. Board Can. pp. 966.

Sink, T.D., Lochmann, R.T., Fecteau, K.A., 2008. Validation, use, and disadvantages of enzyme-linked immunsorbent assay kits for detection of cortisol in channel 
catfish, largemouth bass, red pacu, and golden shiners. Fish Physiol. Biochem. 34. $95-101$.

Sneddon, L.U.. 2003. The evidence for pain in fish: the use of morphine as an analgesic. Appl. Anim. Behav. Sci. 83, 153-162.

Sneddon, L.U., Braithwaite, V.A., Gentle, M.J., 2003. Do fishes have nociceptors? Evidence for the evolution of a vertebrate sensory system. Proc. R. Soc. Lond. B. $270,1115-1121$

Snyder, D.E., 2003. Invited overview: conclusions from a review of electrofishing and its harmful effects on fish. Rev. Fish Biol. Fisher. 13, 445-453.

Soivio, A., Oikari, A., 1976. Haematological effects of stress on a teleost, Esox lucius L., J. Fish Biol. 8, 397-411.

Sokal, R.R., Rohlf, F.J., 1995. Biometry, the principles and practice of statistics in biological research (3rd Edition). W.H. Freeman and Company: New York. pp 887.

Stockwell, C.A., Hendry, A.P., Kinnison, M.T., 2003. Contemporary evolution meets conservation biology. Trends Ecol. Evol. 18, 94-101.

Storck, T.W., Newman, D.L., 1992. Contribution of tiger muskellunge to the sport fishery of a small, centrarchid-dominated impoundment. N. Am. J. Fish. Manag. $12,213-221$ 
Strand, R.F., 1986. Identification of principal spawning areas and seasonal distribution and movements of muskellunge in Leech Lake Minnesota. In: Hall, G.E. (Ed.), Managing Muskies. American Fisheries Society Special Publication (15): Bethesda, Maryland. pp. 62-73.

Sternberg, D. 1992. Northern pike \& muskie. The Hunting and Fishing Library. Cy DeCosse Incorporated: Minnetonka, Minnesota.

Suski, C.D., Cooke, S.J., Danylchuk, A.J., O’Connor, C.M., Gravel, M.A., Redpath, T., Hanson, K.C., Gingerich, A.J., Murchie, K.J., Danylchuk, S.E., Koppelman, J.B., Goldberg, T.L., 2007. Physiological disturbance and recovery dynamics of bonefish (Albula vulpes), a tropical marine fish, in response to variable exercise and exposure to air. Comp. Biochem. Phys. A 148, 664-673.

Suski, C.D., Svec, J.H., Ludden, J.B., Phelan, F.J.S., Philipp, D.P., 2003a. The effect of catch-and-release angling on the parental care behaviour of male smallmouth bass. Trans. Am. Fish. Soc., I32, 210-218.

Suski, C.D., Killen, S.S., Morrissey, M., Lund, S. G., Tufts. B.L, 2003b. Physiological changes in largemouth bass caused by live-release angling tournaments in southeastern Ontario. N. Am. J. Fish. Manage. 23, 760-769.

Thorstad, E. B., Næsje, T.F., Fiske, F., Finstad, B., 2003. Effects of hook and release on Atlantic salmon in the River Alta, northern Norway. Fish. Res., 60, 293-307.

Todd, B.L., Rabeni, C.F. 1989. Movement and habitat use by stream-dwelling smallmouth bass. Trans. Am. Fish. Soc. 118, 229-242. 
Tytler, P.. Calow. P.. 1985. Fish energetics: a new perspective. John Hopkins University Press: Baltimore. pp. 347.

U.S. Department of the Interior, Fish and Wildlife Service (USFWS), and U.S. Department of Commerce. U.S. Census Bureau. 2006 National Survey of Fishing. Hunting. and Wildlife-Associated Recreation.

Venn Beecham, R., Small, B.C., Minchew, C.D., 2006. Using portable lactate and glucose meters for catfish research: acceptable alternatives to established laboratory methods? N. Am. J. Aquacult. 68, 291-295.

Wagner, C.P., Wahl, D.H., 2007. Evaluation of temperature-selection differences among juvenile muskellunge originating from different latitudes. Environ. Biol. Fish. 79. $85-98$.

Walker, R.P., O'Toole, A.C., Whynot, Z., Hanson, K.C., Cooke, S.J., 2010. Evaluation of the aquatic habitat and fish assemblage in an urban reach of the historic Rideau Canal, Ottawa, Canada: implications for management in an engineered system. Urban Ecosys. 13, 563-582.

Wang Y.G., Heigenhauser, J.F., Wood, C.M., 1994. Integrated responses to exhaustive exercise and recovery in rainbow trout white muscle: acid-base, phosphogen. carbohydrate, lipid, ammonia, fluid volume and electrolyte metabolism. J. Exp. Biol. 195, 227-258.

Wedemeyer, G.A., Barton, B.A., McLeay, D.J., 1990. Stress and acclimation. In: 
Schreck, C.B., Moyle. P.B. (Eds.), Methods for fish biology. American Fisheries Society: Bethesda, Maryland. pp. 451-489.

Weeks, J.G.. Hansen, M.J., 2009. Walleye and muskellunge movement in the Manitowish Chain of Lakes. Vilas County, Wisconsin. N. Am. J. Fish. Manage. 29. 791-804.

Wendelaar Bonga, S.E., 1997. The stress response in fish. Physiol. Rev. 77, 591-625.

Werner, E.E., Anholt, B.R., 1993. Ecological consequences of the trade-off between growth and mortality rates mediated by foraging activity. Amer. Field. Nat. 142 , 242-272.

Wilson, R., Shepard, E., Liebsch, N., 2008. Prying into the intimate details of animal lives: use of a daily diary on animals. Endang. Species Res. 4, 123-137.

Wilson, R.P., White, C.R., Quintana, F., Halsey, L.G., Liebsch, N., Martin, G.R., Butler, P.J., 2006. Moving towards acceleration for estimates of activity-specific metabolic rate in free-living animals: the case of the cormorant. J. Anim. Ecol. 75 , 1081-1090.

Wingate, P.J., 1986. Philosophy of muskellunge management. In: Hall, G.E. (Ed.), Managing Muskies. American Fisheries Society Special Publication (15): Bethesda, Maryland. pp. 199-202.

Wood, C.M., 199la. Acid-base and ion balance, metabolism, and their interactions, after exhaustive exercise in fish. J. Exp. Biol., 160, 285-308. 
Wood, C.M.. Lemoigne, J., 1991b. Intracellular acid-base responses to environmental hyperoxia and normoxic recovery in rainbow trout. Resp. Physiol. 86, 91-113.

Wydoski, R.S., 1977. Relation of hooking mortality and sublethal hooking stress to quality fishery management. In: Barnhart, R.A., Roelofs, T.D. (Eds.), Catch-andRelease Fishing as a Management Tool. Humbolt State University: Arcata, California. pp. $43-87$.

Young, M., 1999. Summer diel activity and movement of adult brown trout in highelevation streams in Wyoming, U.S.A. J. Fish Biol. 54, 181-189.

Young, P.S., Cech, Jr., J.J., 1993. Physiological stress responses to serial sampling and confinement in young-of-the-year striped bass, Morone saxatilis (Walbaum). Comp. Biochem. Physiol. 105A, 239-244.

Younk, J.A., Cook, M.F., Goeman, T.J., Spencer, P.D., 1996. Seasonal habitat use and movements of muskellunge in the Mississippi River. Minnesota Department of Natural Resources Investigational Report 446, 1-20.

Zar, J.H., 1984. Biostatistical analysis: $2^{\text {nd }}$ edition. Prentice Hall, New Jersey, 736 pp. 


\section{Appendix I: Alternative options to J-hook swallow rigs for angling muskellunge (Esox masquinongy) with live-bait}

\section{Introduction}

Live-bait angling remains a highly controversial method of angling for muskellunge (Esox masquinongy; Margenau and Petchenik, 2004). Traditionally, the method involved the use of large bait, typically white suckers (Camersonii camersonii), attached at the snout to a large, single J-hook. Muskellunge were allowed to swallow the bait before the angler set the hook (Margenau, 2007). This type of passive angling was proven to be extremely detrimental to the survival of muskellunge (Margenau, 2007). Furthermore, live-bait angling does not require specialized gear compared to using artificial lures (Landsman et al., in press) and is a method generalist anglers often employ because the gear needed is essentially a hook and bait $(\mathrm{H}$. Wachelka, personal communication). New ways to rig live-bait have been developed recently and include quick-strike and circle hook rigs (Margenau and Petchenik, 2004; Margenau, 2007). However, the viability these methods have not been evaluated and their effects on survival are unclear.

The objective of this study was to determine the acceptability of alternative methods to single-hook swallow rigs, though modifications to the single-hook methods were also evaluated. The assessment was determined using survival, injury, and hooking location. 


\section{Methods}

Study site. This study was conducted on the Rideau River at two locations. Most effort was conducted on a portion of the river known as the "Long Reach" centered near Kemptville, Ontario (Figure la). The second area, known as "Eccolands," was located between the Long Island and Black Rapids Locks (Figure lb).

Angling and bait. Local volunteer anglers operating from the project boat were used to help capture muskellunge. Bait consisted of live white suckers, which were obtained primarily from local bait dealers, but during periods of low inventory white suckers were captured via electrofishing. Most bait ranged from $20.3-27.9 \mathrm{~cm}$, but some individuals measured as much as $38.1-43.2 \mathrm{~cm}$. The bait used reflected the sizes available to local anglers and because most local anglers are not willing to incur the added expense (e.g., fuel for travel) of obtaining particular sized bait (personal observation) no attempts to do so were made. In an effort to spread a relatively equal amount of effort between the rigs, a special permit was obtained through the Ministry of Natural Resources that allowed the use of multiple rods per person.

Rigging and angling methods. Four rigging methods were used in this study. The first rig consisted of one treble hook (Mustad 3551 or Eagle Claw 374, size 3/0-4/0) attached to the mid-section of the bait, with a small hook affixed to the snout of the bait to hold the rig in place (Figure 2). This method is known as a "quick-strike" rig because the angler sets the hook immediately after a muskellunge takes the bait. It is designed to minimize the risk of a fish swallowing the bait. The second method consisted of a circle hook (Owner SSW Inline, size 9/0-10/0; Figure 3a, b) rigged through the snout of the bait. To use circle hooks properly, anglers allow the target species to take the bait for a 
period of time. often long enough so that it is swallowed. However. instead of setting the hook with a sharp, upward jerk the angler simply reels quickly and the design of the hook allows it to slide through the fish without attaching to flesh. Eventually, the hook will reach the edge of the mouth where it rotates outward and the point of the hook pivots on the jaw and locks into place (Cooke, 2004; Figure 4). In the present study, angler discretion was used to determine the length of time until pressure was applied to the line and hooking commenced. The final two methods consisted of using J-hooks (Figure 3c) with shortened times-to-hookset. Advice from a local guide suggested 1 and 3 min waiting periods before setting the hook (Anonymous, personal communication). It should be emphasized that this study sought to avoid deep-hooking at all costs by placing a very minimal amount of time between strike and hookset. J-hooks were also placed either at the snout or just beneath the dorsal fin at the angler's discretion. though placement was often dictated by whether the boat was drifting (snout) or sitting relatively motionless (dorsal). These hook placements are common for this type of rigging method (e.g., Sternberg, 1992). For all methods, rigs with and without floats were used and all rigs were attached to either wire or fluorocarbon leaders of 40 or $36 \mathrm{~kg}$ breaking strengths, respectively.

Assessment. Rigging methods were assessed three ways. First, the hooking location and distance-to-hooking location (measured from tip of snout) were noted. Second, injuries were recorded on a scale of 1 to 4 : minimal flesh tearing and no bleeding (i.e., 1); minimal flesh tearing with bleeding (i.e.. 2); moderate flesh tearing with bleeding (i.e., 3); heavy flesh tearing with pulsatile bleeding or deep/esophageal hooking (i.e., 4). The final assessment method used individually coded, external radio 
transmitters to track muskellunge post-release. Transmitters were attached with wires that were passed through the dorsal musculature and into the lumen of two hypodermic needles. A series of haywire twists locked the wire in place and the tag ends were flattened against a small piece of rubber gasket placed on the flank opposite the transmitter to prevent the wires from rubbing against the fish. Survival was deemed if a fish was not repeatedly tracked to the same location at sequential tracking periods (Hightower et al., 2001). Total length (TL) is presented in centimeters as means \pm S.E.

\section{Results}

Fishing occurred between 8 October and 11 November 2009. Five muskellunge $\left(94.8 \pm 6.6 \mathrm{~cm} \mathrm{~L}_{\mathrm{T}} ;\right.$ range $\left.76.2-111.8 \mathrm{~cm} \mathrm{~L} \mathrm{~L}_{\mathrm{T}}\right)$ were successfully captured during this time period with a total of 30 strikes. Sixteen $(53.4 \%)$ strikes occurred using quick-strike rigs, four $(13.3 \%)$ with circle hooks, and $10(33.3 \%)$ with J-hooks.

One fish $\left(111.8 \mathrm{~L}_{\mathrm{T}}\right)$ was captured using a quick-strike rigged white sucker $(38.1$ $\mathrm{cm} \mathrm{L}_{\mathrm{T}}$ ). The distance to hooking location was $9 \mathrm{~cm}$ and it was hooked outside of the mouth on the lower jaw. Injury was scored as 1 due to minimal flesh tearing and no bleeding.

Two fish -88.0 and $99.2 \mathrm{~cm} \mathrm{~L} \mathrm{~L}_{\top}$ - were captured on circle hooks after waiting a period of 5 and 6 minutes, respectively, before applying pressure to the line. Bait lengths were both between 20.3 and $27.9 \mathrm{~cm} \mathrm{~L}$. Hooking occurred in the upper right roof and upper right corner of the jaw at distances of 7.0 and $10.0 \mathrm{~cm}$, respectively. For both fish, injury was scored as 1 . 
Two fish were caught on white suckers $(20.3-27.9 \mathrm{~cm} \mathrm{~L}$ ) rigged with J-hooks. One measuring $108.0 \mathrm{~cm}$ was caught on a J-hook with $1 \mathrm{~min}$ time-to-hookset using bait rigged through the snout. This individual was hooked in the upper jaw at a distance of $15.0 \mathrm{~cm}$ from its snout. Injury was scored as 1 for this fish. Another muskellunge $(76.2$ $\mathrm{cm} \mathrm{L}_{\mathrm{r}}$ ) was caught using a 3 min time-to-hookset and bait rigged beneath the dorsal fin. However, this fish swallowed the bait and was hooked in its esophagus, and injury was scored as 4 because of the hooking location and presence of pulsatile bleeding. As a result of extensive injuries, the fish died in less than $1 \mathrm{hr}$ and was the only recorded mortality in this study.

The following descriptions were made during a post-mortem necropsy of this fish. Distance-to-hooking location was determined to be $24.0 \mathrm{~cm}$ based on the presence of esophageal tears. The hook left a wound of approximately $2.5 \mathrm{~cm}$ in the esophagus (Figure 5a) and also created a small $0.64 \mathrm{~cm}$ tear in the pericardial cavity (i.e., layer of tissue surrounding the heart; Figure 5b). Small abrasions on the liver were noted, as was a small nick in the hepatic portal vein (i.e., drains blood from the gastrointestinal tract to the liver).

\section{Discussion and Conclusions}

This study represents the first field study to evaluate alternative methods to traditional single-hook swallow rig live-bait angling for muskellunge. Margenau (2007) studied the effects of hooking muskellunge with J-hook swallow rigs. Of 40 muskellunge that were transferred into rearing ponds for the study, 14 muskellunge were either not captured or hooked superficially, but 23 muskellunge were hooked in the stomach. Of 
these deep-hooked fish, $22 \%$ died within 50 days and $83 \%$ perished in less than one year (Margenau. 2007). In the present study, one (of two) muskellunge captured using a Jhook with a shortened time-to-hookset (i.e., $3 \mathrm{~min}$ ) perished. Although the time period between initial strike and hookset was less than that reported in Margenau (2007) of 4-37 $\min$, the size of bait in the current study - generally $20.3-27.9 \mathrm{~cm} \mathrm{~L} \mathrm{~L}_{\mathrm{T}}$ - was slightly smaller than that used in Margenau (2007) of 27.0-32.0 $\mathrm{cm} \mathrm{LT}$. It is possible the size of bait in proportion to the fish could be an important factor in determining how long an angler should wait to set the hook. Large prey require longer handling times compared to smaller prey (Nilsson and Brönmark, 2003), but because the angler has no control over the size of fish that may strike their bait it is difficult to recommend an appropriate timeto-hookset that minimizes injury and maximizes capture efficiency. An additional complicating factor may be the effect of hook position on the bait itself, but the impact of this is yet uncertain.

The alternative approaches - quick-strike rigs and circle hooks - to using J-hooks may reduce injury and mortality associated with this method of angling. Although one fish captured on a J-hook received minimal injuries and survived the angling event, so too did the other three fish captured in this study. The design of quick-strike rigs is to reduce the time-to-hookset while increasing the odds of successfully hooking and capturing a fish. The one fish caught in this study on a quick-strike rig was hooked on the outside of the mouth, providing support for the rig's ability to reduce injury. In addition, circle hooks also caused minimal injury to the fish. One muskellunge was hooked exactly as the rig was designed to promote (Figure 6) and another hooked in the 
roof of the mouth. Despite their theoretical benefits, circle hooks may still deep-hook fish and could reduce hooking efficiency (Cooke. 2004; Alós, 2009).

It is worth noting that this study had a very low sample size on which to draw conclusions. There were also other issues associated with the sampling protocol that further confound any potential recommendations. For example, each rig should be given the same amount of fishing time to fairly assess the benefits or detriments of each method. Study sites with a species assemblage comprised mainly of muskellunge are ideal as northern pike (Esox lucius) and walleye (Sander vitreus) were also observed to strike the baits used in this study. This study is less suited for the field as compared to more controlled settings such as small research ponds similar to those used by Margenau (2007). The above factors can be better controlled under these conditions and more robust conclusions can be drawn. As such, a more thorough and comprehensive study is warranted to determine the viability of alternative J-hook swallow rig methods for livebait angling muskellunge.

\section{Acknowledgements}

Many volunteer anglers from the Ottawa Chapter of Muskies Canada Inc. contributed to this study. An additional thanks is extended to G. Lowry for sampling protocol consultation prior to commencement of this study. All sampling was carried out under permits obtained through the Ontario Ministry of Natural Resources. 
Figures

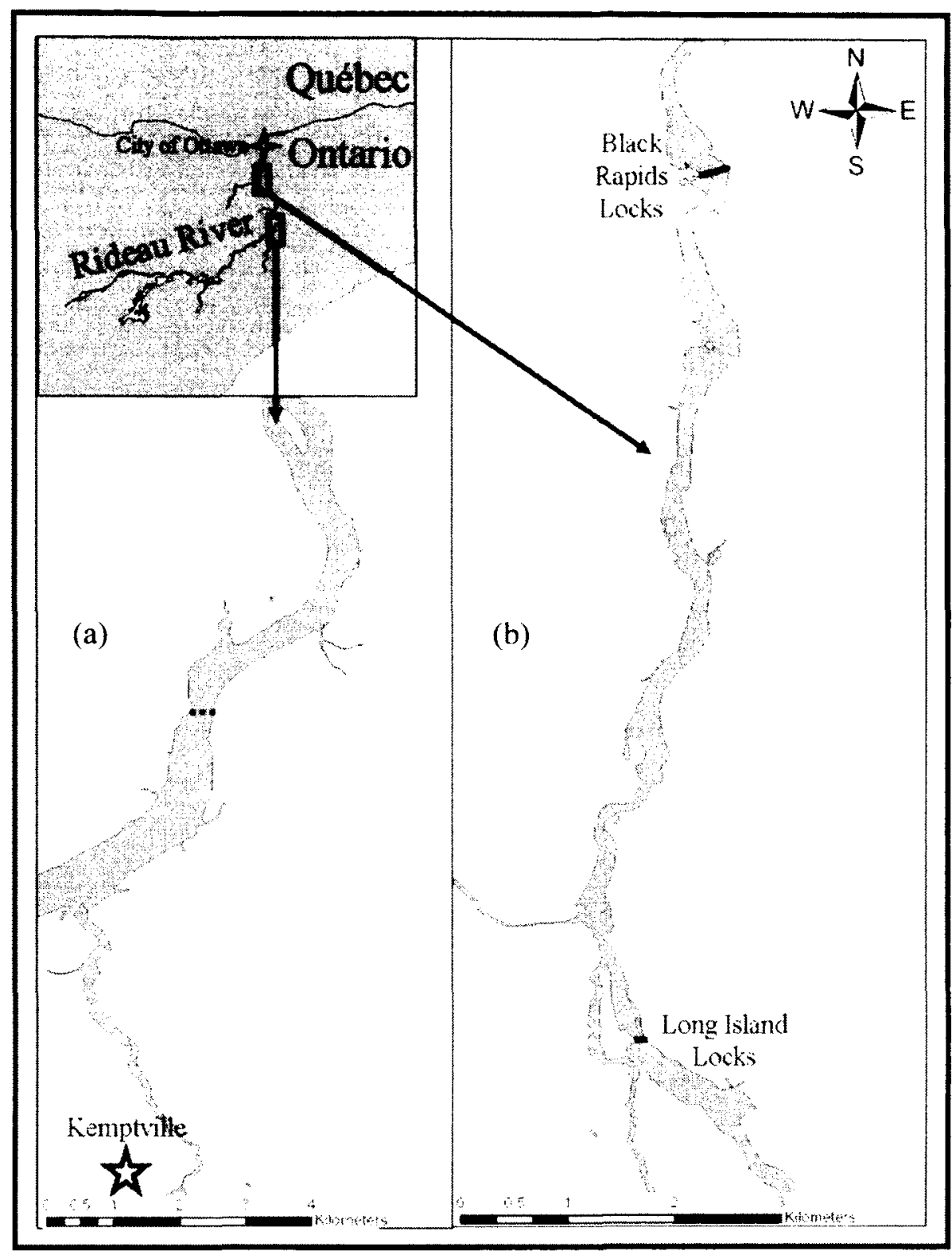

Figure 1-1. Study sites along the Rideau River near Kemptville, Ontario (i.e., Long Reach; a) and between the Long Island and Black Rapids Locks (i.e., Eccolands; b). Solid lines represent locks and dashed lines represent bridges. 


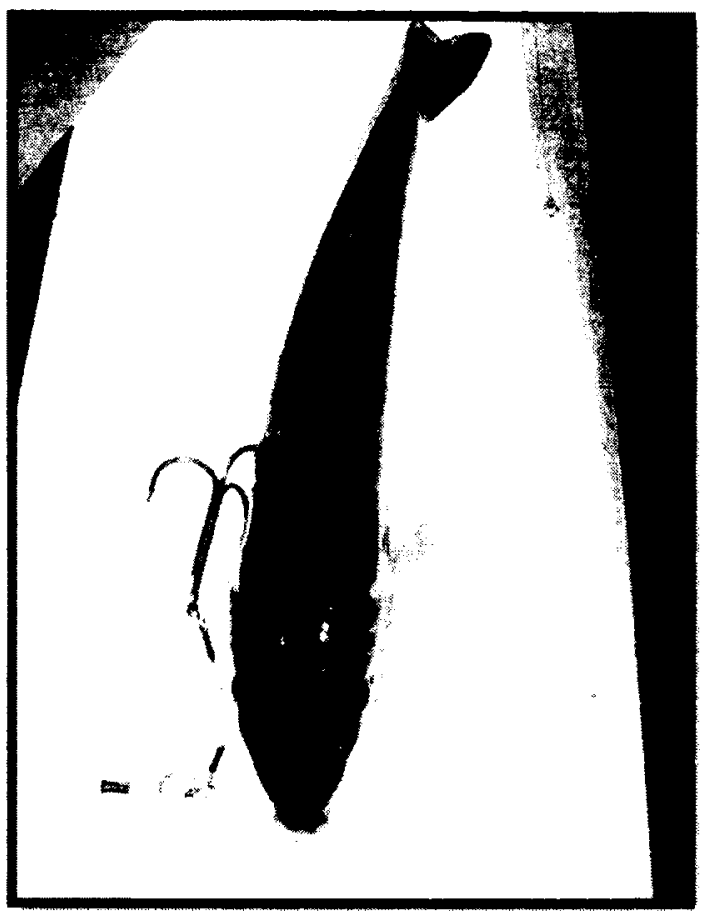

Figure I-2. Quick-strike rigged white sucker (Camersonii camersonii; photo credit John Bette). 


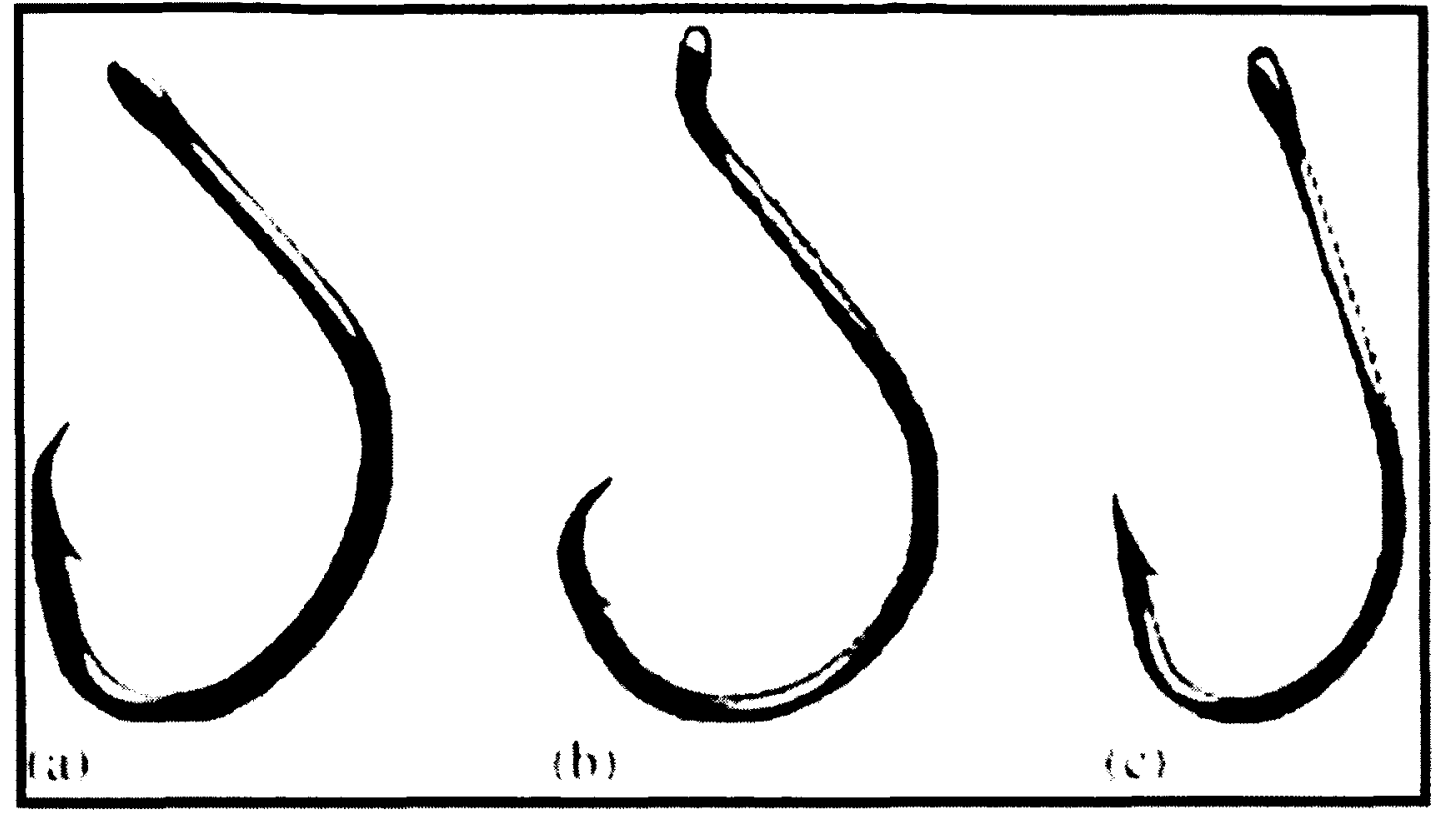

Figure I-3. Two styles of circle hook $(\mathrm{a}, \mathrm{b})$ and a conventional J-hook (c; used with permission from S.J. Cooke). 


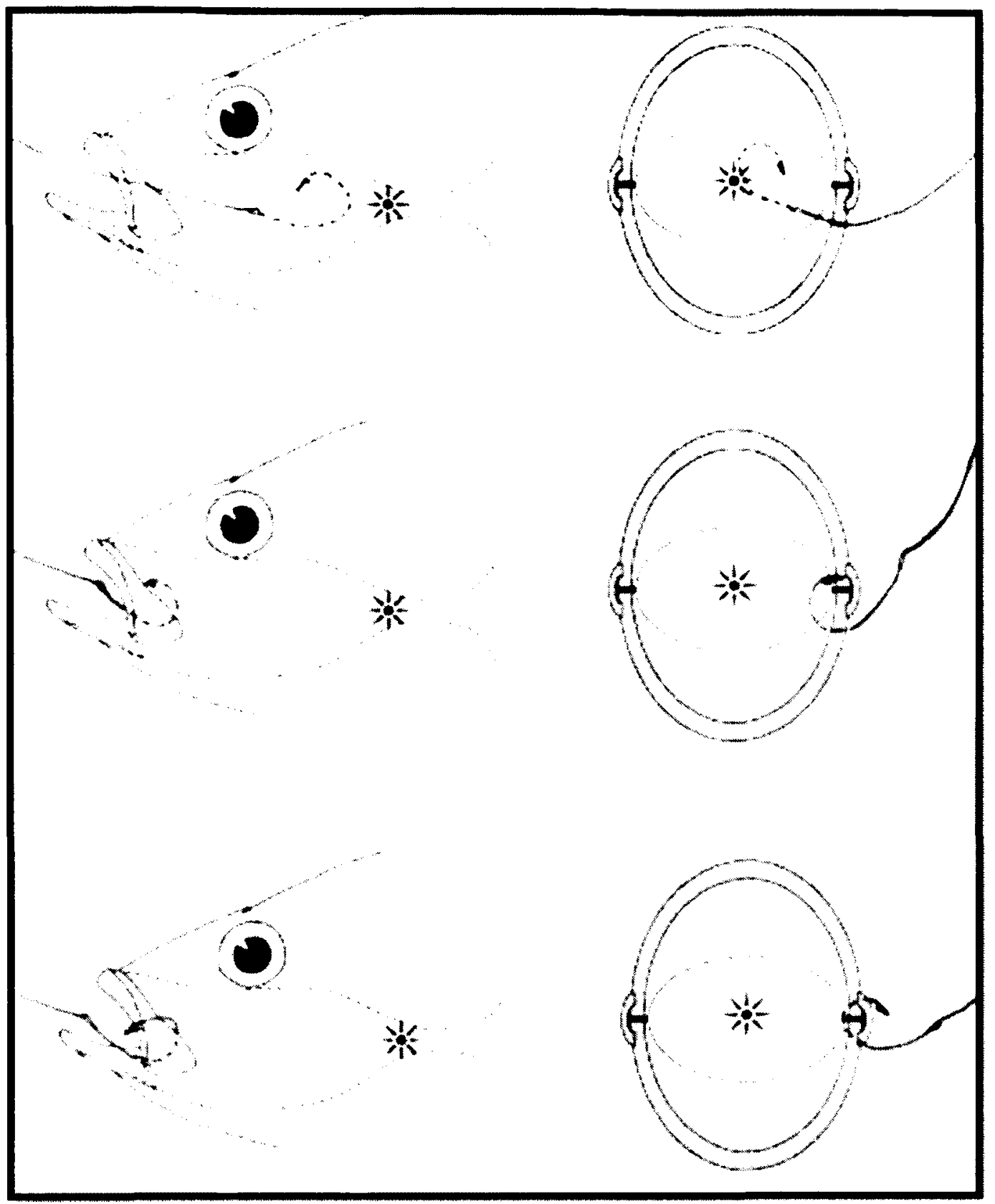

Figure 1-4. Circle hook operation after the angler reels and applies pressure to the line. Both lateral and frontal views are shown (used with permission from S.J. Cooke). 


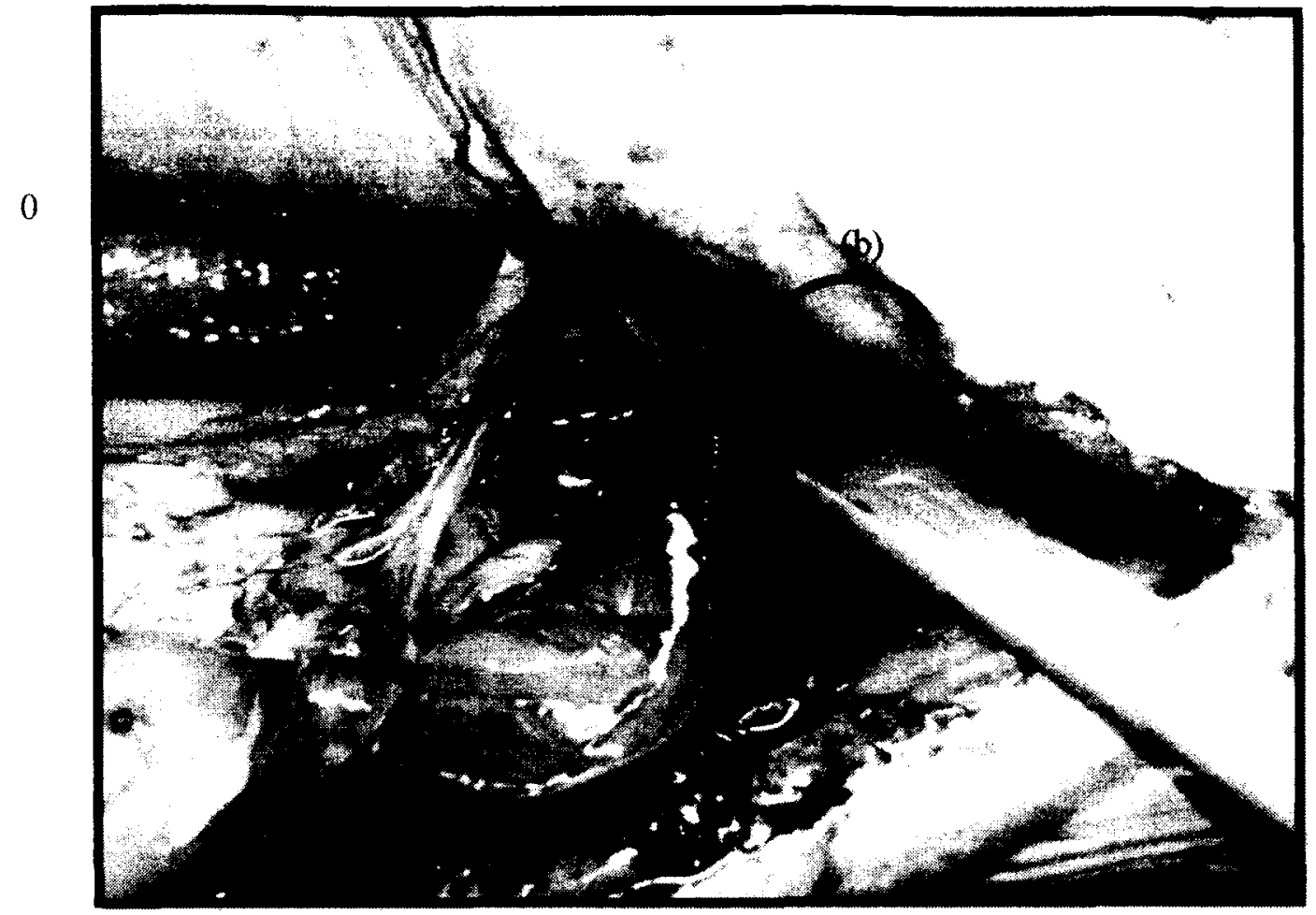

Figure I-5. Photograph of post-mortem necropsy (photo credit S. Landsman). A $2.5 \mathrm{~cm}$ tear (a) is shown and the scalpel handle points to another tear in the pericardial cavity (b). 


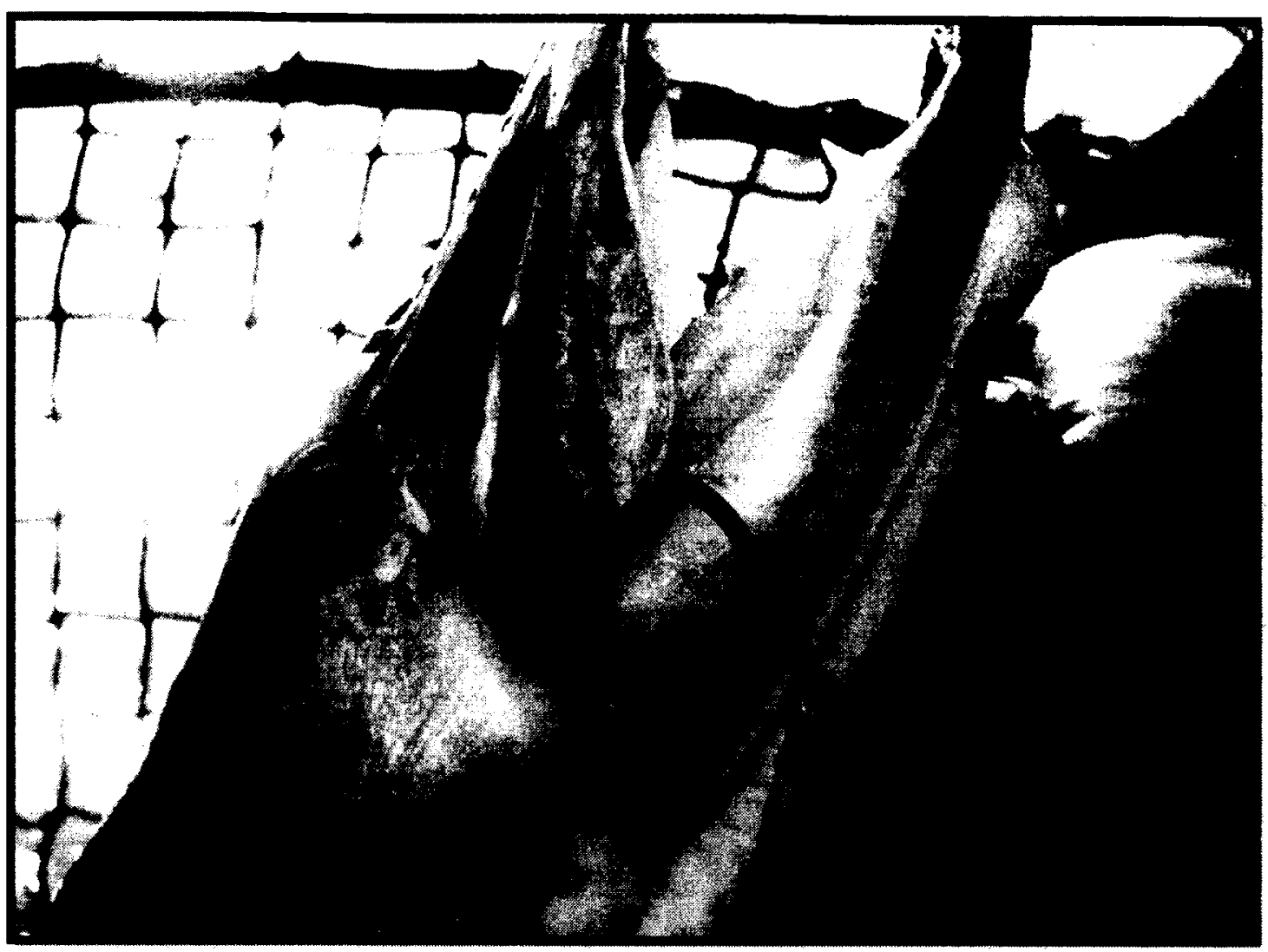

Figure I-6. Ideal hooking location using a circle hook (photo credit S. Landsman). 


\section{Reprint Request and Permissions to Publish}

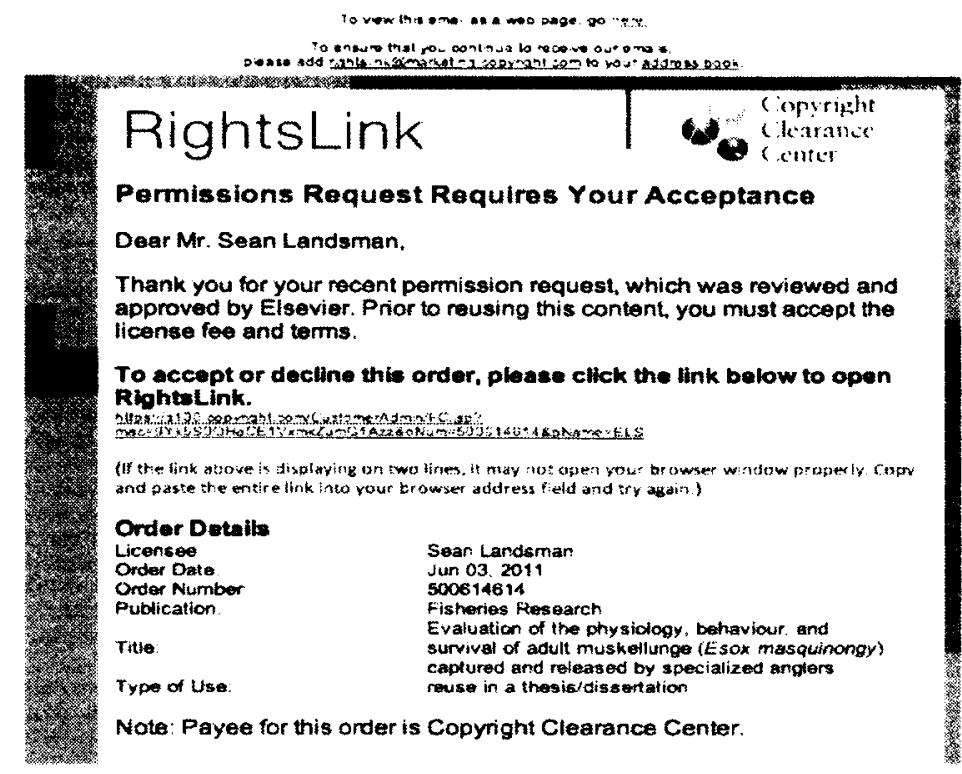

1, Steven James Cooke, hereby give permission to Sean Landsman to include and publish material that / have co-authored for his thesis $\mathrm{SuC}$

1. Hedrik Wachelka, hereby give permission to Scan Landsman to include and publish material that I have co-authored for his thesis.

1, Cory Suski, hereby give permission to Sean Landsman to include and publist material that I have co-authored for his thesis 